"WE ONLY DO FOOD"

SOCIAL ASSUMPTIONS OF POVERTY AND THE IMPLEMENTATION OF EMERGENCY FOOD SERVICES

A Dissertation
presented to
the Faculty of the Graduate School
at the University of Missouri-Columbia
In Partial Fulfillment
of the Requirements for the Degree
Doctorate of Philosophy
Dr. James S. Rikoon, Dissertation Supervisor
by

May, 2020 
The undersigned, appointed by the dean of the Graduate School, have examined the dissertation entitled

\section{"WE ONLY DO FOOD" SOCIAL ASSUMPTIONS OF POVERTY AND THE IMPLEMENTATION OF EMERGENCY FOOD SERVICES}

Presented by Darren Chapman,

A candidate for the degree Doctor of Philosophy,

And herby certify that, in their opinion, it is worthy of acceptance.

Professor James S. Rikoon

Professor Mary Hendrickson

Professor Stephen Jeanetta

Professor Wilson Majee 
"WE ONLY DO FOOD"

\section{ACKNOWLEDGMENTS}

I would like to express my sincerest thanks to my committee for generously donating their time and expertise at all stages of my dissertation work. A special thanks to my committee chair, faculty advisor, and mentor Professor Sandy Rikoon, for his encouragement and belief in my abilities as a writer and a scholar. I would also like to think Bill McKelvey for his mentorship and support in developing as a researcher and community-engaged scholar. Without the support of Feeding Missouri, Ozarks Food Harvest, Harvesters Community Food Network, Second Harvest Community Food Bank, The Food Bank of Central \& Northeast Missouri, St. Louis Area Food Bank, the Southeast Missouri Food Bank, and their affiliate food pantry directors from across the state, this research wouldn't have been possible. I would also like to thank my peers and colleagues who have supported me in my academic endeavors. 
"WE ONLY DO FOOD”

\section{TABLE OF CONTENTS}

ACKNOWLEDGEMENTS

LIST OF TABLES \& FIGURES

ABSTRACT

Research

1. Chapter 1 - Introduction 1

a. Problem Statement 3

b. Study Purpose 4

c. Need for the Study 5

d. Research Questions \& Hypotheses 6

e. Positionality Statement 8

f. Dissertation Organization 9

2. Chapter 2-Literature Review 11

a. Sociological Understandings of Emergency Food 12

b. Food Justice Movement in Emergency Food 18

c. Food Pantry Typologies 24

d. Perceptions and Attitudes about Poverty 25

e. The Connection of Beliefs and Behavior 28

3. Chapter 3-Methodology 34

a. Study Design 34

b. Data Collection 35

c. Survey Development \& Measures 35

d. Sampling 40

e. Data Cleaning 42

f. Data Analysis 42

4. Chapter 4 - Descriptive Data 46

a. Food Pantry Operations 46

b. Food Pantry Services 53

c. Food Pantry Directors 86

d. Attributions of Poverty 90

e. Beliefs About Food Pantry Services 91 
"WE ONLY DO FOOD”

5. Chapter 5 - Multivariate Results 92

a. Food pantry help-giving strategies 92

b. Assumptions of poverty and help-giving strategies 96

c. Director characteristics and help-giving strategies 96

6. Chapter 6-Discussion 100

a. Key Findings 101

b. Implications 115

c. Limitations 118

d. Future Research 122

e. Policy Recommendations 125

$\begin{array}{ll}\text { References } & 131\end{array}$

Appendix

A. 2019 Missouri Food Pantry Director Survey 140

B. Attributions of Poverty- Short Form Adjustments 161

Vita

164 
"WE ONLY DO FOOD”

\section{LIST OF TABLES \& FIGURES}

Table 1. Food Pantry Service/Program Construct Breakdown 37

Table 2. Survey Participation $\quad 46$

Table 3. Pantry days and hours of operation by region 47

Table 4. Operation Statistics by Food Bank Region 47

Table 5. Food Pantry Staffing by Food Bank Region 48

Table 6. Food Pantry Religious Affiliation by Food Bank Region 49

Table 7. Food Pantry Access by Food Bank Region 50

Table 8. Client Documentation Needed by Food Bank Region 51

Table 9: Client Wait Environment by Food Bank Region 51

Table 10. Food selection model by Food Bank Region 52

Table 11. Food Pantry Service/Program Construct Breakdown 53

Table 12. Pantry Service Construct Rank by Importance 54

Table 13. Direct Food Provisions Importance Rank 55

Table 14. Commodity Distribution by Food Bank Region 56

Table 15. Senior Box Distribution by Food Bank Region 56

Table 16. Food Delivery Service by Food Bank Region 57

Table 17. Meal Program by Food Bank Region 57

Table 18. Backpack Food Programs by Food Bank Region 58

Table 19. Specialty Food Provisions by Food Bank Region 58

Table 20. Health Guidelines for Donations by Food Bank Region 59

Table 21. Onsite Community Garden by Food Bank Region 60

Table 22. Recipes for Distributed Foods by Food Bank Region 60

Table 23. Baby Formula Provisions by Food Bank Region 61

Table 24. Other Food Supports Mean Importance Rank by Food Bank Region 61

Table 25. SNAP Enrollment Assistance by Food Bank Region 62

Table 26. WIC Enrollment Assistance by Food Bank Region 63

Table 27. TANF Enrollment Assistance by Food Bank Region 63

Table 28. Off-site Community Gardens by Food Bank Region 64

Table 29. General Cooking/Recipe Demonstrations by Food Bank Region 64

Table 30. Nutrition Education Classes by Food Bank Region 65 
"WE ONLY DO FOOD"

Table 31. General Recipe Provision by Food Bank Region 65

Table 32. Nutrition Information by Food Bank Region 66

Table 33. Gardening Supplies \&/or Education by Food Bank Region 66

Table 34. Health \& Personal Care Supports Mean Rank by Food Bank Region 67

Table 35. Mental Health Screenings by Food Bank Region 68

Table 36. Health Screenings by Food Bank Region 69

Table 37. Dental Screenings by Food Bank Region 69

Table 38. Reproductive Health Supports by Food Bank Region 70

Table 39. Smoking Cessation Supports by Food Bank Region 70

Table 40. Drug and Alcohol Treatment Supports by Food Bank Region 71

Table 41. Chronic Disease Management Supports by Food Bank Region 71

Table 42. Domestic Violence Resource by Food Bank Region 72

Table 43. Health Insurance Information by Food Bank Region 72

Table 44. Personal Care Items by Food Bank Region 73

Table 45. Diaper Provisions by Food Bank Region 73

Table 46. Household Item Provisions by Food Bank Region 74

Table 47. Organizational Structuring Mean Importance Rank by Food Bank Region 74

Table 48. Thrift Shops by Food Bank Region $\quad 75$

Table 49. Religious Programming by Food Bank Region 76

Table 50. Visible Signage by Food Bank Region 76

Table 51. Clearly Identified and Accurate Hours by Food Bank Region 77

Table 52. Up-to-date Website or Social Media Page by Food Bank Region 77

Table 53. Seating Area for Clients by Food Bank Region 78

Table 54. Area for Children by Food Bank Region 78

Table 55. Opportunity for Client Feedback by Food Bank Region 79

Table 56. Opportunity for Clients to Serve on Board/Staff by Food Bank Region 79

Table 57. Social or Cultural Events by Food Bank Region 80

Table 58. Pantry Newsletter by Food Bank Region $\quad 80$

Table 59. Systemic Supports Mean Importance Rank by Food Bank Region 81

Table 60. Utility Assistance by Food Bank Region 81

Table 61. Housing/Rent Assistance by Food Bank Region 82 
"WE ONLY DO FOOD"

Table 62. Transportation Assistance by Food Bank Region 82

Table 63. Engagement with Elected Officials by Food Bank Region 83

Table 64. Job Skills Training by Food Bank Region 84

Table 65. Panty Client Employment Opportunities by Food Bank Region 84

Table 66. Educational Programs or Assistance by Food Bank Region 85

Table 67. Financial Literacy Training by Food Bank Region 85

Table 68. Voter Registration by Food Bank Region $\quad 86$

Table 69. Translation Services by Food Bank Region 86

Table 70. Survey Respondent Demographics 88

Table 71. Average Attribution Domain Scores by Food Bank Region 90

Table 72. Director Primary Poverty Attribution Domain by Food Bank Region 90

Table 73. Food Pantry Director Beliefs About Food Pantry Services 91

Table 74: Latent profile analysis statistics and fit indices $(\mathrm{N}=334)$

Table 75. "Justice-Oriented Pantry" Directors Financial Trend Breakdown 112

Figure 1: Latent profile analysis profile characteristics $(n=334)$

Figure 2. Mean age of directors by food panty typology 99 


\begin{abstract}
Food pantries are a critical social safety net for food insecure households, yet the growth of food pantry services in the United States has not been accompanied by an equal increase in research related to their organizational structuring. A state-wide survey of Missouri food pantries in the Feeding America network was conducted to investigate a) how food pantries are structured, b) the social assumptions of poverty that food pantry directors hold, and c) how these assumptions inform the structuring of services. Latent profile analysis of food pantry structuring identified a clear grouping of pantry service models, with results showing support for emerging food justice strategies to emergency food structuring. While past research has identified links between social beliefs and actions, food pantry director assumptions of poverty were not a strong predictor for food pantry structuring. Additionally, many key demographic indicators that have been previously associated with assumptions of poverty were not strong predictors for food pantry structuring. Results from this study highlight the complexity of how and why food pantries are structured in the ways that they are. While pantry directors identified a number of activities as 'important' to ideal pantry operations, the engagement with these activities at their pantries was often limited, with many not even providing referrals to community support organizations. Future research should focus on better understanding the complexity of what guides directors' organization of pantry services. Research should also extend to understanding the social assumptions that guide emergency food strategies at regional and state levels.
\end{abstract}


"WE ONLY DO FOOD”

\section{Chapter 1: Introduction}

Since the 1980's, the United States has experienced a dramatic growth in the utilization of food pantry services as a strategy for hunger alleviation. The growth of private food assistance programs is strongly tied to periods of economic instability and shifts in government policy away from public assistance programs (Poppendieck, 1999). Moreover, coinciding with the changes to qualifications for public food assistance programs, and the growth of private food assistance, is the increase in hunger in the United States, with food insecurity increasing by 50\% since 1990 . In $2018,11.1 \%$ (14.3 million) of households in the United States faced food insecurity at some point during the year, with $4.3 \%$ (5.6 million) of households facing very-low food security (ColemanJensen, Rabbitt, Gregory, \& Singh, 2019). Despite continued public efforts to fulfill food need in the United States, private organizations, like food pantries and soup kitchens, have emerged to fill gaps in food support for low-income families not met by public programs (Poppendieck, 1999; Gundersen et al., 2016; Mabli \& Worthinton, 2017).

The number of pantry users in the United States has increased dramatically in the past two decades, with $26 \%$ of food insecure households utilizing food pantries in 2017 , a 44\% increase from 18\% in 2001 (Colman-Jenson, 2018). Within their last Hunger in America report, Feeding America, the leading domestic hunger-relief organization in the United States, reported that the agencies within their network provided food assistance to an estimated 46.5 million unique clients, from 15.5 million households each year (Weinfield et al., 2014). This represents an increase of $81 \%$ in individuals served through agencies associated Feeding America since 1997 (Second Harvest, 1997). Feeding America also indicates that a number of their clients are receiving food assistance from 
"WE ONLY DO FOOD"

their network agencies repeatedly throughout the year. (Kim, Ohils, \& Cohen, 2001; O’Brien \& Aldeen, 2001; Mabli, Cohen, Potter, \& Zhao, 2010; Weinfield et al., 2014) Through this growth in private food assistance, food pantries are supplying a growing percentage of monthly food provisions for individuals and households in the United States, and for longer periods of time (Foulkes, Hermsen, Raedeke, Rikoon, \& Whiting, 2005; Foulkes, Heflin, Hermsen, Raedeke, \& Rikoon, 2011; Cafer, Foulkes, Heflin, Hermsen, Raedeke, \& Rikoon, 2013).

These shifts in pantry use trends point to the institutionalization of food pantry services within food acquisition systems and existing social safety nets for those in need of food. In the latest Hunger in America National Report, $63.2 \%$ of food pantry client households planned to get food from charitable food programs each month (Weinfield, et. al., 2014). The dependence on food pantries for monthly food supplies by pantry users deepens the power held by pantries. As clients depend more on food pantries, these organizations, their directors, and the food banks that support them play an increasingly prominent role in the determination of the food that they eat and the experiences they have in acquiring it. Moreover, as the gatekeepers to food provisions, directors often have authority in the determination of potential nutrition standards of foods accepted and distributed, programs offered or supported by the pantry, and the environment in which clients receive food. While these gatekeepers of food pantries are often empowered by the social and organizational structures of the pantries they oversee, previous research has identified associations between food pantry use and disempowerment amongst food pantry clientele, specifically citing social vulnerability and stigma associated with food pantry use (Fisher, 2017; Poppendieck, 1999; Stein, 1989). Several factors, including 
"WE ONLY DO FOOD”

food pantry directors' perceptions of poverty, its causes and consequences, and the assumptions pantry directors have of individuals that experience poverty, are likely to impact power distributions, and in turn, outcomes experienced by pantry users.

The assumptions that surround the causes of poverty are often varied and socially constructed, and in turn influence how individuals perceive and address poverty as a social problem. Discourse on the social constructions of poverty, and the implications of such discourse, has been examined by a number of social sciences, with classical sociological theorists like Emile Durkheim, Karl Marx, Max Weber, and Erving Goffman all examining the causes and consequences of poverty within society. More recently, economists have extended these lines of work by linking assumptions about poverty to assistance programs designed to meet the needs of the impoverished, such that beliefs about poverty have a direct bearing on the organization of social, legal, and political systems designed to help those in need, as well as the pursuit of policies that address social needs (e.g., Schiller, 2007).

\section{Problem Statement}

Although researchers have long speculated about the links between beliefs about poverty and behaviors related to poverty assistance and alleviation, investigation of these associations in the context of food pantry services remains scarce. In light of the growing role that food pantries play in providing food to the hungry, as well as the declining support for public assistance programs, it is imperative that attention be given to how, and to what extent assumptions of poverty, specifically among food pantry directors, influence and shape the organization of food pantries and the well-being of pantry clientele. Through such investigation, food pantry operations and ideologies can be 
"WE ONLY DO FOOD”

challenged and improved to provide the greatest opportunity for effectively promoting food access and general welfare among pantry users.

\section{Study Purpose}

This study seeks to explore associations between the perceptions of poverty and the poor held by food pantry directors and the structure of pantry services and food delivery models. Despite the growth of food pantry services, knowledge and understanding of these organizations has not kept pace with the increased demand and reliance on food pantry services as response to hunger. Without this knowledge foundation, it is difficult to understand or address concerns within food justice work, specifically within the context of the food pantry. A more complete understanding of how food pantries structure their services and how this structuring is influenced by personal beliefs and assumptions about poverty, as well as the demographics of pantry directors (e.g., social class, religiosity, age, gender), provides a greater starting point for interventions. Thus, the goals of this study are three-fold: 1) to explore the ways in which food pantries are structured, 2) to understand the connections between these structures and pantry directors' beliefs and assumptions about poverty and the poor, and 3) to understand the relationship between relevant demographics of pantry directors and the associated pantry directors' beliefs and assumptions about poverty and the poor.

As food pantries are largely autonomous from larger regional and national emergency food entities, the ways in which these organizations structure their services, from the physical space to the programming offered, maintain the propensity to be highly varied. While this autonomy may provide opportunity for grassroots community strategies to be executed, it also creates a barrier to intervention and an environment 
"WE ONLY DO FOOD”

where the pantry lacks formal checks or accountability for the environment they create for clients. Empirical investigation of the factors that influence decisions regarding pantry structuring, as well as the implications of these decisions, is necessary to promote understanding about how pantries operate, and provide a point for further investigation into client outcomes and intervention in improving pantry structures and services for the end user.

Admittedly, this exploration is a dramatic break from how we have traditionally viewed charitable food services in the United States. Through the process of socialization, we have come to question the necessity of critical examination of charitable services within our country. Under most circumstances the feeding of the hungry is an activity that is deemed good, a judgment that renders us unwilling to look deeper into charitable food activities, and what Janet Poppendieck refers to as "The Halo Effect" (p. $150,1998)$. Consequently, some may find it inappropriate or counter-intuitive to question charitable causes or operations, which in turn may result in complacency. As a result of this halo effect, our understanding of food pantry services is largely descriptive; we rarely, if ever, dig deeper and strategically and intentionally question the processes that inform food pantry services. Nevertheless, empirical investigations of food pantry services, including why, how, and under what conditions such services are provided, holds the potential to improve understanding about existing disparities in food pantries and how we may best intervene or improve services for clients.

\section{Need for the Study}

Existing research conducted in relationship to the beliefs of food pantry directors is limited and largely stops at the examination of attributions and beliefs concerning 
"WE ONLY DO FOOD”

poverty. While it is critical to understand how pantry directors view their clientele and the overarching social phenomena that prompts food pantry use, it is also critical to examine how these views may in turn shape the services that food pantries offer their

clients. As the inclusion of specific services and operational styles have been shown to relate to positive client outcomes, and an assumed level of dignity within the services, the understanding of what precipitates the inclusion of these services is critical when investigating the connection between beliefs and behaviors. This is even more critical when trying to understand the disparity that exists between the general assumption of structural causes of poverty promoted by past research and the slow response to implement services and organizational strategies that align with this belief in food pantry services. The proposed study seeks to disrupt previous examinations of food pantries by facilitating a deeper understanding of the context and process through which beliefs and assumptions are materialized into services. Specifically, the proposed study will address three primary research questions:

\section{Research Questions \& Hypotheses}

RQ1: What help-giving typologies exist within food pantries?

H1: Food pantries will cluster into a discernible set of help-giving strategies

(i.e. types of services offered and user experiences) and will follow poverty attribution dispositions.

RQ2: How do the views and assumptions of poverty and the poor shape emergency food services at the pantry level, as determined by food pantry directors? 
"WE ONLY DO FOOD”

H2: $\quad$ Food pantry help-giving strategy typologies will correlate with pantry directors' attributions of poverty (i.e. structural with greater structural biased help-giving services and strategies...).

RQ3: How do food pantry directors' personal characteristics (i.e., social class origin, political orientation, gender, age, race, religiosity, pantry location, years of experience) relate to food pantry help-giving strategies/typologies?

$H 3-A$ : Pantry directors whose social class origin is more similar to pantry users will operate pantries that provide structural help-giving strategies.

$H 3-B$ : Pantry directors whose current financial situation is more secure will have fewer structural help-giving strategies.

H3-C: Pantry directors whose financial security is trending to more secure over time will operate pantries that provide more structural help-giving strategies.

$H 3-D$ : Liberal political orientations will be associated with greater structural help-giving strategies.

H3-E: Female directors will be more likely to provide more structural help-giving strategies.

$H 3-F$ : Age will be negatively correlated with structural help-giving strategies.

H3-G: Non-white directors will be more likely to provide more structural helpgiving strategies.

H3-H: Directors identifying greater levels of religiosity, and/or religious based operations will provide less structural help-giving strategies.

H3-I: Rural pantry directors will provide less structural help-giving strategies. 
"WE ONLY DO FOOD”

H3-J: Years of experience will be positively correlated with greater structural attributions of poverty and more structural help-giving strategies.

\section{Positionality Statement}

While the recognition of a researcher's positionality is more common within various forms of qualitative research, it is often left out of quantitative investigation. Methodological training in quantitative research often promotes an attempt to remove bias from surveys and statistical analysis; however, the theoretical biases and lived experiencers of any researcher shapes the research tools created, analytical approaches utilized, and the interpretation of results within the social sciences.

As a social scientist, I often gravitate to critical theories when investigating social phenomena, attempting to uncover and challenge power structures that promote inequitable experiences for particular groups. I believe that a more complete understanding of social phenomena can be obtained through the critical examination of social, political, and economic structures, and the roles they play in creating and perpetuating disparities and inequities. I believe that opportunities for social change exist within the unmasking of these structures, and the recognition for how social structures shape the potential for agency (Giddens, 1984). Within food scholarship, this theoretical disposition manifests in support for a food justice approach to understanding issues of food access and the recognition for approaches to hunger alleviation that address underlying issues of poverty, racism, and corporate interests in the dominant food system.

My understanding of food pantry services has been shaped by my extensive experience working in, and with, food pantries. Over the last five years, I have worked as a community engaged scholar in food pantries across the state of Missouri. As part of a 
"WE ONLY DO FOOD”

project that promoted community capacity building to provide opportunities for food pantries to expand provided services and increase access to gardening supplies (i.e. seeds, transplants, educational information), I spent a considerable amount of time working oneon-one with food pantry directors, staff, community partners, and clients. Stories of job loss, health emergencies, and lack of adequate social supports was common among food pantry clients. Food pantry directors echoed these roots of the need for food pantry utilization, but often expressed a distrust of clients and a hesitancy to provide services or take action to address these root causes. Further work with food pantry directors also included a nearly state-wide needs assessment of food pantries in Missouri. These experiences shaped both the concept for this research, survey development, and the lens for interpreting results of the study.

\section{Dissertation Organization}

\section{Chapter 1: Introduction}

This chapter provides a background for the study, leading to the identification of the central problem statement that guided the study and the explicit purpose of the study. The specific need for this study is recognized and guiding research questions are provided, with research hypothesis for each research question clearly delineated.

\section{Chapter 2: Literature Review}

This chapter clearly outlines the theoretical frameworks used in this study. Further review of relevant studies is provided with a summary that supports the research purpose, specific need, and guiding questions.

\section{Chapter 3: Methodology}


"WE ONLY DO FOOD"

This chapter outlines research design and an overview of the target population, sampling procedures, and participants. Additionally, a detailed outline of the survey instrument, survey procedures, and analytical strategies for data analysis are identified. Chapter 4: Descriptive Data

A detailed account of pantry organization and structuring is provided. Food pantry services and programs are examined within and across constructs and food bank regions. Additionally, food pantry director demographics are outlined in detail, with the attitudes and opinions of poverty held by directors identified in relationship to food bank affiliation and regional descriptors.

Chapter 5: Multivariate and Bivariate Data Analysis \& Results

Results of data analysis related to each research question is provided in this chapter. Both statistically significant and non-significant results are provided.

\section{Chapter 6: Discussion}

Study findings are examined in relationship to the body of existing literature. Recommendations are made for future research and policies at various levels of emergency food services based upon study findings.

Appendix A: Survey Instrument

Appendix B: Attributions of Poverty Short Form Questionnaire (Original and Edited Questions) 
"WE ONLY DO FOOD"

\section{Chapter 2: Literature Review}

Food systems at both national and global scales exemplify paradoxes of inequality, feeding and paying some while promoting hunger and poverty for others. While world agricultural production produces enough to provide each individual globally with over 2,700 calories daily (Weis, 2007), rates of hunger are rising globally, with $11 \%$ of the global population (815 million people) experiencing hunger (FAO, IFAD, UNICEF, WFP, \& WHO, 2017). Inequalities in food access and distribution result in over 36 million deaths worldwide attributed to hunger and malnutrition each year (Carolan, 2012) as roughly $40 \%$ of all food in developed countries is wasted, much of it on the consumer side (FAO, 2018). Domestically, while food is cheaper in the United States than any other county, with American consumers spending 9.6\% of their disposable income on food, the lowest income households in the United States spend nearly $33 \%$ of their available income on food, while the middle quintile spends only $13 \%$ of their income (USDA, 2016). Despite the abundance and general affordability of food in the United States, $11.1 \%$ of households in the United States are food insecure, with $4.3 \%$ of households having food insecurity with hunger (Coleman-Jensen, Rabbitt, Gregory, \& Singh, 2019).

Addressing the problem of "hunger amid plenty" in the United States takes on many forms. Public, or government funded, assistance programs like the Supplemental Nutrition Assistance Program (SNAP) and Woman, Infant, and Children (WIC) programs provide direct payments to qualifying individuals based on specific poverty guidelines. Additional public funding is in place to provide free and reduced-price school breakfast and lunches, as well as commodity purchase and distribution programs for qualifying 
"WE ONLY DO FOOD”

households and senior-specific programs. Private assistance programs also provide supports for individuals that are unable to access public programs or who's food needs aren't met by the support provided by these programs. These programs have traditionally been viewed as 'emergency' food assistance programs, emerging to address specific household emergencies and burgeoning to address largest economic emergencies affecting large portions of Americans. Private assistance programs take on a range of forms providing meals (i.e. soup kitchens) and food for consumption off-site (i.e. food pantries). While these emergency food programs have existed in the United States in some form since the Great Depression, they were largely small in scale and scope. However, the recession of the 1980's, in combination with sharp cuts to government spending on social programs, prompted the dramatic growth of private emergency food systems (Poppendieck, 1999). These programs have continued to expand even with improving financial times in the United States. Additionally, a growing connection of emergency food systems to public assistance distribution and corporate offloading of product has propped up this system as both an alternative and companion to publicly funded social safety nets. Despite their growth, emergency food systems are not without paradoxes of their own within the larger food system.

\section{Sociological Understandings of Emergency Food}

Food pantries and emergency food systems in the United States were established as a safety net for individuals facing short-term food crises. As emergency food systems have expanded to include a large network of food banks and pantries, redistributing food from private and corporate donors, the term may now be a bit of a misnomer. While the provisions from food pantries may still provide for individuals in specific moments of 


\section{"WE ONLY DO FOOD”}

crisis or disaster, emergency food systems have come to provide food for over 46 million Americans from over 15 million households (Weinfield et al., 2014). This represents an increase of $81 \%$ over the past 20 years. Given this rise in emergency food services, it is not surprising that sociological inquiry into various components of this service has also emerged. The investigation into these services and organizations has traditionally centered on the quantity, types, and quality of foods available to low-income populations through food pantry utilization and the effects of these food provisions on reducing food insecurity for users. However, an increasing number of critical critiques of emergency food systems has gained traction in the last decade, outlining the health and wellness outcomes of food pantry users, engaging with both the physical, social, and emotional components of health. Empirical investigation has also provided evaluations of programming implemented to address growing concerns with client outcomes related to food pantry utilization.

The charitable nature of food pantry services often leaves users at the mercy of donations in regard to the health, quality, and quantity of available foods. Interviews with Missouri food pantry directors indicating little interest in establishing health guidelines for donated or purchased foods (Grow Well Missouri, 2017). Studies of food pantry user diets have found large variations in dietary intake between and within study samples. Despite this wide range, studies consistently indicate that large percentages of food pantry users have intakes below dietary recommendations in both the types of foods they eat and the micronutrient levels of their diet. Regarding food types, systematic reviews of emergency food literature have found that food pantry clients are consuming amounts of fruits, vegetables, dairy, and protein less than suggested by nationally supported dietary 


\section{"WE ONLY DO FOOD"}

guidelines (Bazerghi, McKay, \& Dunn, 2016; Simmet, Depa, Tinnemann, \& StroebeleBenschop, 2017). Furthermore, food pantry users have also been found to have suboptimal intake of many micro-nutrients (Simmet, Depa, Tinnemann, \& StroebeleBenschop, 2017; Teron \& Tarasuk, 1999). Apart from the nutritional quality of emergency food resource, food pantry users often report deficient or undesirable food options within the provisions they receive or have access to through the use of food pantries (Oberholser \& Tuttle, 2004; Verpy, Smith, \& Reicks, 2003). When 'fresh' food options are available, donated produce includes items that stores or suppliers are no longer able to sell, leading to many donations that are near or past a point of spoiling and usefulness.

Inadequacies in dietary intake place emergency food service users at an elevated risk for developing/exacerbating major health problems and exemplifies the rise of the double burden of disease. The double burden of disease is a paradox in which hunger and malnutrition occur concurrently with chronic diseases (WHO, 2017). In the United States, the rates of obesity, high blood pressure, and heart disease have been found to be highest among the poor, the group most likely to also be food insecure (Tanaka, Mooney, \& Wolff, 2014; USDA, 2009; Cook et. al., 2004; Lee \& Frongillo, 2001; Olsen, 1999; Robaina \& Martin, 2013; Stuff et. al., 2004). Supporting this association between food insecurity and negative health outcomes is the disparity in rates of diabetes, high blood

pressure, high cholesterol, and obesity among low income groups, specifically, food pantry users. In longitudinal studies, researchers have found significantly higher rates of the aforementioned negative health outcomes among food pantry users when compared to rates of the general population in corresponding geographic area (Cafer et al., 2013; 
"WE ONLY DO FOOD”

Foulkes et al. 2011). While research on emergency food use seems to point toward an exacerbation of negative health outcomes, publicly funding programs of SNAP and TANF have been found to attenuate the association between fair/poor health among food insecure populations (Cook et. al, 2004).

As mentioned in the introduction, the number of individuals relying on emergency food services for food provisions at some point during the year is growing. Not only is the number of users growing, but clients are increasingly relying on emergency food for longer periods of time, with a growing number of emergency food service users receiving food assistance from agencies repeatedly throughout the year. (Kim, Ohils, \& Cohen, 2001; O’Brien \& Aldeen, 2001; Mabli, Cohen, Potter, \& Zhao, 2010; Weinfield et al., 2014). Additionally, research has indicated that food pantries are supplying a growing percentage of monthly food provisions for clients, and for longer periods of time (Foulkes, Hermsen, Raedeke, Rikoon, \& Whiting, 2005; Foulkes, Heflin, Hermsen, Raedeke, \& Rikoon, 2011; Cafer, Foulkes, Heflin, Hermsen, Raedeke, \& Rikoon, 2013). This trend of increasing dependence is likely tied to funding for public food assistance programs and changing qualifications requirements that limit their use for some users. With increasing household dependence on pantry provisions, the capacity for emergency foods to fill the gap and allow for food security among clients is of increasing importance. Research indicates however, that food pantry use does little to raise people out of a state of food insecurity (Daponte, Lewis, Sanders, \& Taylor, 1998; Daponte, 2000; Foulkes, Hermsen, Raedeke, Rikoon, \& Whiting, 2005; Foulkes, Heflin, Hermsen, Raedeke, \& Rikoon, 2011; Cafer, Foulkes, Heflin, Hermsen, Raedeke, \& Rikoon, 2013; Tarasuk \& Beaton; 1999). 
"WE ONLY DO FOOD”

Research on the outcomes associated with emergency food use have also extended beyond health and food security assessment, incorporating measures of social and emotional outcomes. Food assistance research within this area examined the stigma associated with food assistance use. Research has indicated levels of stigma associated with both public and private food assistance use (Bhattari, Duffy, \& Raymond, 2005; Daponte, Sanders, \& Taylor, 1999; Tarasuk \& Beaton; 1999; Poppendieck, 1998; Fisher, 2017; Saul \& Curtis 2013); however, results from this research posit varied findings, with the stigma of various food acquisition strategies varying by age and race (Martin, Cook, Rogers, \& Joseph, 2003). The admittance of a personal failure to provide enough food, and the reliance on food that others have deemed lesser in some capacity is a powerful force within emergency foods. However, this critical evaluation of emergency food systems is often met with a perceived need for graciousness in receiving this support, regardless of its quality (Poppendieck, 1998), and carries the potential to shape critical study and client challenge.

While the study of emergency food service has grown, the study of this hunger alleviation strategy is lacking in comparison to the scope of assistance it provides. For the research that does exist, studies of food pantries, and emergency food services more broadly, are often highly varied in methodology and measurement strategies, inconsistent at times in their findings, and large-scale assessments limited and difficult to conduct. By nature, the study of emergency food faces limitations through the organizational structure of these services. Agencies that serve as the point of contact with clients are largely autonomous, only loosely connected to regional food banks, who are tied to larger state and national agencies. As such, individual food pantries vary considerably in how they 


\section{"WE ONLY DO FOOD”}

structure their services, the data they collect from users, and the reporting that they are responsible for to larger agencies. Additionally, many food pantries in the United States are run nearly entirely by volunteer labor. These volunteers, already strained with increased pressure to meet the growing demand on food panties, are limited in their time, efforts, and skills to engage with or prompt further inquiry.

In looking at the research conducted around emergency food systems, many studies and critiques seem to fall into the same trap that is outlined by other scholars within this area of study, namely the problems associated with our measurements of success (and inherently failures) within emergency foods. The research being funded and conducted by emergency food organizations often seeks to obtain measurements that relate to how success is operationalized within emergency food work, namely pounds of food distributed, and number of people served. Through this focus, what work is being done is directed away from a more critical analysis of food pantry services that engages with clients and work that extends beyond headcounts and scale measurements, preserving the Halo Effect of emergency foods and charitable work.

The ways in which research into food pantry work is conducted has the potential to become something that holds food scholars and emergency food organizations back in more fully understanding the repercussions of this system and approach to hunger alleviation. "The more society celebrates its charitable food achievements, the further it defines these achievements as the solution to hunger rather than as an unfortunate activity it feels morally obligated to undertake because of our societal failure to prevent hunger in the first place." (Fisher, p.67) Efforts in the emergency food system to address deeper structural concerns needs to be accompanied by empirical investigation. Through 
"WE ONLY DO FOOD"

increases in this this type of research, emergency food scholarship can act as translational research to provide a framework for social change that is informed by a more complete understanding of client needs and the value of emergency food services in meeting those needs.

\section{Food Justice Movement in Emergency Food}

Given the sociological inquiry and critiques of emergency food services outlined above, it is evident that the utility of emergency foods as an alternative to publicly funded social programs is limited. Emergency food supports appear to be limited to just that, emergencies, with the provision of foods inconsistent and lacking in dietary quality and cultural acceptability. More broadly, the charitable assistance model does little to address issues that are causing lines to get longer at food pantries, instead aiming to simply fulfill this growing need through increasing food distributions. In light of this realization, efforts are emerging to address these concerns in the specific context of emergency foods.

Food justice efforts have largely emerged in response to the inequities that are created and perpetuated by the dominant food system and in response to concerns with the ability of community food security approaches ability to make a meaningful difference in the dominant practices of the larger food system in the United States. In response, community food justice efforts have "blended alternative food movement organizing with critical perspectives from the environmental justice movement and a historical understanding of struggles against economic and racial exploitation" (Broad, 2016, p. 53). This emerging approach is showing up in emergency food systems through the centering of a community and client-driven endeavors and recognizing and 
"WE ONLY DO FOOD"

addressing social determinants of health and food access rooted within larger unjust systems.

\section{Improved Conditions \& Supplies}

Responses to concerns with food pantry supplies and pantry conditions are centered on improving the response to hunger within the existing model of emergency food. The solutions tend to focus on bigger and better buildings, alternative models of engagement with clients, and alterations of policies centered around health standards of accepted foods. Within this rationality, if food pantries secured a larger building with better storage capabilities, they would be able to obtain and distribute more food to their clients.

Beyond physical capacity, emergency food organizations are implementing some form of national standards for donations or seeking out and establishing partnerships with local growers and state organizations to obtain greater quantities of fruits, vegetables, and protein sources. Additionally, changing distribution models to include choice models would provide greater efficiencies in getting food to emergency food users that they would actually use and provide an increased level of dignity within the context of a charitable emergency food model.

Issues with this response are summarized through the sentiments of a food pantry director in Missouri when asked about concerns with the health of the food offered:

"I think a lot of the people we see in the pantry could benefit from a nutritional diet as opposed to the hostess Twinkies. But on the other hand, if the people at Twinkie and hostess are donating the food... we're appreciative to get it...

Personally, I'd love to see a lot more fresh vegetables, potatoes, carrots... 
"WE ONLY DO FOOD”

anything like that that is raw and not in a box. But that's my personal preference.

Do I think there needs to be guidelines... I don't know. It's like looking a gift horse in the mouth... So, it would be nice if there were some types of guidelines that were followed, but if it meant ruling out food, then... I'd say food is food." While there may be a desire for improving the quality of foods received, the underlying issues of a charitable response to hunger stagnate efforts for change within the system. Without a more direct alteration of the lens though which emergency foods are seen, there may be little hope for transformative changes to occur that extend beyond users choosing between marginally better food options in a newer or nicer building.

\section{Increased Political Activism}

In an attempt to engage with deeper structural issues that create and perpetuate hunger in the United States, one area of potential progress is in increasing the efforts of food pantries and food banks to lobby for social change. Through more direct social and political activism, emergency food organizations can utilize their social capital to encourage political change. Food banks could begin supporting calls for increases to minimum wage, economic development, workers' rights, and access to affordable housing and medical care. It is through this political engagement that emergency food systems can not only provide food but also engage in social justice efforts.

Despite the pressure to engage deeper in the political landscape as advocacy partners for the clients that they serve, the answer may not be so simple. Not all advocacy is created equal, and simply incorporating advocacy policies does not ensure that political advocacy by emergency food entities will target structural causes of hunger and inequality (i.e. minimum wage increases, immigration reform, expansion of public 
"WE ONLY DO FOOD”

hunger alleviation programs). Organizations may instead lobby for continued or expanded supports for charitable solutions strategies. Feeding America, the leading domestic hunger-relief organization in the United States, identifies political advocacy as a critical component of their operations. Their activism centers on "advocating for funding for the programs that help feed people facing hunger", "working to strengthen federal tax policies that support charitable giving" and promoting policies in the Farm Bill that protect SNAP, TEFAP, and CSFP programs (Feeding America, 2017). As advocacy generally falls further up the emergency food chain, situated within organizational entities with greater ties and dependency on industry relations, it isn't surprising that advocacy practices would seek to promote its financial interest (the growth and sustaining of food banks) and the relations it has with corporate donors.

In examining the "justice" approach through a political economy lens, one can see that the answer is not so simple, with causes for concern still present. Capitalistic and neo-liberal forces are very entrenched in our society and inevitably the solutions to social problems that we have. Food banks have transitioned into an institution whose rationality conflicts with the interests of clients. Food banks must sustain financial capital to maintain fleets of trucks and trailers, distribution and storage centers, and administrative costs, often turning to corporate interests that play a critical role in creating and supporting injustices that food pantries are attempting to address. To challenge corporate powers not only endangers food donations, but also large financial supports.

\section{A Complete Paradigm Shift}

Given the sociological inquiry and critiques of emergency food services outlined above, it is evident that the utility of emergency foods as an alternative to publicly funded 
"WE ONLY DO FOOD”

social programs is limited. Emergency food appears to be limited to just that, emergencies. Their provision of foods is inconsistent and lacking in dietary quality and cultural acceptability, with research pointing toward a connection between health disparities among low income populations relying on emergency food and the diets that they have access to through these resources. Additionally, the charitable assistance model does little to address issues that are causing lines to get longer at food pantries, instead aiming to fulfill this growing need. In light of this realization, it appears that emergency food systems are a Band-Aid solution on the gaping social wound of hunger (Poppendieck, 1998; Fisher, 2017). In recognizing this, it appears that the best step forward within emergency food services is a complete paradigm shift that no longer embraces emergency food as an alternative, but instead utilizes it as a tool for change. The institutionalization of emergency food over the past thirty years has created a space and platform for social influence and the growth of a food justice movement within this system.

The call for a paradigm shift is not a new concept, with Janet Poppendieck starting the conversation nearly two decades ago. However, it is only in the past decade that this concept has gained traction on a larger scale. A growing number of individuals researching emergency food programs and a few emergency food service organizations have begun to organize, establishing national conferences, retooling food bank mission statements, expanding food programs that support local food systems and promote healthy and fresh food access for all people, and refocusing efforts on efforts that promote relationships and capacity building within and between individuals and communities. 
"WE ONLY DO FOOD"

It is within this vein of thought where promise for emergency food research, activism, and outreach lies. Through reorienting emergency foods to food justice work, steps can be made to not only meet food needs of users, but promote larger social shifts that allow them to no longer need assistance in meeting food needs. Examples of this transformative shift in food pantry services have been documented in efforts in both the U.S. and Canada, where pantries establish spaces and programs for community engagement and capacity building, provide greater dignity in the quality of food available and their right to client choice, and engage clients in the direction, organization, and implementation of services (Saul \& Curtis, 2013; Martin, Wu, Wolff, Colantonio, \& Grady; 2013). This transformative work is often slow, as it is stands in stark contrast to existing emergency food systems. What started as an unplanned response and burgeoned over the last thirty years into the institutionalized network of multi-million-dollar organizations capturing, storing, and trucking millions of pounds of food around the United States will likely take time to change (Fisher, 2017).

Within scholarly emergency food work, our guiding questions must shift from questions of "How can we help to find ways to increase the food supply through food banks and food pantries?" to "What can we do to help emergency food services utilize their resources to effect social change that makes them no longer needed?". While I don't imagine a world or nation in which social inequalities don't exist, I believe that shifting our guiding questions to deeper structural questions and loftier goals provides an opportunity that would promote more just and equitable solutions to hunger that provide opportunity for extending positive outcomes beyond food to the improvement of communities, effectively addressing all of the critiques outlined above. Emergency food 
"WE ONLY DO FOOD”

can no longer be the frame for which our solution is built, but instead a tool through which a solution can be achieved. A shift must occur to identify that reliance on emergency food does not promote food security, unless we deem emergency food a socially accepted form of food acquisition.

\section{Food Pantry Typologies}

Driving this emerging field of investigation should be a clear understanding of the baseline from which the food justice work is starting. A clear understanding of food pantry programming and the components that pantry directors see as critical to operating their ideal vision of a food pantry are necessary for understanding the capacity and path to change within the current emergency food system. However, past research on food pantry operations has been limited, both in quantity and the nature of the empirical research.

Previous investigations have looked into the individual demographics of pantry users, the types of food distributed by pantries, health outcomes of pantry users (physical and emotional), who runs food pantries, and a few studies investigating the client outcomes associated with specific operational structures or specific food distribution strategies. Through all of this research, the empirical knowledge that has been created has failed to investigate the intervention in a more holistic nature, specifically the basis for

why and how this intervention is being carried out. We know very little about the drivers of determining the structures of food pantries or the services that they offer, despite recognition that some level of variability of services exists.

This variability is a key component of this study. Food pantries and research around this intervention largely treat these individual entities as a fairly homogenous 
"WE ONLY DO FOOD”

group, disguising the variability in services offered, general environment created for human interaction, and attempts at maintaining dignity within a socially vulnerable situation. Variability in methods of food distribution may range from fully autonomous shopping models to predetermined boxes. Clients may be limited in when or how often they can use pantry services, and may have to provide a range of personal documentation at each visit or only once a year. These are only a few examples of the variability that exists within pantry organization. Through a more complete understanding of the range of ways that pantries can structure services and engage with clients, a collective dialogue can take place with a shared vocabulary and more complete understanding of the role that food pantries play addressing hunger among food pantry directors.

\section{Perceptions and Attitudes about Poverty}

The United States, in a global context, is a nation of wealth, power, and opportunity. Americans earn higher average incomes and have greater access to education and health resources than almost all other countries. Despite this high level of affluence, 40.6 million Americans still experience poverty (Semega, Ronternot, \& Kollar, 2017). While the context of poverty may differ from other countries, the disparities in financial resources within the United States remain real and persistent. Poverty is not only a problem recognized by the impoverished, as opinion polls from the general public often cite poverty as one of the main problems facing the United States (Schiller, 2001). Attempts to distinguish public opinion on the causes of poverty is historically linked to attempts in gauging support for government programs to address poverty, an effort that originated in the 1960 's. Since that time, concerns about poverty have risen consistently 
"WE ONLY DO FOOD”

among the American public (Schiller, 2001), with current political campaigns attending to this issue in the wake of the recent recession and a changing global economy.

Explanations and assumptions around poverty, like any other topic, are highly influenced by culture and processes of socialization (Triandis, 1995). Early research on American's attitudes toward poverty pointed toward a rough consensus or "dominant ideology". This dominant ideology posits that Americans hold to a belief that widespread economic opportunity exists, individuals are responsible for their lives, and some level of economic inequality is fair and just (Kluegel \& Smith, 1986). Given this disposition, Americans are most likely to explain poverty as a result of individual flaws when attempting to identify the causes of poverty for others (Ferrante, 2006; Hopkins, 2009; Seccombe, James, \& Walters, 1998). This tendency to 'otherize' individuals experiencing hardship may act as a self-protective measure and a means by which individuals may separate themselves from realities they perceive as negative or adverse (Seccombe, James, \& Walters, 1998).

Interestingly, in cases where individuals themselves are experiencing economic hardship, however, shifts in attitudes about poverty are more common. Americans who describe themselves as financially stable are more likely to cite intrinsic reasons for poverty when explaining why others are in poverty, whereas Americans who describe themselves as financially unstable are more likely to cite extrinsic reasons for poverty (Crumley, 2013). Again, these attributions are often self-preserving and serve to protect the interests of the individuals making the attributions. Collectively, these assumptions and patterns in attribution seem to align with many of the dominant stereotypes surrounding individuals utilizing both public and private food assistance, most notably 
"WE ONLY DO FOOD"

the "welfare queen" stereotypes that emerged during the 1980's. Even among recipients of welfare, the tendency to attribute the use of welfare by others to individualistic causes is seen (Seccombe, James, \& Walters, 1998).

Although research into the causes and attributions of poverty among Americans has identified this common ideology, multi-dimensional views of poverty have sought to extend the understanding of poverty attributions and account for findings that point toward individualistic and structural attributions not being mutually exclusive ideological alternatives. Multi-dimensional frameworks have received a great deal of interest, with the development of psychometric tools taking off during the 1970's, in promoting a more complex and complete understanding of individual beliefs (Weiner, 2010; Weiner, 2014). Based largely on the dimensions promoted by Feagin, much of the existing multidimensional research on the perceptions of poverty has centered on the interpretations of poverty within the areas of Individual, Structural, and Fatalistic explanations. Within individualistic explanations, the impetus of poverty is placed on the flawed characteristics of the poor; that is, poor individuals are poor because they are lazy, uneducated, drug users, etc. Structural explanations stress the role of social circumstances or systems in the creation and perpetuation of poverty; in other words, individuals are poor because of restricted opportunity. Finally, fatalistic explanations identify fate as the driver of poverty, such that individuals are poor because of bad luck, illness, or the alignment of the stars. In simplest form, others have consolidated these explanations of poverty to either factors outside an individual's control (extrinsic) or individual flaws (intrinsic) (Feagin 1972; Feagin, 1975). 
"WE ONLY DO FOOD”

\section{The Connection of Beliefs and Behavior}

Sociological scholarly investigation has firm roots within the connection between ones beliefs and the actions or behaviors that one undertakes. Theoretical dispositions shape our ontological and epistemological assumptions, and the ways in researchers study phenomenon of interest. Moreover, scholars from a variety of disciplines, including medicine, public health, and social work, have examined how one's beliefs and assumptions shape human interactions, as well as interventions for aid.

Evidence of these associations is not bound to academic discourse. After his appointment as Housing and Urban Development Secretary, Dr. Ben Carson stated in an interview with Armstrong Williams:

Poverty to a large extent is also a state of mind. You take somebody that has the right mindset, you can take everything from them and put them on the street, and I guarantee you in a little while they'll be right back up there. And you take somebody with the wrong mindset, you can give them everything in the world, they'll work their way right back down to the bottom.

Given the power of the Dr. Carson's position, his beliefs play a critical role in deciding if, how, and to what extent assistance is provided to those in poverty. His personal beliefs have the power to shape the public tone surrounding institutional assistance. Such a connection becomes even more apparent as Dr. Carson further posits how to address poverty in his interview:

So, a lot of it also has to do with what we teach children. Because parenting is a very difficult job. You have to instill into that child the mindset of a winner, if they're likely to become a winner. If you're always telling them they're no good, 
"WE ONLY DO FOOD"

they're rotten, they hear that constantly, they see that around them, then it shouldn't surprise anybody that that's where the vast majority of them are going to go.

Through specifically defining the source of the problem as parenting and intrinsic qualities, one also implicitly defines the range of solutions that available to address the issue of concern. By identifying a personal mindset as the root of poverty, the solution to the problem inherently becomes one in which individuals must change the way they think about themselves, specifically through a change in parenting, rather than a range of alternatives that may include increasing access to quality education, increasing access to jobs that pay fair wages, or providing access to affordable, convenient, quality healthcare.

Within food pantry services. Despite the wide range of literature on attributions of poverty and the significance that beliefs play within social intervention, only a handful of studies have examined the attitudes that pantry directors have toward poverty. Additionally, amongst these studies, even fewer have specifically explored the associations between the beliefs of pantry directors' and behaviors related to pantry operations and organization. Within existing literature, we have a glimpse into the reality of how beliefs and actions are connected within emergency food systems.

In one of the available studies, Molnar, Duffy, Claxton, and Bailey identified that personal connections with clients in rural food pantries was associated with more extrinsic attributions and less stigmatized and personal experiences for clients than those in urban settings (2001). Race and educational attainment were also found to correlate to attribution style. African Americans and individuals with higher educational attainment were more likely to attribute poverty to structural and extrinsic causes than individual 


\section{"WE ONLY DO FOOD”}

flaws. In Stein's examination of food pantry and soup kitchen workers, the attitudes toward clients was largely shaped by the social environment of the soup kitchen or food pantries. In organizations that had social environments among workers where clients were identified as ungrateful or abusing services, staff was more likely to demonstrate short tempers and less patience with clients (1989). Additionally, the services at food pantries was found to change based upon the attitudes of directors within one study. Specifically, directors with more structural views were also more likely to include new and additional services within pantry operations, including educational and economic assistance programs (Robinson, 2012) In comparison, another study found that directors with more individualistic attributions were more likely to report misuse or abuse of welfare and pantry services (Duffy et al., 2006).

Despite efforts to connect attribution styles of food pantry directors to activities at food pantries, the body of empirical literature examines the assumptions within the context of specific actions by food pantry directors, while little is done to understand how these assumptions shape the organization of services on a larger scale and in relationship to overall programming. This study provides the opportunity to investigate this gap in literature and develop an understanding for the role that social assumptions of poverty play in the various forms that food pantry services can take on.

Other social service contexts. In related disciplines, such as social work, variation within individual attitudes and attributions of poverty is common, yet findings generally yield a preference for more positive attitudes toward individuals in poverty and emphasize the role of structural causes of poverty among clients. In Reeser and Epstein's study of social workers in New York City, an increasingly structural attribution of 


\section{"WE ONLY DO FOOD”}

poverty was seen from the late 1960 's to the early 1980's. While structural attributions

are the most prevalent in the samples within the included studies, similarities were also found in the ranking of the remaining attributional types. Fatalistic attributions were commonly ranked second to structural attributions, with individualistic attributions being the least common among social workers (1987).

Although it is important to understand beliefs about and attributions of poverty, it is the intersection of belief and behavior that is of critical interest for this study, specifically in the context of poverty and food pantry directors. Given the existing gaps in the existing body of literature in this area, one must look to related fields to examine how beliefs shape behaviors and services of social service professions with the aim of assisting individuals and families in poverty. Research from other disciplines can provide a starting point for discussion and investigation. Scholars within the disciplines of medicine, public health, and social work, have examined how one's beliefs and assumptions shape human interactions, as well as interventions for aid.

In a study of Medicaid office workers, employees' personal beliefs about causes of poverty significantly predicted if, how, and to what extent they helped individuals seeking Medicaid services (Seccombe, 2013). Further, in Kingfisher's (1998) examination of social workers in Michigan, negative perceptions of clients dictated the support that was provided to clients, including the programs and assistance that were encouraged to apply for despite legal eligibility. As social workers assisted in the distribution and completion of applications, individual worker attitudes played a role in whether or not patrons were encouraged to apply for services, which in turn impacted service acquisition and scope of assistance garnered through the services. Reingold and 


\section{"WE ONLY DO FOOD"}

Liu found similar trends in their 2009 study in Indiana. Social Service directors who held stronger individualistic attributions of poverty were less likely to increase services or engage in political activities to boost social supports. Comparatively, directors who more strongly endorsed structural causes of poverty were more likely to engage in progressive organizations, adopt new programs and develop collaborative strategies.

In some cases, job experiences of social service industry workers (e.g., time in position) have been shown to be associated with a more positive attitude toward poverty and greater structural and fatalistic attributions (Rehner, Ishee, Salloum, \& Velasues, 1997). Moreover, variations in attribution trends have been found between types of service providers. Research by Reingold \& Liu (2009) indicated that faith-based and government organizations were more likely to hold individualistic attributions of poverty over non-governmental and food service agencies. Considered collectively, such findings suggest that some factors, such as greater experience with clients or job type, may facilitate a move away from individualistic attributions to more extrinsic attributions. The mixed results from research in this area provide an even more compelling reason to further investigate the associations between beliefs and behaviors, and the factors that may disrupt negative, pervasive connections.

As a profession, service-industry workers (e.g., social workers, government employees, non-profit administrators) are called to assist in the acquisition of resources and improvement of social welfare amongst individuals they serve, particularly lowincome populations. With consistent interaction with poverty and often acting as the gatekeepers to helpful services, the perceptions that these workers have of their clients is crucial to the quality and types of services provided. Food pantry workers are no 
"WE ONLY DO FOOD”

different; workers have consistent contact with populations that are experiencing the consequences and hardships associated with poverty, and the decisions they make can, and often do, significantly impact the day-to-day lives of individuals and families in their communities. Decisions about how to operate their pantry, the foods they purchase for distribution, the food donations they accept, and the programs they offer (or don't offer) have important implications for their pantry, and empirical investigation regarding the impact of poverty beliefs on food pantry services is needed. 
"WE ONLY DO FOOD”

\section{Chapter 3: Methodology}

Research methodologies were selected based upon the proposed research questions:

$R Q 1: \quad$ What help-giving typologies exist within food pantries?

RQ2: How do the views and assumptions of poverty and the poor shape emergency food services at the pantry level, as determined by food pantry directors?

RQ3: How do food pantry directors' personal characteristics (i.e., social class origin, political orientation, gender, age, race, religiosity, pantry location, years of experience) relate to food pantry help-giving strategies/typologies?

\section{Study Design}

A cross-sectional survey research design was utilized for this study. The utilization of this methodology was predicated on the specificity of time and population from which data were to be collected (Visser, Krosnick, \& Lavrakas, 2000). More specifically, the study was designed to assess the frequency of various food pantry practices and organizational structures, in addition to the beliefs of food pantry directors. This data was collected at a given point in time, within a specific population of directors that operate food pantries affiliated with one of the six regional food banks that are a part of the Feeding Missouri network ${ }^{1}$. Cross-sectional survey methodologies are most traditionally utilized to document the frequencies of behaviors and held beliefs and attitudes within social science research. Additionally, this methodology provides opportunity to assess relationships between variables and sub-groups within the population/sample (Visser, Krosnick, \& Lavrakas, 2000).

\footnotetext{
${ }^{1}$ A $7^{\text {th }}$ regional food bank in St. Louis, Operation Food Search, was not included in this study, as they are not affiliated with Feeding America.
} 
"WE ONLY DO FOOD”

\section{Data Collection}

The survey was created and self-administered through the online survey tool, QualtricsXM. This program provides a computer-based platform alternative to traditional paper survey distributions. Survey data is collected and stored securely in the online platform, with a range of data export options to match software utilized for analysis.

The survey was available to food pantry directors across the state of Missouri over a three-week period in February and March of 2019, through an anonymous and secure internet link. This mode of administration was selected on the basis cost, accessibility, timeframe, and potential for higher response rates. In comparison to traditional mail surveys, or in-person/phone interviews, the use of the internet-based survey provides a great cost savings. Funds for printing, mailing, travel, facilities, and staffing costs were not required for administering the survey through the online survey tool. This platform also provides the greatest potential for collecting data in the timeliest manner, again, as mailing and individual survey administration are not required (Evans \& Mathur 2018). Finally, engagement with online surveys has shown higher response rates than other forms of survey administration (Beebe, Jacobson, Jenkins, Lackore, \& Finney Rutten, 2018; Greenlaw \& Brown-Welty, 2009; Griffis, Goldsby, \& Cooper, 2003).

\section{Survey Development \& Measures}

The survey tool was composed of three general sections: Food Pantry Structuring, Attributions and Assumption of Poverty, and Demographic/Background Information. The survey was constructed, tested, and distributed in the online survey tool, QualtricsXM (Qualtrics, Provo, UT). Development of the survey followed a multi-step approach that began with initial question construction by the researcher, with additional refinement and 


\section{"WE ONLY DO FOOD"}

revisions completed through collaboration with other members of the Interdisciplinary Center for Food Security at the University of Missouri. The survey was also distributed to Feeding Missouri and the six regional food banks across the state for review prior to distribution to food pantry directors. Recommendations and revisions from these partner agencies were used in finalizing the survey wording and order. After content was established, the survey underwent testing to ensure proper skip and display logic for all possible combinations, with 20 pre-tests completed. The final survey was distributed through an anonymous and secure link, created for the survey through the QualtricsXM platform, included in recruitment emails to all potential participant. The final version of the survey included 73 questions across the three general sections. A complete version of the survey is included in Appendix A.

The survey instrument included three primary sections: Food Pantry Operations, Attitudes toward Poverty, and Demographics. Questions followed an identical flow for each participant except for those in the Attitudes toward Poverty section. Questions in this section were randomized to ensure that respondents weren't answering questions related to each attribution style in order ${ }^{2}$.

Food Pantry Operations. Participants identified key features of operations at their food pantry. Items within this list were based on extensive experience implementing programs in food pantries, observing the ways in which food panties structure their operations and the services that they do or do not provide, previous survey development for a nearly state-wide food pantry needs assessment (Taking Stock, 2016), and program classification by Feeding America (Feeding America, 2014). A total of 52 programs,

\footnotetext{
${ }^{2}$ Randomization of the Attributions of Poverty - Short Form measure follows administration of the measure during development.
} 
"WE ONLY DO FOOD”

services, and organizational strategies were included, across five distinct categories:

Direct Food Provisions, Other Food Supports, Health/Personal Care Supports,

Organizational Structuring, and Systemic Supports.

Table 1. Food Pantry Service/Program Construct Breakdown

\begin{tabular}{|c|c|c|c|c|}
\hline $\begin{array}{l}\text { Direct Food } \\
\text { Provisions }\end{array}$ & $\begin{array}{l}\text { Other Food } \\
\text { Supports }\end{array}$ & $\begin{array}{c}\text { Health/Personal } \\
\text { Care Supports }\end{array}$ & $\begin{array}{l}\text { Organizational } \\
\text { Structuring }\end{array}$ & Systemic Supports \\
\hline $\begin{array}{l}\text { Commodity } \\
\text { Distribution }\end{array}$ & SNAP Enrollment & $\begin{array}{l}\text { Mental Health } \\
\text { Services }\end{array}$ & Thrift Shop & Utility Assistance \\
\hline Senior Box & WIC Enrollment & Health Screenings & $\begin{array}{l}\text { Religious } \\
\text { Programming }\end{array}$ & $\begin{array}{l}\text { Housing/Rent } \\
\text { Assistance }\end{array}$ \\
\hline Food Delivery & TANF Enrollment & Dental Screenings & Visible Signage & $\begin{array}{l}\text { Transportation } \\
\text { Assistance }\end{array}$ \\
\hline $\begin{array}{l}\text { Meal Program/ } \\
\text { Soup Kitchen }\end{array}$ & $\begin{array}{l}\text { Off-Site Community } \\
\text { Garden }\end{array}$ & Reproductive Health & $\begin{array}{l}\text { Clearly Identified } \\
\text { Hours of Operation }\end{array}$ & $\begin{array}{l}\text { Engagement } w / \\
\text { elected officials }\end{array}$ \\
\hline $\begin{array}{l}\text { Buddy Pack/ } \\
\text { BackSnack }\end{array}$ & $\begin{array}{l}\text { Cooking } \\
\text { Demonstrations }\end{array}$ & Smoking Cessation & $\begin{array}{l}\text { Up-to-date } \\
\text { Website/Social } \\
\text { Media }\end{array}$ & Job skills training \\
\hline $\begin{array}{l}\text { Food for chronic } \\
\text { conditions }\end{array}$ & $\begin{array}{l}\text { Nutrition Education } \\
\text { Courses }\end{array}$ & $\begin{array}{l}\text { Drug \& Alcohol } \\
\text { Treatment }\end{array}$ & $\begin{array}{l}\text { Seating area for } \\
\text { clients }\end{array}$ & $\begin{array}{l}\text { Employment } \\
\text { opportunities }\end{array}$ \\
\hline $\begin{array}{l}\text { Health guidelines } \\
\text { for food donations }\end{array}$ & General Recipes & $\begin{array}{l}\text { Chronic Disease } \\
\text { Management }\end{array}$ & Area for children & $\begin{array}{l}\text { Educational } \\
\text { Programs/Assistanc } \\
\text { e }\end{array}$ \\
\hline $\begin{array}{l}\text { Onsite Community } \\
\text { Garden }\end{array}$ & $\begin{array}{l}\text { Nutrition } \\
\text { Information via } \\
\text { posters or flyers }\end{array}$ & Domestic Violence & $\begin{array}{l}\text { Opportunity for } \\
\text { client feedback }\end{array}$ & $\begin{array}{l}\text { Financial Literacy } \\
\text { Training }\end{array}$ \\
\hline $\begin{array}{l}\text { Recipes for } \\
\text { distributed foods }\end{array}$ & $\begin{array}{l}\text { Gardening Supplies } \\
\text { \&/or education }\end{array}$ & $\begin{array}{l}\text { Health Insurance } \\
\text { Information }\end{array}$ & $\begin{array}{l}\text { Opportunity for } \\
\text { clients to serve on } \\
\text { board/staff }\end{array}$ & Voter Registration \\
\hline Formula & & $\begin{array}{l}\text { Personal Care Items } \\
\text { Diapers } \\
\text { Household/cleaning } \\
\text { Items }\end{array}$ & $\begin{array}{l}\text { Pantry Newsletter } \\
\text { Social \&/or Cultural } \\
\text { events }\end{array}$ & Translation Services \\
\hline
\end{tabular}

Food pantry directs identified if their pantry provided the service, offered referrals

to organizations that provided assistance for the specific service, or did neither.

Additionally, directors identified if pantries utilized distinct client interaction and 
"WE ONLY DO FOOD”

engagement approaches. After identification of the engagement with each item, food pantry directors identified how important they felt offering the service or organizational approach is to operating what they would consider their 'ideal' food pantry. Importance was measured using a 5-point likert scale, with ' 1 ' being "Not at all important" and ' 5 ' being "Very Important".

Attitudes toward poverty. Individual attitudes toward poverty were measured using an adjusted form of the Attitudes Toward Poverty-Short Form (ATP-SF) scale developed by Hyun Yun \& Weaver (2010). Hyun \& Weaver's short form assessment is an extension of Atherton et al.'s (1993) single-factor Attitude toward Poverty scale, with allowances made for the multidimensionality of attitudes toward poverty promoted by previous research and measures promoted by Feagin (1972), Cryns (1977), and Golding \& Middleton (1982). In the development of this short-form measure, high levels of internal consistency and convergent validity with the original 37-item attitude toward poverty scale $(\propto=.87)$ were observed (Hyun \& Weaver, 2010)

Hyun \& Weaver's ATP-SF measure includes 21 items across three attribution dimensions related to poverty: 1) personal deficiency, 2) stigma, and 3) structural perspectives. Respondents were shown statements relating to causes of poverty and behaviors of individuals in poverty in a random order determined by the survey platform. Food pantry directors then indicated their level of agreement with the statement on a 5point Likert scale with 1= "Strongly Agree" and 5= "Strongly Disagree".

The ATP-SF measure included in the survey was not left in its original form. Changes were made to question wording, as common points of concern were noted by the researcher, other food systems researchers, and food bank affiliates. It was common 
"WE ONLY DO FOOD”

consensus between reviewers and pre-test participants that multiple questions contained wording that highlighted negative social stereotypes and utilized an overly deficit-based communication model. Given the social/food justice framework that guided this research, changes to wording were made in an attempt to balance negative assumptions that individuals may have, and a person-first approach. For example, the original question:

“Welfare mothers have babies to get more money.” (Hyun Yun \& Weaver, 2010) included a problematic patriarchal stereotype associated with poverty, and placed greater value on the use of welfare instead of the person rooted within the assumption. This question was reworded to read:

"Parents on welfare have additional children to get more money."

This alteration promotes the identification of the individual before the context. Additionally, it avoids the priming language of "welfare mothers" that carries political, cultural, and gender biases. All questions within the ATP-SF measure were assessed and changed following a similar format. Appendix $B$ provides the original questions and the questions utilized in the survey.

Demographic information. Respondents' demographic characteristics of economic social class origin (self-identified measure of perceived socioeconomic status of family respondent was raised in), political affiliation, gender identity, age, race, personal religious affiliation, pantry location (ZIP code), years of experience with food pantry, current financial security, and financial security trajectory during the past five years. The inclusion of these items is based on previous research and their role as predictive measures of attitudes toward poverty and service outcomes while working with populations commonly experiencing poverty (i.e. social workers; Seccombe, 2013). 
"WE ONLY DO FOOD"

\section{Sampling}

Food pantries are independent/self-governing organizations, loosely connected through regional, state, and national emergency food organizations and distribution chains. Because of this organizational structure, it is difficult to locate a comprehensive list of food pantries, within any geographic context, apart from the record of affiliates of regional food banks. The best opportunity for wide-range engagement with the population in question was through partnership with regional food banks and reliance on self-selection into participation.

Participants were recruited through their connection with one of six Missouri regional food banks affiliated with Feeding Missouri ${ }^{3}$. Participants self-selected to participate through recruitment emails distributed through regional food bank email listservs. This form of convenience sampling was utilized due to constraints in access to the population of interest, and a desire to obtain the largest sample possible of food pantry directors across the state.

A partnership was established with Feeding Missouri before reaching out to regional food bank affiliates. Support from Feeding Missouri provided the ability to utilize their name and affiliation in outreach communications, as well as opportunity for input in the construction of the survey. The endorsement from Feeding Missouri provided a unifying organization to recruit regional food banks to assist in study activities. Once support was obtained from the state-wide organization, connections were established with the six regional food banks under the Feeding Missouri umbrella. Partnerships with the regional food banks, and access to their email listservs, provided the point of contact for

\footnotetext{
${ }^{3}$ Operation Food Search, a St. Louis Food Bank, was not included in this study, as they are not affiliated with Feeding Missouri
} 


\section{"WE ONLY DO FOOD”}

all food pantry directors across the state of Missouri affiliated with the largest emergency food organizations at both state and national levels. This population is the most likely to include the agencies that provide the greatest emergency food supports for off-site consumption within the state. The reliance on partnerships with these larger state and regional organizations was done to strengthen the perceived value of participation among both the regional food banks and food pantry directors; as well as, promoting a unified state-wide study. These partnerships also simplified access to, and communication with, food pantry directors to solicit participation, while ideally increasing the response rates of pantry directors. This reliance on larger organizations and networks was informed by previous attempts to conduct state-wide research with food pantry directors in Missouri. In this past research, partnering with food banks, distributing the survey through their organizational communication channels, and collaborating with Feeding Missouri, has provided the best strategy for coordinating efforts across regional food banks and has yielded response rates of roughly $40 \%$ in past online surveys (Taking Stock, 2016).

Respondents were recruited through regional food bank email listservs of affiliate food pantry directors. To be eligible to participate, respondents were 1) at least 18 years of age, 2) English-speaking, 3) self-identified as a director of a food pantry in the state of Missouri affiliated with a regional food bank, and 4) have an email included in the regional food banks listserv. A link to the survey was sent to regional food bank staff along with a short message about the survey and instructions for participants. Regional food bank staff then sent the anonymous link and accompanying messaging explaining the survey to food pantry directors via email at set intervals during February and March 2019. An initial email was sent, with a reminder email sent 10 days, and 20 days, after 
"WE ONLY DO FOOD"

the initial email to promote increased response rates. Participation incentives also included a raffle drawing for one of ten \$50 Visa gift cards. Eligible respondents were able to self-select into the raffle following completion of the survey

\section{Data Cleaning}

Data was exported from the online survey tool after data collection was closed. All available data from every respondent was included in the original transfer. All responses that didn't complete the Informed Consent question $(n=91)$, or didn't consent to participation $(n=2)$ were removed from the data set. Next, all respondents that hadn't completed the Attributions of Poverty portion of the survey $(n=90)$ were excluded from the final sample, providing a final sample of $n=334$.

After the final sample was identified, cleaning of individual variables was completed. For data on the average number of individuals and households that utilize the food pantry, responses that were provided as a range were transposed to the median of the range (i.e. $20-40 \rightarrow 30$ ). Pantry operation times were converted to the number of hours the pantry was open each day during a typical month (i.e. 8:00 a.m. $-12: 00$ p.m. $\rightarrow 4$ hours). Food pantry open hours were then totaled for each week, and across the month. For food pantries that identified a religious affiliation, text entry responses indicating their specific affiliation were coded, based upon PEW Research Center categories, into a new variable. Respondents that reported their age as a range (i.e. "50's", “50-55”, or “Over 60") were assigned as missing. Respondents who selected multiple racial identifications were coded as "More than one".

\section{Data Analysis}


"WE ONLY DO FOOD"

Latent profile analysis (LPA), a form of finite mixture modeling (Berlin, Williams, \& Parra, 2014), was used to identify subgroupings within the data and organize pantries according to common discernible help-giving strategies/typologies underlying food pantry operations (i.e. services provided, user experience). LPA recovers subgroups, or latent classes, that occur naturally within observed data and share similar characteristics, allowing the researcher to identify distinct patterns in help-giving among food pantry directors. LPA provides both the profile/group affiliation for each subject within the selected model, and the likelihood of belonging to a specific subgroup for each respondent. While other LPA is similar to other clustering techniques in data modeling, it was chosen or it's greater flexibility. As LPA is based on an explicit model of the data, it accounts for the uncertainty in recovered groups. Additionally, the continuous nature of the observed data utilized in the model promoted the use of LPA over modeling techniques.

LPA was conducted using responses from food pantry directors related to the provision of various services through their pantry. Depending on the service, pantry directors were able to indicate if a service was provided, a referral \&/or voucher was provided for the identified service, or no such service was provided or referred. Individual services and programs, were grouped within the thematically similar constructs previously identified for analysis. Individual scores were given for varying levels of engagement across each service. For most items, scores of: $2=$ "Provides Service", 1= "Referral \&/or Voucher", 0= "No Service" were given. This was altered for services or activities in which a referral was not a plausible option: 1= "Provide Service", $0=$ "No Service". Composite scores were then calculated for each respondent in each 
"WE ONLY DO FOOD”

construct. These composite scores were the basis for LPA analysis, and met the analytical criteria of utilizing continuous variables for the selected form of statistical modeling.

Latent profile analysis provides insight into a range of possible latent profile compositions, requiring the evaluation of model fit. A combination of statistical indices were utilized for evaluating model fit. Akaikie Information Criterion (AIC; Akaikie, 1987), Bayesian Information Criterion (BIC; Schwartz, 1978), Entropy, and the LoMendel-Rubin Adjusted Likelihood Ration Test (LMR-LRT; Lo, Mendel, \& Rubin, 2001) were utilized. Additionally, consideration was given to theoretical background to identify the most appropriate identification and application of sub-group membership.

Akaikie Information Criterion (AIC) and Bayesian Information Criterion (BIC) are the original and most prevalent indices for model selection. Both rooted in maximum likelihood estimates of model parameters, AIC and BIC assist in selection of the most parsimonious and correct model. Lower vales represent a better model fit for each of these measures.

Entropy indices provide a measure of classification certainty for each potential profile. As a measure of aggregated classification uncertainty, normalized entropy scores ranging from " $0-1$ " provide an indication of the level of separation that exists between the classes in the model (Tien, Coxe, \& Cham, 2013). Higher entropy values are indicative of better model fit, with values $>0.80$ associated with a model in which latent classes are considered highly discriminating (Muthén \& Muthén, 2007).

Finally, the Lo-Mendel-Rubin Adjusted Likelihood Ration Test (LMR-LRT) was utilized as a benchmark for comparing the improvement of model fit between different profiles. The $p$ value provided by LMR-LRT is used to determine if the inclusion of an 
"WE ONLY DO FOOD”

additional class is statistically significant improvement over the more parsimonious model. A non-significant LMR-LRT value indicates that the model doesn't provide a significantly better explanation than the model with one fewer profiles.

As noted, the use of these indices is only a component of evaluating model fit within LPA analysis. Consideration is also given to substantive theory, results from previous studies, and the appeal for the most parsimonious model (Berlin et al., 2014; Collins \& Lanza, 2010; Nylund, Asparouhov, \& Muthén, 2007). After the desired number of latent profiles is identified through model fit evaluation, the model is run to establish latent group membership and estimates of the proportion of individual in each profile are made (Collins \& Lanza, 2010).

Following identification of a preferred latent profile model, multivariate analysis of variance (MANOVA) was utilized to explore the group differences across pantry models identified in LPA analysis, i.e. class membership, in relationship to director assumptions of poverty $(R Q 2)$. The utilization of the MANOVA was best suited for the investigation of the effects of the categorical independent variable on the continuous outcomes.

Additional analysis included multinomial logistic regression to evaluate the predictive nature of food pantry demographic characteristics on food pantry model (RQ3). This extension of binary logistic regression was selected due to its ability to accommodate a 4-level categorical dependent variable and the nature of sample data. As multinomial logistic regression doesn't assume normality, linearity, or homoscedasticity, this analytical tool allows for the variation of observed cases within the categorical dependent variable. 
"WE ONLY DO FOOD”

\section{Chapter 4: Descriptive Data}

The survey was distributed to all food pantry directors affiliated with the six regional food banks in the Feeding Missouri network and included in their agency email listserv. The final population from which the sample would be drawn included 933 individual food pantry directors that were included in comprehensive and up-to-date email listservs of each regional food bank. Of potential respondents, 517 (55.4\%) accessed the survey through the anonymous link. Of those that accessed the survey, 424 $(82.0 \%)$ consented to participation in the survey. Of those that consented to participation, a final usable sample of 334 was established, providing a response rate of $35.8 \%$ of all food pantry directors affiliated with the six regional food banks and included in agency listservs. Inclusion in the final sample required the respondent to complete a minimum of $95 \%$ of the survey, including all questions within the Attributions of Poverty measure. This criteria for inclusion resulted in a completion rate of $78.8 \%$ among those that consented to participation in the survey and $35.8 \%$ of the target population.

Table 2. Survey Participation

\begin{tabular}{|c|c|c|c|c|c|c|c|}
\hline & & \multirow[b]{2}{*}{ Harvesters } & \multirow[b]{2}{*}{$\begin{array}{l}\text { Second } \\
\text { Harvest }\end{array}$} & \multirow[b]{2}{*}{$\begin{array}{c}\text { Central \& } \\
\text { Northeast }\end{array}$} & \multirow[b]{2}{*}{ St. Louis } & \multirow[b]{2}{*}{ Southeast } & \multirow[b]{2}{*}{ Total } \\
\hline & $\begin{array}{c}\text { Ozark } \\
\text { Food } \\
\text { Harvest }\end{array}$ & & & & & & \\
\hline Possible Participants & 132 & 351 & 55 & 76 & 180 & 139 & 933 \\
\hline Respondents & 61 & 102 & 19 & 44 & 62 & 37 & 334 \\
\hline Response Rate & $46.2 \%$ & $29.1 \%$ & $34.5 \%$ & $57.9 \%$ & $34.4 \%$ & $26.6 \%$ & $35.8 \%$ \\
\hline Sample Proportion & $18.3 \%$ & $30.5 \%$ & $5.7 \%$ & $13.2 \%$ & $18.6 \%$ & $11.1 \%$ & \\
\hline
\end{tabular}

\section{Food Pantry Operations}

Food pantries in this study vary greatly in how their operations are structured and number of clients that they serve. Food pantries represented in this sample were open an average of 9 days each month, with a range of one to 28 open days in a typical month. 
"WE ONLY DO FOOD”

Additionally, pantries were open an average of 36 open hours across the typical month, with a range of one to 224 total open hours each month.

Table 3. Pantry days and hours of operation by region

\begin{tabular}{|c|c|c|c|c|c|c|c|}
\hline & & & & & & & \\
\hline & $\begin{array}{c}\text { Ozark } \\
\text { Food } \\
\text { Harvest }\end{array}$ & Harvesters & $\begin{array}{l}\text { Second } \\
\text { Harvest }\end{array}$ & $\begin{array}{l}\text { Central \& } \\
\text { Northeast }\end{array}$ & St. Louis & Southeast & Tota \\
\hline Average Days Open/Month & 9 & 8 & 9 & 7 & 9 & 8 & 9 \\
\hline Minimum & 1 & 1 & 1 & 1 & 1 & 1 & 1 \\
\hline Maximum & 28 & 24 & 20 & 20 & 28 & 21 & 28 \\
\hline $\begin{array}{l}\text { Average Hours } \\
\text { Open/Month }\end{array}$ & 43.82 & 33.5 & 31.25 & 31.27 & 33.7 & 35.48 & 36 \\
\hline Minimum & 1.5 & 1 & 4 & 2 & 1 & 2 & 1 \\
\hline Maximum & 170 & 216 & 180 & 170 & 224 & 163 & 224 \\
\hline
\end{tabular}

Pantry directors self-identified the service area of their food pantry. Directors identified if their pantry many served a rural population, small town, large town, or metropolitan city. Pantries surveyed primarily serve small towns or rural populations $(n=200,59.9 \%$ ), with Harvesters and St. Louis food bank regions encompassing the primary metropolitan centers in the state.

Pantries across the state serve an average of 271 households and 723 individuals each month. Food pantries in Missouri range from very small, serving as few as 3 households each month, to very large, serving up to 4000 households. The vast majority of food pantries in the study are serving more $(n=148,44.4 \%)$ or about the same $(n=149$, $44.7 \%$ ) number of people than they were in the previous year.

Table 4. Operation Statistics by Food Bank Region

\begin{tabular}{|c|c|c|c|c|c|c|c|}
\hline & $\begin{array}{c}\text { Ozark } \\
\text { Food } \\
\text { Harvest }\end{array}$ & Harvesters & $\begin{array}{l}\text { Second } \\
\text { Harvest }\end{array}$ & $\begin{array}{l}\text { Central \& } \\
\text { Northeast }\end{array}$ & St. Louis & Southeast & Total \\
\hline Average Number of $\mathrm{HH}$ & 285 & 221 & 153 & 400 & 333 & 166 & 271 \\
\hline Average Number of Indiv. & 862 & 569 & 453 & 1037 & 934 & 420 & 723 \\
\hline Use Trends & & & & & & & \\
\hline
\end{tabular}


"WE ONLY DO FOOD”

\begin{tabular}{|c|c|c|c|c|c|c|c|}
\hline \multirow[b]{2}{*}{ More People } & \multirow[b]{2}{*}{$41.0 \%$} & \multirow[b]{2}{*}{$42.6 \%$} & \multirow[b]{2}{*}{$47.4 \%$} & \multirow[b]{2}{*}{$43.2 \%$} & \multirow[b]{2}{*}{$50.0 \%$} & \multirow[b]{2}{*}{$48.6 \%$} & \multirow[b]{2}{*}{$44.4 \%$} \\
\hline & & & & & & & \\
\hline About the Same & $55.7 \%$ & $39.6 \%$ & $31.6 \%$ & $47.7 \%$ & $41.9 \%$ & $40.5 \%$ & $44.7 \%$ \\
\hline Fewer People & $3.3 \%$ & $17.8 \%$ & $21.1 \%$ & $49.1 \%$ & $8.1 \%$ & $10.8 \%$ & $11.1 \%$ \\
\hline \multicolumn{8}{|l|}{ Service Area } \\
\hline Metropolitan City & $3.3 \%$ & $46.5 \%$ & $5.3 \%$ & $0 \%$ & $53.2 \%$ & $0 \%$ & $25.8 \%$ \\
\hline Large Town & $11.5 \%$ & $18.8 \%$ & $5.3 \%$ & $13.6 \%$ & $14.5 \%$ & $10.8 \%$ & $14.1 \%$ \\
\hline Small Town & $44.3 \%$ & $28.7 \%$ & $57.9 \%$ & $40.9 \%$ & $9.7 \%$ & $48.6 \%$ & $33.6 \%$ \\
\hline Rural Area & $41.0 \%$ & $5.9 \%$ & $31.6 \%$ & $45.5 \%$ & $22.6 \%$ & $40.5 \%$ & $26.4 \%$ \\
\hline
\end{tabular}

Food pantries in this study, and across the state, largely function through the work of volunteer staff. The majority of food pantries in this study have no paid staff $(n=204$, $61.1 \%)$, and of the food pantries with any paid staff, $56(43.1 \%)$ only have one paid staff member. Furthermore, $88.5 \%$ of pantries with paid staff have fewer than 5 total paid staff. Conversely, $97.3 \%$ of food pantries reported using volunteers each month. Food pantries utilize from one to 650 volunteers per month, with an average of 33 volunteers assisting with food pantry operations each month.

Table 5. Food Pantry Staffing by Food Bank Region

\begin{tabular}{|c|c|c|c|c|c|c|c|}
\hline & $\begin{array}{c}\text { Ozark } \\
\text { Food } \\
\text { Harvest }\end{array}$ & Harvesters & $\begin{array}{l}\text { Second } \\
\text { Harvest }\end{array}$ & $\begin{array}{l}\text { Central \& } \\
\text { Northeast }\end{array}$ & St. Louis & Southeast & Total \\
\hline \multicolumn{8}{|c|}{ Full-time Paid Staff } \\
\hline None & $70.5 \%$ & $72.5 \%$ & $68.4 \%$ & $79.5 \%$ & $74.2 \%$ & $75.7 \%$ & $73.1 \%$ \\
\hline $1-5$ & $27.9 \%$ & $27.5 \%$ & $31.6 \%$ & $15.9 \%$ & $22.6 \%$ & $21.6 \%$ & $25.1 \%$ \\
\hline $6+$ & $1.6 \%$ & $0 \%$ & $0 \%$ & $4.5 \%$ & $3.2 \%$ & $2.7 \%$ & $1.8 \%$ \\
\hline \multicolumn{8}{|c|}{ Part-time Paid Staff } \\
\hline None & $72.1 \%$ & $76.5 \%$ & $78.9 \%$ & $63.6 \%$ & $83.0 \%$ & $75.7 \%$ & $75.7 \%$ \\
\hline $1-5$ & $29.9 \%$ & $22.5 \%$ & $21.1 \%$ & $36.4 \%$ & $16.1 \%$ & $18.9 \%$ & $23.4 \%$ \\
\hline $6+$ & $0 \%$ & $1.0 \%$ & $0 \%$ & $0 \%$ & $0 \%$ & $5.4 \%$ & $0.9 \%$ \\
\hline \multicolumn{8}{|c|}{ Total Paid Staff } \\
\hline None & $55.7 \%$ & $61.8 \%$ & $57.9 \%$ & $59.1 \%$ & $67.7 \%$ & $62.2 \%$ & $61.1 \%$ \\
\hline $1-5$ & $41.0 \%$ & $35.3 \%$ & $36.8 \%$ & $31.8 \%$ & $29.0 \%$ & $29.7 \%$ & $34.4 \%$ \\
\hline $6-10$ & $3.3 \%$ & $2.0 \%$ & $5.3 \%$ & $9.1 \%$ & $0 \%$ & $5.4 \%$ & $3.3 \%$ \\
\hline
\end{tabular}


"WE ONLY DO FOOD”

\begin{tabular}{|c|c|c|c|c|c|c|c|}
\hline $11+$ & $0 \%$ & $1.0 \%$ & $0 \%$ & $0 \%$ & $3.2 \%$ & $2.7 \%$ & $1.2 \%$ \\
\hline \multicolumn{8}{|c|}{ Volunteers (Average) } \\
\hline None & $0 \%$ & $2.9 \%$ & $0 \%$ & $0 \%$ & $1.6 \%$ & $10.8 \%$ & $2.7 \%$ \\
\hline $1-10$ & $29.5 \%$ & $40.2 \%$ & $31.6 \%$ & $25.0 \%$ & $23.0 \%$ & $43.2 \%$ & $33.0 \%$ \\
\hline $11-25$ & $41.0 \%$ & $28.4 \%$ & $42.1 \%$ & $43.2 \%$ & $27.9 \%$ & $21.6 \%$ & $32.1 \%$ \\
\hline $26-50$ & $19.7 \%$ & $19.6 \%$ & $15.8 \%$ & $15.9 \%$ & $24.6 \%$ & $18.9 \%$ & $20.1 \%$ \\
\hline $51-100$ & $4.9 \%$ & $8.8 \%$ & $10.5 \%$ & $6.8 \%$ & $14.8 \%$ & $2.7 \%$ & $8.1 \%$ \\
\hline $101-200$ & $1.6 \%$ & $0 \%$ & $0 \%$ & $9.1 \%$ & $3.3 \%$ & $2.7 \%$ & $2.4 \%$ \\
\hline $200+$ & $3.3 \%$ & $0 \%$ & $0 \%$ & $0 \%$ & $4.9 \%$ & $0 \%$ & $1.5 \%$ \\
\hline
\end{tabular}

The majority of food pantries across the state are religiously affiliated $(n=229$, $68.8 \%$ ), with most connected to a Protestant organization $(n=137,59.8 \%)$. More specifically, food pantries are most commonly affiliated with Evangelical Protestant organizations (i.e. Southern Baptist Convention, Free Will Baptist, Congregational Methodist, Nondenominational Christian, Free Lutheran, Assemblies of God, Church of Christ) (Pew Research Center, 2015). Furthermore, many religious alliances or religious collaborations are collections of protestant churches. Affiliation with a religious organization can take on many forms for food pantries. Churches may physically house the food pantry, own or lease an off-site location, coordinate and supply volunteers and staff, and/or provide financial assistance to cover operating costs.

Table 6. Food Pantry Religious Affiliation by Food Bank Region

\begin{tabular}{|c|c|c|c|c|c|c|c|}
\hline \multirow[b]{2}{*}{ Religious Affiliation } & $\begin{array}{c}\text { Ozark } \\
\text { Food } \\
\text { Harvest }\end{array}$ & Harvesters & $\begin{array}{l}\text { Second } \\
\text { Harvest }\end{array}$ & $\begin{array}{l}\text { Central \& } \\
\text { Northeast }\end{array}$ & St. Louis & Southeast & Total \\
\hline & & & & & & & \\
\hline Yes & $59.0 \%$ & $75.5 \%$ & $47.4 \%$ & $54.5 \%$ & $79.0 \%$ & $72.2 \%$ & $68.8 \%$ \\
\hline No & $41.0 \%$ & $24.5 \%$ & $52.6 \%$ & $45.5 \%$ & $21.0 \%$ & $27.8 \%$ & $31.2 \%$ \\
\hline Catholic & $8.3 \%$ & $9.1 \%$ & $22.2 \%$ & $4.2 \%$ & $34.7 \%$ & $15.4 \%$ & $14.8 \%$ \\
\hline Evangelical Protestant & $50.0 \%$ & $58.4 \%$ & $11.1 \%$ & $37.5 \%$ & $36.7 \%$ & $57.7 \%$ & $47.2 \%$ \\
\hline Mainline Protestant & $2.8 \%$ & $22.1 \%$ & $11.1 \%$ & $4.2 \%$ & $10.2 \%$ & $11.5 \%$ & $12.7 \%$ \\
\hline Multiple/Alliance & $30.6 \%$ & $5.2 \%$ & $44.4 \%$ & $37.5 \%$ & $10.2 \%$ & $0 \%$ & $15.3 \%$ \\
\hline Not Identified & $5.6 \%$ & $5.2 \%$ & $11.1 \%$ & $16.7 \%$ & $8.2 \%$ & $15.4 \%$ & $10.0 \%$ \\
\hline
\end{tabular}


"WE ONLY DO FOOD”

In terms of access, most food pantries have fully accessible buildings ( $n=260$, 78.1\%), providing full access for individuals with mobility restrictions. Most food pantries that aren't fully accessible, have limited or alternate access possibilities $(n=63$, $18.9 \%$ ) to provide some accommodation for mobility restrictions. Clients are mostly commonly allowed to utilize pantries on a monthly basis $(n=207,63.9 \%)$. It should also be noted that some pantries have tiered guidelines for pantry utilizations. Multiple pantries in the study provide access to full pantry services on a "monthly" or "bimonthly" schedule, but allow clients to access fresh fruits and vegetables on a weekly or as needed basis.

Table 7. Food Pantry Access by Food Bank Region

\begin{tabular}{|c|c|c|c|c|c|c|c|}
\hline & $\begin{array}{c}\text { Ozark } \\
\text { Food } \\
\text { Harvest }\end{array}$ & Harvesters & $\begin{array}{l}\text { Second } \\
\text { Harvest }\end{array}$ & $\begin{array}{l}\text { Central \& } \\
\text { Northeast }\end{array}$ & St. Louis & Southeast & Total \\
\hline \multicolumn{8}{|l|}{ Panty Accessibility } \\
\hline No, with no access & $0 \%$ & $2.0 \%$ & $0 \%$ & $6.8 \%$ & $4.8 \%$ & $5.4 \%$ & $3.0 \%$ \\
\hline Yes, with limited/alt. access & $11.5 \%$ & $27.7 \%$ & $21.1 \%$ & $4.5 \%$ & $27.4 \%$ & $8.1 \%$ & $18.9 \%$ \\
\hline Yes, fully accessible & $88.5 \%$ & $70.3 \%$ & $78.9 \%$ & $88.6 \%$ & $67.7 \%$ & $86.5 \%$ & $78.1 \%$ \\
\hline \multicolumn{8}{|l|}{ Pantry Utilization Guidelines } \\
\hline Anytime & $8.2 \%$ & $7.1 \%$ & $11.8 \%$ & $4.7 \%$ & $8.1 \%$ & $8.6 \%$ & $7.7 \%$ \\
\hline Weekly & $3.3 \%$ & $22.2 \%$ & $5.9 \%$ & $2.3 \%$ & $18.0 \%$ & $8.6 \%$ & $12.7 \%$ \\
\hline Twice a Month & $4.9 \%$ & $10.1 \%$ & $5.9 \%$ & $7.0 \%$ & $11.5 \%$ & $0 \%$ & $7.7 \%$ \\
\hline Monthly & $72.1 \%$ & $52.5 \%$ & $64.7 \%$ & $76.7 \%$ & $60.7 \%$ & $71.4 \%$ & $63.9 \%$ \\
\hline Less than Monthly & $8.2 \%$ & $5.1 \%$ & $11.8 \%$ & $7.0 \%$ & $0 \%$ & $2.9 \%$ & $4.9 \%$ \\
\hline Emergencies & $3.3 \%$ & $3.0 \%$ & $0 \%$ & $2.3 \%$ & $1.6 \%$ & $8.6 \%$ & $3.1 \%$ \\
\hline
\end{tabular}

The majority of food pantries in this study require some form of documentation to access food pantry services $(n=284,85.0 \%)$. The documentation needed varies by food pantry, but most require proof of address $(n=207,62.0 \%)$ and photo identification $(n=179,53.6 \%)$ for individuals accessing pantry services. Pantries require clients to 
"WE ONLY DO FOOD"

present necessary documents on different schedules, but most require documents to be provided on a yearly basis $(n=109,32.6 \%)$ or each visit $(n=96,28.7 \%)$.

Table 8. Client Documentation Needed by Food Bank Region

\begin{tabular}{|c|c|c|c|c|c|c|c|}
\hline & $\begin{array}{c}\text { Ozark } \\
\text { Food } \\
\text { Harvest }\end{array}$ & Harvesters & $\begin{array}{l}\text { Second } \\
\text { Harvest }\end{array}$ & $\begin{array}{l}\text { Central \& } \\
\text { Northeast }\end{array}$ & St. Louis & Southeast & Total \\
\hline \multicolumn{8}{|l|}{ Document Requirements } \\
\hline None & $4.9 \%$ & $19.6 \%$ & $5.3 \%$ & $6.8 \%$ & $17.7 \%$ & $24.3 \%$ & $15.0 \%$ \\
\hline $\begin{array}{l}\text { Phot Identification } \\
\text { Other Personal }\end{array}$ & $57.4 \%$ & $56.9 \%$ & $26.3 \%$ & $59.1 \%$ & $59.7 \%$ & $40.5 \%$ & $53.6 \%$ \\
\hline Identification & $18.0 \%$ & $18.6 \%$ & $15.8 \%$ & $27.3 \%$ & $17.7 \%$ & $8.1 \%$ & $18.3 \%$ \\
\hline Social Security Card & $59.0 \%$ & $21.6 \%$ & $10.5 \%$ & $38.6 \%$ & $19.4 \%$ & $0 \%$ & $27.2 \%$ \\
\hline Proof of Address & $85.2 \%$ & $58.8 \%$ & $52.6 \%$ & $70.5 \%$ & $58.1 \%$ & $40.5 \%$ & $62.0 \%$ \\
\hline Proof of Individuals in $\mathrm{HH}$ & $41.0 \%$ & $31.4 \%$ & $26.3 \%$ & $47.7 \%$ & $38.7 \%$ & $18.9 \%$ & $34.1 \%$ \\
\hline Verbal Statement of Need & $26.2 \%$ & $11.8 \%$ & $52.6 \%$ & $40.9 \%$ & $25.8 \%$ & $35.1 \%$ & $26.0 \%$ \\
\hline Proof of Financial Need & $50.8 \%$ & $18.6 \%$ & $26.3 \%$ & $22.7 \%$ & $22.6 \%$ & $21.6 \%$ & $26.6 \%$ \\
\hline \multicolumn{8}{|l|}{ Documents Needed } \\
\hline Each Visit & $26.2 \%$ & $28.4 \%$ & $21.1 \%$ & $25.0 \%$ & $32.3 \%$ & $37.8 \%$ & $28.7 \%$ \\
\hline Multiple Times Per Year & $8.2 \%$ & $3.9 \%$ & $5.3 \%$ & $6.8 \%$ & $3.2 \%$ & $10.8 \%$ & $5.7 \%$ \\
\hline Once a Year & $39.3 \%$ & $27.5 \%$ & $47.4 \%$ & $47.7 \%$ & $33.9 \%$ & $13.5 \%$ & $32.6 \%$ \\
\hline Only with Status Change & $21.3 \%$ & $20.6 \%$ & $15.8 \%$ & $13.6 \%$ & $16.1 \%$ & $10.8 \%$ & $18.0 \%$ \\
\hline Never & $4.9 \%$ & $19.6 \%$ & $10.5 \%$ & $6.8 \%$ & $14.5 \%$ & $27.0 \%$ & $15.0 \%$ \\
\hline
\end{tabular}

Missouri food pantries commonly have spaces inside with seating for clients to check-in for food pantry services $(n=230,69.5 \%)$ and wait to receive /select food items $(n=216,65.9 \%)$. The majority of food pantry directors indicated that clients typically wait less than 10 minutes to check-in $(n=229,68.8 \%)$ and another 10 minutes or less to receive or select food after checking-in ( $n=216,64.9 \%)$.

Table 9: Client Wait Environment by Food Bank Region

\begin{tabular}{|c|c|c|c|c|c|c|c|}
\hline & $\begin{array}{c}\text { Ozark } \\
\text { Food } \\
\text { Harvest }\end{array}$ & Harvesters & $\begin{array}{l}\text { Second } \\
\text { Harvest }\end{array}$ & $\begin{array}{l}\text { Central \& } \\
\text { Northeast }\end{array}$ & St. Louis & Southeast & Total \\
\hline $\begin{array}{l}\text { Check-In Type } \\
\text { Outside waiting w/o }\end{array}$ & $161 \%$ & $150 \%$ & & & & & \\
\hline 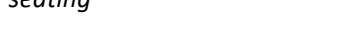 & $10.4 \%$ & $0.0 \%$ & 070 & 20.510 & 17.710 & $10.2 \%$ & $13.1 \%$ \\
\hline Outside waiting $\mathrm{w} /$ seating & $3.3 \%$ & $5.0 \%$ & $0 \%$ & $2.3 \%$ & $1.6 \%$ & $0 \%$ & $3.0 \%$ \\
\hline Inside waiting w/o seating & $11.5 \%$ & $12.0 \%$ & $5.3 \%$ & $9.3 \%$ & $16.1 \%$ & $10.8 \%$ & $11.8 \%$ \\
\hline
\end{tabular}


"WE ONLY DO FOOD”

\begin{tabular}{|c|c|c|c|c|c|c|c|}
\hline Inside waiting $w /$ seating & $68.9 \%$ & $68.0 \%$ & $94.7 \%$ & $67.4 \%$ & $64.5 \%$ & $73.0 \%$ & $69.5 \%$ \\
\hline \multicolumn{8}{|l|}{ Check-In Wait Time } \\
\hline $0-10$ minutes & $73.8 \%$ & $73.3 \%$ & $89.5 \%$ & $43.2 \%$ & $67.7 \%$ & $67.6 \%$ & $68.8 \%$ \\
\hline 10-30 minutes & $19.7 \%$ & $26.7 \%$ & $10.5 \%$ & $54.4 \%$ & $30.6 \%$ & $29.7 \%$ & $28.8 \%$ \\
\hline $30-60$ minutes & $6.6 \%$ & $0 \%$ & $0 \%$ & $2.3 \%$ & $0 \%$ & $2.7 \%$ & $2.1 \%$ \\
\hline $60+$ minutes & $0 \%$ & $0 \%$ & $0 \%$ & $0 \%$ & $1.6 \%$ & $0 \%$ & $0.3 \%$ \\
\hline Wait to receive/select food & & & & & & & \\
\hline seating & $3.3 \%$ & $10.0 \%$ & $0 \%$ & $11.6 \%$ & $13.1 \%$ & $13.5 \%$ & $9.1 \%$ \\
\hline Outside waiting $w /$ seating & $5.0 \%$ & $5.0 \%$ & $0 \%$ & $7.0 \%$ & $6.6 \%$ & $2.7 \%$ & $5.2 \%$ \\
\hline Inside waiting w/o seating & $23.3 \%$ & $17.0 \%$ & $5.6 \%$ & $20.9 \%$ & $19.7 \%$ & $24.3 \%$ & $19.8 \%$ \\
\hline Inside waiting $\mathrm{w} /$ seating & $68.3 \%$ & $68.0 \%$ & $94.4 \%$ & $60.5 \%$ & $60.7 \%$ & $59.5 \%$ & $65.9 \%$ \\
\hline \multicolumn{8}{|l|}{ Wait time to receive food } \\
\hline 0-10 minutes & $62.3 \%$ & $58.4 \%$ & $78.9 \%$ & $59.1 \%$ & $66.1 \%$ & $78.4 \%$ & $64.9 \%$ \\
\hline 10-30 minutes & $32.8 \%$ & $38.6 \%$ & $21.1 \%$ & $36.4 \%$ & $30.6 \%$ & $13.5 \%$ & $30.9 \%$ \\
\hline 30-60 minutes & $4.9 \%$ & $3.0 \%$ & $0 \%$ & $4.5 \%$ & $3.2 \%$ & $5.4 \%$ & $3.9 \%$ \\
\hline $60+$ minutes & $0 \%$ & $0 \%$ & $0 \%$ & $0 \%$ & $0 \%$ & $2.7 \%$ & $0.3 \%$ \\
\hline
\end{tabular}

Food selection strategies vary by food pantry; however, clients are most commonly given a predetermined and packaged selection of food $(n=104,31.2 \%)$. The vast majority of food panties utilize a model where food is handled and packaged by volunteers $(n=277,83.2 \%$ ), even when some form of client choice of foods is provided $(n=173,52.0 \%)$. A small group of pantries across the state provide a client choice shopper-model for food selection $(n=56,16.8 \%)$, providing clients with the opportunity to select foods with $(n=36,10.8 \%)$ or without a formula $(n=20,6.0 \%)$.

Table 10. Food selection model by Food Bank Region

\begin{tabular}{|c|c|c|c|c|c|c|c|}
\hline & $\begin{array}{c}\text { Ozark } \\
\text { Food } \\
\text { Harvest } \\
\end{array}$ & Harvesters & $\begin{array}{l}\text { Second } \\
\text { Harvest }\end{array}$ & $\begin{array}{l}\text { Central \& } \\
\text { Northeast }\end{array}$ & St. Louis & Southeast & Total \\
\hline $\begin{array}{l}\text { Volunteers select and } \\
\text { package foods based on a } \\
\text { formula }\end{array}$ & $34.4 \%$ & $16.7 \%$ & $21.1 \%$ & $37.2 \%$ & $32.3 \%$ & $59.5 \%$ & $31.2 \%$ \\
\hline $\begin{array}{l}\text { Volunteers select and } \\
\text { package most foods, and } \\
\text { clients select a portion }\end{array}$ & $21.3 \%$ & $23.5 \%$ & $26.3 \%$ & $14.0 \%$ & $38.7 \%$ & $13.5 \%$ & $23.4 \%$ \\
\hline
\end{tabular}


"WE ONLY DO FOOD”

\begin{tabular}{|c|c|c|c|c|c|c|c|}
\hline $\begin{array}{l}\text { Clients select their food } \\
\text { based on a formula and } \\
\text { volunteers pack and handle } \\
\text { food }\end{array}$ & $32.8 \%$ & $34.3 \%$ & $42.1 \%$ & $30.2 \%$ & $14.5 \%$ & $21.6 \%$ & $28.5 \%$ \\
\hline $\begin{array}{l}\text { Clients select, pack, and } \\
\text { handle food based on a } \\
\text { formula }\end{array}$ & $6.6 \%$ & $16.7 \%$ & $10.5 \%$ & $11.6 \%$ & $9.7 \%$ & $2.7 \%$ & $10.8 \%$ \\
\hline $\begin{array}{l}\text { Clients select, pack and } \\
\text { handle food without a } \\
\text { formula }\end{array}$ & $4.9 \%$ & $8.8 \%$ & $0 \%$ & $7.0 \%$ & $4.8 \%$ & $2.7 \%$ & $6.0 \%$ \\
\hline
\end{tabular}

\section{Food Pantry Services}

Food pantries can provide or refer a wide range of services for pantry clients, either through direct services or partnerships with other area agencies. Available services at food pantries vary between each organization, as they are dependent on the desires of pantry directors, food pantry boards, and availability of community resources. The following results provide an outline of food pantry services provided across the state and within each food bank region. Services are organized within larger conceptually similar groups: Direct food provisions, Other food supports, Health/personal care supports, Organizational structuring, and Systemic Supports. The organization of services and the identified groupings was based on previous survey work with Missouri food pantries (Taking Stock, 2016) and program classification by Feeding America (Feeding America, 2014).

Table 11. Food Pantry Service/Program Construct Breakdown

\begin{tabular}{|c|c|c|c|c|}
\hline $\begin{array}{l}\text { Direct Food } \\
\text { Provisions }\end{array}$ & Other Food Supports & $\begin{array}{c}\text { Health/Personal Care } \\
\text { Supports }\end{array}$ & $\begin{array}{l}\text { Organizational } \\
\text { Structuring }\end{array}$ & Systemic Supports \\
\hline $\begin{array}{l}\text { Commodity } \\
\text { Distribution }\end{array}$ & SNAP Enrollment & Mental Health Services & Thrift Shop & Utility Assistance \\
\hline Senior Box & WIC Enrollment & Health Screenings & $\begin{array}{l}\text { Religious } \\
\text { Programming }\end{array}$ & Housing/Rent Assistance \\
\hline Food Delivery & TANF Enrollment & Dental Screenings & Visible Signage & $\begin{array}{l}\text { Transportation } \\
\text { Assistance }\end{array}$ \\
\hline
\end{tabular}


"WE ONLY DO FOOD"

\begin{tabular}{|c|c|c|c|c|}
\hline $\begin{array}{l}\text { Meal Program/Soup } \\
\text { Kitchen }\end{array}$ & $\begin{array}{l}\text { Off-Site Community } \\
\text { Garden }\end{array}$ & Reproductive Health & $\begin{array}{l}\text { Clearly Identified } \\
\text { Hours of Operation }\end{array}$ & $\begin{array}{l}\text { Engagement w/ elected } \\
\text { officials }\end{array}$ \\
\hline $\begin{array}{l}\text { Buddy Pack/ } \\
\text { BackSnack }\end{array}$ & $\begin{array}{l}\text { Cooking } \\
\text { Demonstrations }\end{array}$ & Smoking Cessation & $\begin{array}{l}\text { Up-to-date } \\
\text { Website/Social Media }\end{array}$ & Job skills training \\
\hline $\begin{array}{l}\text { Food for chronic } \\
\text { conditions }\end{array}$ & $\begin{array}{l}\text { Nutrition Education } \\
\text { Courses }\end{array}$ & $\begin{array}{l}\text { Drug \& Alcohol } \\
\text { Treatment }\end{array}$ & $\begin{array}{l}\text { Seating area for } \\
\text { clients }\end{array}$ & $\begin{array}{l}\text { Employment } \\
\text { opportunities }\end{array}$ \\
\hline $\begin{array}{l}\text { Health guidelines for } \\
\text { food donations }\end{array}$ & General Recipes & $\begin{array}{l}\text { Chronic Disease } \\
\text { Management }\end{array}$ & Area for children & $\begin{array}{l}\text { Educational } \\
\text { Programs/Assistance }\end{array}$ \\
\hline $\begin{array}{l}\text { Onsite Community } \\
\text { Garden }\end{array}$ & $\begin{array}{l}\text { Nutrition Information } \\
\text { via posters or flyers }\end{array}$ & Domestic Violence & $\begin{array}{l}\text { Opportunity for client } \\
\text { feedback }\end{array}$ & Financial Literacy Training \\
\hline $\begin{array}{l}\text { Recipes for } \\
\text { distributed foods }\end{array}$ & $\begin{array}{l}\text { Gardening Supplies } \\
\text { \&/or education }\end{array}$ & $\begin{array}{l}\text { Health Insurance } \\
\text { Information }\end{array}$ & $\begin{array}{l}\text { Opportunity for } \\
\text { clients to serve on } \\
\text { board/staff }\end{array}$ & Voter Registration \\
\hline Formula & & $\begin{array}{l}\text { Personal Care Items } \\
\text { Diapers } \\
\text { Household/cleaning } \\
\text { Items }\end{array}$ & $\begin{array}{l}\text { Pantry Newsletter } \\
\text { Social \&/or Cultural } \\
\text { events }\end{array}$ & Translation Services \\
\hline
\end{tabular}

Food pantry directors were presented with a list of potential pantry services, and asked if their pantry provided the service, offered referrals for the service, or didn't provide the service or a referral. Additionally, pantry directors were asked to rate the importance of each service to the operation of 'ideal' food pantry on 5-point likert scale, with ' 5 ' being Very Important. This measure is based on the director's personal assumptions of what the 'ideal' food pantry operations and services would include, and not identified or primed by the researcher a priori. Importance rankings were averaged across and within food pantry service \& organization constructs and allow for a ranking of services in their perceived importance to ideal food pantry services among directors.

Table 12. Pantry Service Construct Rank by Importance

\begin{tabular}{|c|c|c|c|c|c|c|c|}
\hline & $\begin{array}{c}\text { Ozark } \\
\text { Food } \\
\text { Harvest }\end{array}$ & Harvesters & $\begin{array}{l}\text { Second } \\
\text { Harvest }\end{array}$ & $\begin{array}{l}\text { Central \& } \\
\text { Northeast }\end{array}$ & St. Louis & Southeast & Total \\
\hline Direct Food Provisions & 2 & 2 & 2 & 2 & 3 & 1 & 2 \\
\hline Other Food Supports & 4 & 4 & 4 & 4 & 5 & 4 & 5 \\
\hline
\end{tabular}


"WE ONLY DO FOOD”

Health/Personal Care
Supports
Organizational Structuring
Systemic Supports

3
1
5

3
1
5

3
1
5

\begin{tabular}{|c|c|c|c|}
\hline 3 & 2 & 3 & 3 \\
\hline 1 & 1 & 2 & 1 \\
\hline 5 & 4 & 5 & 4 \\
\hline
\end{tabular}

\section{Direct Food Provisions}

Food pantries are most often associated with the distribution of emergency food provisions directly to clients. However, direct food provisioning at food pantries can take on a number of forms, dependent upon the various programs or avenues through which food is provided to clients and the programs and policies in place to support the provisioning of quality foods to fit a range of dietary and personal preferences. Direct food provisions were ranked $2^{\text {nd }}$ of 5 pantry service domains in importance to ideal food pantry services $(\mathrm{M}=3.04)$ among respondents.

Table 13. Direct Food Provisions Importance Rank

\begin{tabular}{|c|c|c|c|c|c|c|c|}
\hline & $\begin{array}{c}\text { Ozark Food } \\
\text { Harvest }\end{array}$ & Harvesters & $\begin{array}{l}\text { Second } \\
\text { Harvest }\end{array}$ & $\begin{array}{l}\text { Central \& } \\
\text { Northeast }\end{array}$ & St. Louis & Southeast & Total \\
\hline Commodity Distribution & 1 & 1 & 1 & 1 & 1 & 1 & 1 \\
\hline Senior Box & 4 & 6 & 3 & 4 & 5 & 2 & 5 \\
\hline Food Delivery & 7 & 10 & 9 & 7 & 7 & 8 & 7 \\
\hline Meal Program/Soup Kitchen & 10 & 9 & 10 & 10 & 10 & 5 & 10 \\
\hline Buddy Pack/ BackSnack & 8 & 8 & 7 & 8 & 8 & 9 & 8 \\
\hline Food for chronic conditions & 2 & 2 & 4 & 5 & 2 & 6 & 2 \\
\hline $\begin{array}{l}\text { Health guidelines for food } \\
\text { donations }\end{array}$ & 5 & 5 & 5 & 6 & 4 & 7 & 6 \\
\hline Onsite Community Garden & 9 & 7 & 8 & 9 & 9 & 10 & 9 \\
\hline Recipes for distributed foods & 3 & 3 & 2 & 2 & 6 & 4 & 3 \\
\hline Formula & 6 & 4 & 6 & 3 & 3 & 3 & 4 \\
\hline
\end{tabular}

Commodity Distribution. Apart from the distribution of donated food items, food pantries can participate in the distribution of U.S. Department of Agriculture (USDA) commodity foods. U.S. produced foods purchased by the USDA are provided 
"WE ONLY DO FOOD”

through the Emergency Food Assistance Program (TEFAP) for distribution through State Distributing Agencies. Additionally, this program provides administrative funds to states for carrying out food distributions (USDA, 2020). Foods are most commonly distributed to qualifying individuals for household consumption. Participants must meet income eligibility requirements, complete an application, be a resident of the state in which they are receiving foods, and meet qualifying criteria for the definition of a "household". Commodity distribution was identified as the most important component to 'ideal' food pantry services within direct food provisioning among respondents $(\mathrm{M}=3.87, \mathrm{SD}=1.45)$.

Table 14. Commodity Distribution by Food Bank Region

\begin{tabular}{|c|c|c|c|c|c|c|c|}
\hline & $\begin{array}{c}\text { Ozark Food } \\
\text { Harvest }\end{array}$ & Harvesters & $\begin{array}{l}\text { Second } \\
\text { Harvest }\end{array}$ & $\begin{array}{l}\text { Central \& } \\
\text { Northeast }\end{array}$ & St. Louis & Southeast & Total \\
\hline No Service & $34.4 \%$ & $54.9 \%$ & $21.1 \%$ & $38.6 \%$ & $43.5 \%$ & $45.9 \%$ & $44.0 \%$ \\
\hline Referral & $3.3 \%$ & $2.9 \%$ & $5.3 \%$ & $2.3 \%$ & $1.6 \%$ & $5.4 \%$ & $3.0 \%$ \\
\hline Direct Service & $62.3 \%$ & $42.2 \%$ & $73.7 \%$ & $59.1 \%$ & $54.8 \%$ & $48.6 \%$ & $53.0 \%$ \\
\hline Mean Importance & 3.97 & 3.71 & 3.95 & 3.91 & 3.79 & 4.14 & 3.87 \\
\hline
\end{tabular}

Senior Box. Food pantries can act as the conduit though which food is provided to low-income persons over the age of 60 through the USDA Commodity Supplemental Food Program (CSFP), often referred to as the 'Senior Box'. Participants must be below income eligibility requirements and complete an application to participate. Qualifying seniors receive supplemental food boxes in addition to regular commodity provisions through the distribution agencies. Senior box distribution ranked $5^{\text {th }}$ in importance to ideal food pantry operations within direct food provisions $(\mathrm{M}=3.3, \mathrm{SD}=1.60)$.

Table 15. Senior Box Distribution by Food Bank Region

\begin{tabular}{l|c|c|c|c|c|c|c|} 
& $\begin{array}{c}\text { Ozark Food } \\
\text { Harvest }\end{array}$ & Harvesters & $\begin{array}{c}\text { Second } \\
\text { Harvest }\end{array}$ & $\begin{array}{c}\text { Central \& } \\
\text { Northeast }\end{array}$ & St. Louis & Southeast & Total \\
\cline { 2 - 10 } No Service & $63.9 \%$ & $82.4 \%$ & $52.6 \%$ & $56.8 \%$ & $61.3 \%$ & $59.5 \%$ & $67.4 \%$ \\
\hline Referral & $1.6 \%$ & $2.0 \%$ & $10.5 \%$ & $0 \%$ & $1.6 \%$ & $5.4 \%$ & $2.4 \%$ \\
\hline Direct Service & $34.4 \%$ & $15.7 \%$ & $36.8 \%$ & $43.2 \%$ & $37.1 \%$ & $35.1 \%$ & $30.2 \%$ \\
\hline
\end{tabular}


"WE ONLY DO FOOD"

Mean Importance 3.56 3.00 3.21 3.5

Food Delivery Service. Food pantries can, and do, provide food delivery services for seniors and individuals that face issues related to mobility or transportation. Delivery services can help to reduce the barriers to accessing food supports and provide an additional level of support for diverse client needs. Food delivery services were ranked $7^{\text {th }}$ among direct food provisions in their importance to ideal food pantry services $(\mathrm{M}=2.58, \mathrm{SD}=1.38)$.

Table 16. Food Delivery Service by Food Bank Region

\begin{tabular}{l|c|c|c|c|c|c|c|} 
& $\begin{array}{c}\text { Ozark Food } \\
\text { Harvest }\end{array}$ & Harvesters & $\begin{array}{c}\text { Second } \\
\text { Harvest }\end{array}$ & $\begin{array}{c}\text { Central \& } \\
\text { Northeast }\end{array}$ & St. Louis & Southeast & Total \\
\cline { 2 - 10 } No Service & $90.2 \%$ & $83.3 \%$ & $78.9 \%$ & $68.2 \%$ & $95.2 \%$ & $73.0 \%$ & $83.5 \%$ \\
Referral & $0 \%$ & $2.0 \%$ & $0 \%$ & $6.8 \%$ & $1.6 \%$ & $8.1 \%$ & $2.7 \%$ \\
Direct Service & $9.8 \%$ & $14.7 \%$ & $21.1 \%$ & $25.0 \%$ & $3.2 \%$ & $18.9 \%$ & $13.8 \%$ \\
Mean Importance & 2.69 & 2.46 & 2.05 & 2.77 & 2.61 & 2.65 & 2.58
\end{tabular}

Meal Program/ Soup Kitchen. While food provisions at food pantries are primarily for preparation and consumption at the client's place of residence, food pantries may also provide or connect clients with opportunities to access a hot or cold meal in addition to pantry provisions. Meal programs were ranked last in importance for ideal food pantry services within direct food supports $(\mathrm{M}=2.22, \mathrm{SD}=1.50)$.

Table 17. Meal Program by Food Bank Region

\begin{tabular}{|c|c|c|c|c|c|c|c|}
\hline & $\begin{array}{c}\text { Ozark Food } \\
\text { Harvest }\end{array}$ & Harvesters & $\begin{array}{l}\text { Second } \\
\text { Harvest }\end{array}$ & $\begin{array}{l}\text { Central \& } \\
\text { Northeast }\end{array}$ & St. Louis & Southeast & Total \\
\hline No Service & $88.5 \%$ & $84.3 \%$ & $89.5 \%$ & $86.4 \%$ & $93.5 \%$ & $59.5 \%$ & $84.4 \%$ \\
\hline Referral & $1.6 \%$ & $5.9 \%$ & $5.3 \%$ & $4.5 \%$ & $4.8 \%$ & $16.2 \%$ & $6.0 \%$ \\
\hline Direct Service & $9.8 \%$ & $9.8 \%$ & $5.3 \%$ & $9.1 \%$ & $1.6 \%$ & $24.3 \%$ & $9.6 \%$ \\
\hline Mean Importance & 2.25 & 2.57 & 2.63 & 2.39 & 2.24 & 2.46 & 2.22 \\
\hline
\end{tabular}


"WE ONLY DO FOOD"

BuddyPack/ BackSnack Program. Food pantries may partner with area schools, the regional food banks, and other organizations to create and distribute back packs with child-friendly food to school children to take home over the weekend. Food pantries direct participation is often as a community partner/intermediary to pick-up foods, pack foods, and deliver to schools. School staff are then responsible for the identification of school children that need the service and the distribution of backpacks. Backpack food programs were ranked $8^{\text {th }}$ in importance to ideal food pantry services within direct food provisions $(\mathrm{M}=2.5, \mathrm{SD}=1.58)$.

Table 18. Backpack Food Programs by Food Bank Region

\begin{tabular}{|c|c|c|c|c|c|c|c|}
\hline & $\begin{array}{c}\text { Ozark Food } \\
\text { Harvest }\end{array}$ & Harvesters & $\begin{array}{l}\text { Second } \\
\text { Harvest }\end{array}$ & $\begin{array}{l}\text { Central \& } \\
\text { Northeast }\end{array}$ & St. Louis & Southeast & Total \\
\hline No Service & $91.8 \%$ & $86.3 \%$ & $84.2 \%$ & $90.9 \%$ & $93.5 \%$ & $86.5 \%$ & $88.9 \%$ \\
\hline Referral & $0 \%$ & $2.0 \%$ & $0 \%$ & $0 \%$ & $0 \%$ & $8.1 \%$ & $1.5 \%$ \\
\hline Direct Service & $8.2 \%$ & $11.8 \%$ & $15.8 \%$ & $9.1 \%$ & $6.5 \%$ & $5.4 \%$ & $9.6 \%$ \\
\hline Mean Importance & 2.62 & 2.57 & 2.63 & 2.39 & 2.24 & 2.46 & 2.50 \\
\hline
\end{tabular}

Food for Chronic Conditions/Allergies/Preference. Clients at food pantries report higher incidences of negative health conditions often correlated to poor dietary intake. Additionally, clients at food pantries may have allergies or dietary preferences that limit the foods that they would be able to utilize. Having food available that meets a variety of dietary restrictions provides additional levels of supports for clients with varying needs. Having specialty food options for dietary restrictions was ranked $2^{\text {nd }}$ in importance to ideal food pantry services within direct food provisions ( $\mathrm{M}=3.51$, $\mathrm{SD}=1.44)$.

Table 19. Specialty Food Provisions by Food Bank Region

\begin{tabular}{|c|c|c|c|c|c|c|c|}
\hline & $\begin{array}{c}\text { Ozark Food } \\
\text { Harvest }\end{array}$ & Harvesters & $\begin{array}{l}\text { Second } \\
\text { Harvest }\end{array}$ & $\begin{array}{c}\text { Central \& } \\
\text { Northeast }\end{array}$ & St. Louis & Southeast & Total \\
\hline No Service & $59.0 \%$ & $59.8 \%$ & $68.4 \%$ & $84.1 \%$ & $58.1 \%$ & $89.2 \%$ & $66.5 \%$ \\
\hline Direct Service & $41.0 \%$ & $40.2 \%$ & $31.6 \%$ & $15.9 \%$ & $41.9 \%$ & $10.8 \%$ & $33.5 \%$ \\
\hline
\end{tabular}


"WE ONLY DO FOOD”

Mean Importance

3.7

3.61

3.16

3.45

3.63

2.95

3.51

Health Guidelines for Purchased or Donated Foods. To help address the social determinants of health related to available food in food pantries, organizations can establish health guidelines for food donations and food items that pantries purchase to supplement contributions from the food bank and other donations. These guidelines are instituted to promote the distribution and consumption of healthier food options for pantry clients. It is important to note that these guidelines can vary by pantry and can have varying degrees of adherence to. The majority of food pantries in the study do not have health guidelines for donated food items $(n=217,65.0 \%)$. Health guidelines for donations was ranked $6^{\text {th }}$ in importance to ideal food pantry services within direct food provisions $(\mathrm{M}=3.22, \mathrm{SD}=1.56)$.

Table 20. Health Guidelines for Donations by Food Bank Region

\begin{tabular}{l|c|c|c|c|c|c|c|} 
& $\begin{array}{c}\text { Ozark Food } \\
\text { Harvest }\end{array}$ & Harvesters & $\begin{array}{c}\text { Second } \\
\text { Harvest }\end{array}$ & $\begin{array}{c}\text { Central \& } \\
\text { Northeast }\end{array}$ & St. Louis & Southeast & Total \\
\cline { 2 - 8 } No Service & $57.4 \%$ & $66.7 \%$ & $42.1 \%$ & $77.3 \%$ & $58.1 \%$ & $81.1 \%$ & $65.0 \%$ \\
Direct Service & $42.6 \%$ & $33.3 \%$ & $57.9 \%$ & $22.7 \%$ & $41.9 \%$ & $18.9 \%$ & $35.0 \%$ \\
Mean Importance & 3.48 & 3.32 & 3.05 & 3.0 & 3.37 & 2.73 & 3.22 \\
\hline
\end{tabular}

Onsite Community Garden. Food pantries may manage onsite community gardens at their pantry location. Community gardens at pantries may be organized as a single collective plot, divided into individual plots, or a combination of the two. These spaces may be organized and managed by the food pantry or a partnering agency or group (i.e. Master Gardener Groups). Gardens may be worked by volunteers, clients, or provide a space for volunteers and clients to interact. Produce grown in these gardens may go directly back to the pantry to be distributed to clients, or clients may have opportunities to grow their own produce in supplied individual or group plots. Most 
"WE ONLY DO FOOD"

organizations in this study didn't have on-site community gardens at the food pantry ( $n=296,88.6 \%)$. Having an onsite community garden ranked $9^{\text {th }}$ in importance to ideal food pantry services within direct food provisions $(\mathrm{M}=2.36, \mathrm{SD}=1.45)$.

Table 21. Onsite Community Garden by Food Bank Region

\begin{tabular}{l|c|c|c|c|c|c|c|} 
& $\begin{array}{c}\text { Ozark Food } \\
\text { Harvest }\end{array}$ & Harvesters & $\begin{array}{c}\text { Second } \\
\text { Harvest }\end{array}$ & $\begin{array}{c}\text { Central \& } \\
\text { Northeast }\end{array}$ & St. Louis & Southeast & Total \\
\cline { 2 - 10 } No Service & $90.2 \%$ & $85.3 \%$ & $73.7 \%$ & $90.9 \%$ & $88.7 \%$ & $97.3 \%$ & $88.6 \%$ \\
Direct Service & $9.8 \%$ & $14.7 \%$ & $26.3 \%$ & $9.1 \%$ & $11.3 \%$ & $2.7 \%$ & $11.4 \%$ \\
Mean Importance & 2.37 & 2.6 & 2.28 & 2.35 & 2.02 & 2.29 & 2.36 \\
\hline
\end{tabular}

Recipes for Distributed Foods. To assist clients in utilizing foods provided through the food pantry, many organizations will offer recipes for specific food distributed. These recipes focus on items that clients may not know how to use but are routinely distributed (i.e. dried beans), or more obscure items (i.e. eggplant, zucchini, acorn squash) that pantries may receive as a windfall for distribution. Providing recipes may help clients learn how to use a product for the first time or in a new way. These recipes are created by both staff at individual pantries, food banks, or partner agencies like university extension liaisons. Providing recipes for distributed foods ranked $3^{\text {rd }}$ in importance of ideal food pantry services within direct food provisions $(\mathrm{M}=3.46$, $\mathrm{SD}=1.38)$.

Table 22. Recipes for Distributed Foods by Food Bank Region

\begin{tabular}{|c|c|c|c|c|c|c|c|}
\hline & \multirow[b]{2}{*}{$\begin{array}{c}\text { Ozark Food } \\
\text { Harvest }\end{array}$} & \multirow[b]{2}{*}{ Harvesters } & \multirow[b]{2}{*}{$\begin{array}{c}\text { Second } \\
\text { Harvest } \\
\end{array}$} & \multirow[b]{2}{*}{$\begin{array}{c}\text { Central \& } \\
\text { Northeast }\end{array}$} & \multirow[b]{2}{*}{ St. Louis } & \multirow[b]{2}{*}{ Southeast } & \multirow[b]{2}{*}{ Total } \\
\hline & & & & & & & \\
\hline No Service & $57.4 \%$ & $52.0 \%$ & $57.9 \%$ & $56.8 \%$ & $50.0 \%$ & $67.6 \%$ & $56.0 \%$ \\
\hline Referral & $1.6 \%$ & $2.0 \%$ & $0 \%$ & $0 \%$ & $3.2 \%$ & $5.4 \%$ & $2.1 \%$ \\
\hline Direct Service & $41.0 \%$ & $46.1 \%$ & $42.1 \%$ & $43.2 \%$ & $46.8 \%$ & $27.0 \%$ & $41.9 \%$ \\
\hline Mean Importance & 3.69 & 3.6 & 3.35 & 3.81 & 3.05 & 3.11 & 3.46 \\
\hline
\end{tabular}

Formula. Many households that utilize food pantries have children. Food pantries may provide formula, or offer referrals to agencies that provide this resource, for 
"WE ONLY DO FOOD”

individuals or families with infants. Providing this resource allows for additional support for diverse client food needs and meets the needs of the youngest members of food insecure households. Providing formula for families with infants ranked $4^{\text {th }}$ in importance to ideal food pantry services within direct food provisions $(\mathrm{M}=3.4, \mathrm{SD}=1.58)$.

Table 23. Baby Formula Provisions by Food Bank Region

\begin{tabular}{l|c|c|c|c|c|c|c} 
& $\begin{array}{c}\text { Ozark Food } \\
\text { Harvest }\end{array}$ & Harvesters & $\begin{array}{c}\text { Second } \\
\text { Harvest }\end{array}$ & $\begin{array}{c}\text { Central \& } \\
\text { Northeast }\end{array}$ & St. Louis & Southeast & Total \\
\cline { 2 - 10 } No Service & $68.9 \%$ & $54.9 \%$ & $57.9 \%$ & $56.8 \%$ & $51.6 \%$ & $67.6 \%$ & $58.4 \%$ \\
Referral & $4.9 \%$ & $2.9 \%$ & $0 \%$ & $2.3 \%$ & $4.8 \%$ & $5.4 \%$ & $3.6 \%$ \\
Direct Service & $26.2 \%$ & $42.2 \%$ & $42.1 \%$ & $40.9 \%$ & $43.5 \%$ & $27.0 \%$ & $38.0 \%$ \\
Mean Importance & 3.2 & 3.53 & 2.88 & 3.53 & 3.4 & 3.31 & 3.4 \\
\hline
\end{tabular}

\section{Other Food Supports}

The food provided at food pantries is often not enough to meet the food needs of clients alone. Furthermore, many of their clients often qualify for public food assistance programs and additional supports. Food pantries my work to connect clients to these broader public food assistance programs and other local programs that provide food both directly and indirectly. Additional food-related supports at pantries can extend to improving client knowledge and skills related to food preparation and nutrition, as well at supports in personal food production. Providing additional food supports was ranked $5^{\text {th }}$ of 5 pantry service domains in importance to ideal food pantry services $(M=2.61)$.

Table 24. Other Food Supports Mean Importance Rank by Food Bank Region

\begin{tabular}{l|c|c|c|c|c|c|c} 
& $\begin{array}{c}\text { Ozark Food } \\
\text { Harvest }\end{array}$ & Harvesters & $\begin{array}{c}\text { Second } \\
\text { Harvest }\end{array}$ & $\begin{array}{c}\text { Central \& } \\
\text { Northeast }\end{array}$ & St. Louis & Southeast & Total \\
\hline SNAP Enrollment & 4 & 5 & 7 & 7 & 5 & 4 & 5 \\
WIC Enrollment & 8 & 6 & 7 & 9 & 6 & 9 & 6 \\
TANF Enrollment & 9 & 7 & 9 & 8 & 7 & 8 & 9 \\
\hline Off-Site Community Garden & 7 & 9 & 5 & 6 & 8 & 7 & 8 \\
Cooking Demonstrations & 4 & 4 & 3 & 3 & 4 & 5 & 4
\end{tabular}


"WE ONLY DO FOOD"

\begin{tabular}{|c|c|c|c|c|c|c|c|}
\hline Nutrition Education Courses & 3 & 1 & 4 & 1 & 3 & 2 & 2 \\
\hline General Recipes & 2 & 3 & 1 & 1 & 1 & 1 & 1 \\
\hline $\begin{array}{l}\text { Nutrition Information via } \\
\text { poster or flyers }\end{array}$ & 1 & 2 & 2 & 3 & 2 & 3 & 2 \\
\hline $\begin{array}{l}\text { Gardening supplies or } \\
\text { educational materials }\end{array}$ & 6 & 8 & 6 & 5 & 9 & 6 & 7 \\
\hline
\end{tabular}

SNAP Enrollment. Many food pantry clients meet income eligibility requirements to receive Supplemental Nutrition Assistance Program (SNAP) benefits. Formerly known as Food Stamps, SNAP provides low-income individuals and families financial benefits that can be used in stores to purchase food at qualifying supermarkets, stores, and farmers markets. Enrollment and participation in this public food assistance program provides qualifying clients with additional supports beyond the allotment of food provided by the food pantry. Despite many food pantry clients qualifying for SNAP benefits, many don't participate in the public food assistance program due a lack of knowledge or understanding around this program (Daponte, Sanders, \& Taylor, 1999) or the uncomfortability and stigma of accessing the resource (Martin, Cook, Rogers, \& Joseph, 2003). Food pantries may provide direct enrollment assistance for qualifying clients, refer to organizations that can assist in applying for SNAP benefits, or post information on where clients can receive assistance. SNAP enrollment assistance ranked $5^{\text {th }}$ in importance for ideal food pantry services within other food supports $(M=2.58$, $\mathrm{SD}=1.55)$

Table 25. SNAP Enrollment Assistance by Food Bank Region

\begin{tabular}{|c|c|c|c|c|c|c|c|}
\hline & $\begin{array}{c}\text { Ozark Food } \\
\text { Harvest }\end{array}$ & Harvesters & $\begin{array}{l}\text { Second } \\
\text { Harvest }\end{array}$ & $\begin{array}{l}\text { Central \& } \\
\text { Northeast }\end{array}$ & St. Louis & Southeast & Total \\
\hline No Service & $72.1 \%$ & $75.5 \%$ & $84.2 \%$ & $81.8 \%$ & $74.2 \%$ & $70.3 \%$ & $75.7 \%$ \\
\hline Referral & $8.2 \%$ & $11.8 \%$ & $5.3 \%$ & $4.5 \%$ & $1.6 \%$ & $13.5 \%$ & $8.1 \%$ \\
\hline Direct Service & $19.7 \%$ & $12.7 \%$ & $10.5 \%$ & $13.6 \%$ & $24.2 \%$ & $16.2 \%$ & $16.2 \%$ \\
\hline Mean Importance & 2.84 & 2.87 & 1.74 & 2.09 & 2.50 & 2.59 & 2.58 \\
\hline
\end{tabular}


"WE ONLY DO FOOD”

WIC Enrollment. The Special Supplemental Nutrition Program for Women, Infants, \& Children (WIC) provides supplemental foods, nutrition education, and health care referrals to women and children that qualify based on income or found to be at nutritional risk through federal grants to states. Enrollment and participation in this public food assistance program may help to provide additional nutrition and supports for individuals and children during critical stages of physical and cognitive development. WIC enrollment assistance ranked $6^{\text {th }}$ in importance to ideal food pantry services within other food supports $(\mathrm{M}=2.3, \mathrm{SD}=1.49)$.

Table 26. WIC Enrollment Assistance by Food Bank Region

\begin{tabular}{l|c|c|c|c|c|c|c|} 
& $\begin{array}{c}\text { Ozark Food } \\
\text { Harvest }\end{array}$ & Harvesters & $\begin{array}{c}\text { Second } \\
\text { Harvest }\end{array}$ & $\begin{array}{c}\text { Central \& } \\
\text { Northeast }\end{array}$ & St. Louis & Southeast & Total \\
\cline { 2 - 9 } No Service & $91.8 \%$ & $89.2 \%$ & $100 \%$ & $97.7 \%$ & $98.4 \%$ & $83.8 \%$ & $92.5 \%$ \\
Referral & $6.6 \%$ & $4.9 \%$ & $0 \%$ & $0 \%$ & $1.6 \%$ & $13.5 \%$ & $4.8 \%$ \\
Direct Service & $1.6 \%$ & $5.9 \%$ & $0 \%$ & $2.3 \%$ & $0 \%$ & $2.7 \%$ & $2.7 \%$ \\
Mean Importance & 2.38 & 2.6 & 1.74 & 2.02 & 2.21 & 2.02 & 2.30 \\
\hline
\end{tabular}

TANF Enrollment. The Temporary Assistance for Needy Families (TANF) program is a time limited programs that assists low-income families with children that are not able to provide for the family's basic needs. Funded by federal grants provided to states, the program provides cash benefits for clothing, utilities, and other benefits, while also providing employment and training services. This program may help to address systemic causes of hunger and food pantry utilization. TANF enrollment assistance ranked last in importance to ideal food pantry services within other food supports $(\mathrm{M}=2.16, \mathrm{SD}=1.47)$.

Table 27. TANF Enrollment Assistance by Food Bank Region

\begin{tabular}{l|c|c|c|c|c|c|c|} 
& $\begin{array}{c}\text { Ozark Food } \\
\text { Harvest }\end{array}$ & Harvesters & $\begin{array}{c}\text { Second } \\
\text { Harvest }\end{array}$ & $\begin{array}{c}\text { Central \& } \\
\text { Northeast }\end{array}$ & St. Louis & Southeast & Total \\
\cline { 2 - 9 } No Service & $82.0 \%$ & $93.1 \%$ & $84.2 \%$ & $70.5 \%$ & $82.3 \%$ & $81.1 \%$ & $84.1 \%$ \\
Referral & $3.3 \%$ & $2.9 \%$ & $0 \%$ & $2.3 \%$ & $4.8 \%$ & $13.5 \%$ & $4.5 \%$ \\
\hline
\end{tabular}


"WE ONLY DO FOOD”

\begin{tabular}{|l|c|c|c|c|c|c|c|}
\hline Direct Service & $14.8 \%$ & $3.9 \%$ & $15.8 \%$ & $27.3 \%$ & $12.9 \%$ & $5.4 \%$ & $11.4 \%$ \\
\hline Mean Importance & 2.31 & 2.21 & 1.68 & 2.05 & 2.15 & 2.19 & 2.16 \\
\hline
\end{tabular}

Offsite Community Garden. Food pantries may manage an off-site community garden or coordinate with a community garden that is not located on food pantry property. Partnerships may provide produce back to food pantry for distribution (i.e. sponsor a row, etc.), or provide opportunities for clients to work group or individual plots for personal consumption. Offsite community gardens ranked $8^{\text {th }}$ in importance to ideal food pantry services within other food supports $(\mathrm{M}=2.2, \mathrm{SD}=1.36)$.

Table 28. Off-site Community Gardens by Food Bank Region

\begin{tabular}{l|c|c|c|c|c|c|c} 
& $\begin{array}{c}\text { Ozark Food } \\
\text { Harvest }\end{array}$ & Harvesters & $\begin{array}{c}\text { Second } \\
\text { Harvest }\end{array}$ & $\begin{array}{c}\text { Central \& } \\
\text { Northeast }\end{array}$ & St. Louis & Southeast & Total \\
\cline { 2 - 11 } No Service & $86.9 \%$ & $94.1 \%$ & $100 \%$ & $88.6 \%$ & $93.5 \%$ & $91.9 \%$ & $92.2 \%$ \\
Referral & $1.6 \%$ & $1.0 \%$ & $0 \%$ & $0 \%$ & $1.6 \%$ & $5.4 \%$ & $1.5 \%$ \\
Direct Service & $11.5 \%$ & $4.9 \%$ & $0 \%$ & $11.4 \%$ & $4.8 \%$ & $2.7 \%$ & $6.3 \%$ \\
Mean Importance & 2.39 & 2.11 & 1.83 & 2.49 & 2.1 & 2.23 & 2.2
\end{tabular}

General Cooking/Recipe Demonstrations. Food pantries my provide cooking or recipe demonstrations for more general recipes, not necessarily items distributed through the pantry. These demonstrations may be done by volunteers at the food pantry or in partnership with other area agencies like university extension liaisons. Providing general cooking/recipe demonstrations at the pantry ranked $4^{\text {th }}$ in importance to ideal food pantry services within other food supports $(\mathrm{M}=2.86, \mathrm{SD}=1.42)$.

Table 29. General Cooking/Recipe Demonstrations by Food Bank Region

\begin{tabular}{l|c|c|c|c|c|c|c|} 
& $\begin{array}{c}\text { Ozark Food } \\
\text { Harvest }\end{array}$ & Harvesters & $\begin{array}{c}\text { Second } \\
\text { Harvest }\end{array}$ & $\begin{array}{c}\text { Central \& } \\
\text { Northeast }\end{array}$ & St. Louis & Southeast & Total \\
\cline { 2 - 11 } No Service & $62.3 \%$ & $72.5 \%$ & $79.8 \%$ & $75.0 \%$ & $72.6 \%$ & $81.1 \%$ & $72.5 \%$ \\
Referral & $3.3 \%$ & $2.9 \%$ & $5.3 \%$ & $0 \%$ & $3.2 \%$ & $2.7 \%$ & $3.0 \%$ \\
Direct Service & $34.4 \%$ & $24.5 \%$ & $15.8 \%$ & $25.0 \%$ & $24.2 \%$ & $16.2 \%$ & $24.6 \%$ \\
Mean Importance & 2.84 & 3.06 & 2.56 & 3.0 & 2.65 & 2.51 & 2.86 \\
\hline
\end{tabular}


"WE ONLY DO FOOD”

Nutrition Education Classes. Pantries may provide classes or seminars on nutrition to assist clients in choosing and preparing food to be as nutritious as possible. These classes may be provided by food pantry staff, volunteers, or community partner agencies. Providing or supporting nutrition education classes ranked tied for $2^{\text {nd }}$ in importance to ideal food pantry services within other food supports $(\mathrm{M}=3.05, \mathrm{SD}=1.48)$.

Table 30. Nutrition Education Classes by Food Bank Region

\begin{tabular}{l|c|c|c|c|c|c|c|} 
& $\begin{array}{c}\text { Ozark Food } \\
\text { Harvest }\end{array}$ & Harvesters & $\begin{array}{c}\text { Second } \\
\text { Harvest }\end{array}$ & $\begin{array}{c}\text { Central \& } \\
\text { Northeast }\end{array}$ & St. Louis & Southeast & Total \\
\cline { 2 - 9 } No Service & $80.3 \%$ & $77.5 \%$ & $68.4 \%$ & $86.4 \%$ & $83.9 \%$ & $86.5 \%$ & $80.5 \%$ \\
Referral & $1.6 \%$ & $3.9 \%$ & $5.3 \%$ & $2.3 \%$ & $3.2 \%$ & $0 \%$ & $3.0 \%$ \\
Direct Service & $18.0 \%$ & $18.6 \%$ & $26.3 \%$ & $11.4 \%$ & $12.9 \%$ & $13.5 \%$ & $16.5 \%$ \\
Mean Importance & 3.11 & 3.33 & 2.5 & 3.09 & 2.78 & 2.83 & 3.05
\end{tabular}

General Recipes. Pantries may provide access to more general recipes, not necessarily for items distributed through the food pantry. These recipes may be identified and distributed by pantry volunteers or through local partners like university extension liaisons. These recipes are generally meals or dishes that can be prepared at a lower-cost and may be meal identified as a healthy alternative. Providing general recipes ranked $1^{\text {st }}$ in importance to ideal food pantry services within other food supports $(M=3.08$, $\mathrm{SD}=1.32)$.

Table 31. General Recipe Provision by Food Bank Region

\begin{tabular}{|c|c|c|c|c|c|c|c|}
\hline & $\begin{array}{c}\text { Ozark Food } \\
\text { Harvest }\end{array}$ & Harvesters & $\begin{array}{l}\text { Second } \\
\text { Harvest }\end{array}$ & $\begin{array}{l}\text { Central \& } \\
\text { Northeast }\end{array}$ & St. Louis & Southeast & Total \\
\hline No Service & $31.1 \%$ & $43.1 \%$ & $52.6 \%$ & $38.6 \%$ & $46.8 \%$ & $62.2 \%$ & $43.4 \%$ \\
\hline Referral & $0 \%$ & $3.9 \%$ & $0 \%$ & $0 \%$ & $3.2 \%$ & $2.7 \%$ & $2.1 \%$ \\
\hline Direct Service & $68.9 \%$ & $52.9 \%$ & $47.4 \%$ & $61.4 \%$ & $50.0 \%$ & $35.1 \%$ & $54.4 \%$ \\
\hline Mean Importance & 3.25 & 3.19 & 2.82 & 3.09 & 2.93 & 2.86 & 3.08 \\
\hline
\end{tabular}

Nutrition Information (i.e. Posters or Fliers). Food pantries may post nutritional information for specific food, or more general nutritional information. This 
"WE ONLY DO FOOD”

information can help to provide opportunities for clients to make informed decisions about the foods that they are choosing or increase knowledge and awareness of nutrition recommendations. Materials are often available from multiple local national organizations. Providing nutrition information to pantry clients ranked tied for $2^{\text {nd }}$ in importance to ideal food pantry services within other food supports $(\mathrm{M}=3.05, \mathrm{SD}=1.45)$.

Table 32. Nutrition Information by Food Bank Region

\begin{tabular}{|c|c|c|c|c|c|c|c|}
\hline & $\begin{array}{c}\text { Ozark Food } \\
\text { Harvest }\end{array}$ & Harvesters & $\begin{array}{l}\text { Second } \\
\text { Harvest }\end{array}$ & $\begin{array}{c}\text { Central \& } \\
\text { Northeast }\end{array}$ & St. Louis & Southeast & Total \\
\hline No Service & $52.5 \%$ & $54.9 \%$ & $52.6 \%$ & $72.7 \%$ & $62.9 \%$ & $73.0 \%$ & $60.8 \%$ \\
\hline Referral & $3.3 \%$ & $3.9 \%$ & $5.3 \%$ & $0 \%$ & $4.8 \%$ & $2.7 \%$ & $3.6 \%$ \\
\hline Direct Service & $44.3 \%$ & $41.2 \%$ & $42.1 \%$ & $27.3 \%$ & $32.3 \%$ & $24.3 \%$ & $35.6 \%$ \\
\hline Mean Importance & 3.22 & 3.28 & 2.71 & 3.0 & 2.88 & 2.77 & 3.05 \\
\hline
\end{tabular}

Gardening Supplies \&/or Education. A number of food pantries are providing gardening supplies and education both directly and through partnerships with local organizations. Furthermore, past research in Missouri has found that food pantry clients often utilize gardens as a seasonal food source (Foulkes, Heflin, Hermsen, Raedeke, \& Rikoon, 2011). Gardening programs may distribute gardening materials, like seeds and transplants at little to no charge to clients, or educational information help clients improve the success of personal gardens. Providing access to garden supplies or education ranked $7^{\text {th }}$ in importance to ideal food pantry services within other food supports $(\mathrm{M}=2.25, \mathrm{SD}=1.34)$.

Table 33. Gardening Supplies \&/or Education by Food Bank Region

\begin{tabular}{|c|c|c|c|c|c|c|c|}
\hline & $\begin{array}{c}\text { Ozark Food } \\
\text { Harvest }\end{array}$ & Harvesters & $\begin{array}{l}\text { Second } \\
\text { Harvest }\end{array}$ & $\begin{array}{l}\text { Central \& } \\
\text { Northeast }\end{array}$ & St. Louis & Southeast & Total \\
\hline No Service & $80.3 \%$ & $92.2 \%$ & $100 \%$ & $88.6 \%$ & $93.5 \%$ & $94.6 \%$ & $90.7 \%$ \\
\hline Referral & $0 \%$ & $1.0 \%$ & $0 \%$ & $2.3 \%$ & $0 \%$ & $2.7 \%$ & $0.9 \%$ \\
\hline Direct Service & $19.7 \%$ & $6.9 \%$ & $0 \%$ & $9.1 \%$ & $6.5 \%$ & $2.7 \%$ & $8.4 \%$ \\
\hline Mean Importance & 2.51 & 2.19 & 1.82 & 2.67 & 1.92 & 2.37 & 2.25 \\
\hline
\end{tabular}


"WE ONLY DO FOOD”

\section{Health \& Personal Care Supports}

The inequity of negative health outcomes for food pantry has been clearly documented, specifically in the context of Missouri emergency food systems (Foulkes, Heflin, Hermsen, Raedeke, \& Rikoon, 2011). A growing number of food pantries are attempting to better meet the broad health needs of their clients beyond improving the quality of the foods that they provide through their organizations. Pantries may partner with local or regional agencies to provide services, screenings, or education during food pantry distributions, have consultants available to refer to appropriate health agencies, or provide information and literature related to available health services in their area. Health and personal care supports ranked $3^{\text {rd }}$ of 5 pantry service domains in importance to ideal food pantry services $(M=2.92)$ among respondents.

Table 34. Health \& Personal Care Supports Mean Rank by Food Bank Region

\begin{tabular}{|c|c|c|c|c|c|c|c|}
\hline & $\begin{array}{c}\text { Ozark Food } \\
\text { Harvest }\end{array}$ & Harvesters & $\begin{array}{l}\text { Second } \\
\text { Harvest }\end{array}$ & $\begin{array}{l}\text { Central \& } \\
\text { Northeast }\end{array}$ & St. Louis & Southeast & Total \\
\hline Mental Health Screenings & 10 & 7 & 7 & 6 & 6 & 6 & 7 \\
\hline Health Screenings & 8 & 5 & 7 & 4 & 4 & 4 & 4 \\
\hline Dental Screenings & 9 & 8 & 10 & 8 & 9 & 5 & 9 \\
\hline Reproductive Health & 12 & 12 & 10 & 12 & 12 & 11 & 12 \\
\hline Smoking Cessation & 7 & 11 & 7 & 7 & 11 & 10 & 10 \\
\hline Drug \& Alcohol Treatment & 6 & 9 & 6 & 10 & 8 & 7 & 8 \\
\hline Chronic Disease Management & 11 & 10 & 12 & 11 & 9 & 12 & 11 \\
\hline Domestic Violence Assistance & 5 & 6 & 4 & 8 & 5 & 8 & 5 \\
\hline Health Insurance Information & 4 & 6 & 4 & 5 & 7 & 9 & 6 \\
\hline Personal Care Items & 1 & 1 & 1 & 1 & 1 & 1 & 1 \\
\hline Diapers & 3 & 3 & 2 & 3 & 3 & 2 & 3 \\
\hline Household Items & 2 & 2 & 2 & 2 & 2 & 3 & 2 \\
\hline
\end{tabular}


"WE ONLY DO FOOD"

Mental Health Screenings. Food insecurity has been associated with increased risks of mood and behavioral disorders (McLaughlin, et. al., 2012) To help provide for the diverse needs of clients, food pantries may host mental health screenings in collaboration with local mental health organizations, hospitals, or clinics. Pantries may also provide information and referrals to organizations or local events in which mental health screenings will be provided. Providing or connecting clients to mental health screenings ranked $7^{\text {th }}$ in importance to ideal food pantry services within health and personal care supports $(\mathrm{M}=2.66, \mathrm{SD}=1.55)$.

Table 35. Mental Health Screenings by Food Bank Region

\begin{tabular}{|c|c|c|c|c|c|c|c|}
\hline & $\begin{array}{c}\text { Ozark Food } \\
\text { Harvest }\end{array}$ & Harvesters & $\begin{array}{l}\text { Second } \\
\text { Harvest }\end{array}$ & $\begin{array}{l}\text { Central \& } \\
\text { Northeast }\end{array}$ & St. Louis & Southeast & Total \\
\hline No Service & $91.8 \%$ & $88.2 \%$ & $94.7 \%$ & $86.4 \%$ & $85.5 \%$ & $91.9 \%$ & $88.6 \%$ \\
\hline Referral & $3.3 \%$ & $6.9 \%$ & $0 \%$ & $11.4 \%$ & $11.3 \%$ & $8.1 \%$ & $7.8 \%$ \\
\hline Direct Service & $4.9 \%$ & $4.9 \%$ & $5.3 \%$ & $2.3 \%$ & $3.2 \%$ & $0 \%$ & $3.6 \%$ \\
\hline Mean Importance & 2.54 & 2.86 & 1.78 & 2.6 & 2.74 & 2.60 & 2.66 \\
\hline
\end{tabular}

Health Screenings. Food pantry clients have higher rates of negative health outcomes and often have to choose between purchasing food and paying for medical expenses or getting medical assistance (Weinfield et. al., 2014). To help address unmet health needs of clients, food pantries may host health screenings in collaboration with local health organizations, hospitals, or clinics. For pantries that don't provide screening opportunities onsite, they have opportunity to provide information and referrals to organizations or local events where health screenings are available. Providing or connecting clients to health screenings ranked $4^{\text {th }}$ in importance to ideal food pantry services within health and personal care supports $(\mathrm{M}=2.81, \mathrm{SD}=1.53)$. 
"WE ONLY DO FOOD"

Table 36. Health Screenings by Food Bank Region

\begin{tabular}{|c|c|c|c|c|c|c|c|}
\hline & $\begin{array}{c}\text { Ozark Food } \\
\text { Harvest }\end{array}$ & Harvesters & $\begin{array}{l}\text { Second } \\
\text { Harvest } \\
\end{array}$ & $\begin{array}{l}\text { Central \& } \\
\text { Northeast }\end{array}$ & St. Louis & Southeast & Total \\
\hline No Service & $86.9 \%$ & $89.2 \%$ & $89.5 \%$ & $79.5 \%$ & $77.4 \%$ & $75.7 \%$ & $83.5 \%$ \\
\hline Referral & $4.9 \%$ & $2.0 \%$ & $0 \%$ & $13.6 \%$ & $6.5 \%$ & $5.4 \%$ & $5.7 \%$ \\
\hline Direct Service & $8.2 \%$ & $8.8 \%$ & $10.5 \%$ & $6.8 \%$ & $16.1 \%$ & $18.9 \%$ & $10.8 \%$ \\
\hline Mean Importance & 2.6 & 3.03 & 1.78 & 2.79 & 3.07 & 2.71 & 2.81 \\
\hline
\end{tabular}

Dental Screenings. To assist in the unmet dental needs of clients, food pantries may host dental screenings in collaboration with local organizations or dental clinics. For pantries that don't provide screening opportunities on onsite, they have opportunity to provide information and referrals to organizations or local events where dental screenings are available. Providing dental screenings ranked $9^{\text {th }}$ in importance to ideal food pantry services within health and personal care supports $(\mathrm{M}=2.56, \mathrm{SD}=1.47)$.

Table 37. Dental Screenings by Food Bank Region

\begin{tabular}{|c|c|c|c|c|c|c|c|}
\hline & $\begin{array}{c}\text { Ozark Food } \\
\text { Harvest }\end{array}$ & Harvesters & $\begin{array}{l}\text { Second } \\
\text { Harvest }\end{array}$ & $\begin{array}{l}\text { Central \& } \\
\text { Northeast }\end{array}$ & St. Louis & Southeast & Total \\
\hline No Service & $95.1 \%$ & $92.2 \%$ & $94.7 \%$ & $88.6 \%$ & $87.1 \%$ & $91.9 \%$ & $91.3 \%$ \\
\hline Referral & $4.9 \%$ & $3.9 \%$ & $5.3 \%$ & $9.1 \%$ & $9.7 \%$ & $8.1 \%$ & $6.6 \%$ \\
\hline Direct Service & $0 \%$ & $3.9 \%$ & $0 \%$ & $2.3 \%$ & $3.2 \%$ & $0 \%$ & $2.1 \%$ \\
\hline Mean Importance & 2.58 & 2.72 & 1.67 & 2.56 & 2.51 & 2.69 & 2.56 \\
\hline
\end{tabular}

Reproductive Health. To meet unmet reproductive health needs of clients, food pantries may provide reproductive health supplies, opportunities for consultations, or referrals to local organizations that provide reproductive health supports for low-income individuals and households. Reproductive health services can provide contraceptives, medicines and treatment for sexually transmitted illnesses, and medicines and supports to promote healthy pregnancies and deliveries. Providing reproductive health supports or referrals ranked last in importance to ideal food pantry services within health and personal care supports $(\mathrm{M}=2.2, \mathrm{SD}=1.38)$. 
"WE ONLY DO FOOD”

Table 38. Reproductive Health Supports by Food Bank Region

\begin{tabular}{|c|c|c|c|c|c|c|c|}
\hline & $\begin{array}{c}\text { Ozark Food } \\
\text { Harvest }\end{array}$ & Harvesters & $\begin{array}{l}\text { Second } \\
\text { Harvest }\end{array}$ & $\begin{array}{c}\text { Central \& } \\
\text { Northeast }\end{array}$ & St. Louis & Southeast & Total \\
\hline No Service & $98.4 \%$ & $96.1 \%$ & $100 \%$ & $97.7 \%$ & $93.5 \%$ & $89.2 \%$ & $95.5 \%$ \\
\hline Referral & $1.6 \%$ & $2.9 \%$ & $0 \%$ & $2.3 \%$ & $6.5 \%$ & $10.8 \%$ & $4.2 \%$ \\
\hline Direct Service & $0 \%$ & $1.0 \%$ & $0 \%$ & $0 \%$ & $0 \%$ & $0 \%$ & $0.3 \%$ \\
\hline Mean Importance & 2.26 & 2.33 & 1.67 & 2.19 & 2.1 & 2.20 & 2.2 \\
\hline
\end{tabular}

Smoking Cessation. Low-income and food insecure populations have higher rates of smoking (Jamal, et. al., 2015; Perkett, et. al., 2017) and limited access to smoking cessation programs for those that desire to quit (Burns, Deaton, \& Levinson, 2011; Sheffer, Stitzer, Landes, Brackman, Munn, \& Moore, 2012; Huddleston, Ratschen, \& Murray, 2015). Pantries may provide space for smoking cessation programs in partnership with local organizations or refer clients to local opportunities to access smoking cessation programs and supplies for low-income populations. Providing smoking cessation supports or referrals ranked $10^{\text {th }}$ in importance to ideal food pantry services within health and personal care supports $(\mathrm{M}=2.46, \mathrm{SD}=1.48)$.

Table 39. Smoking Cessation Supports by Food Bank Region

\begin{tabular}{|c|c|c|c|c|c|c|c|}
\hline & $\begin{array}{c}\text { Ozark Food } \\
\text { Harvest }\end{array}$ & Harvesters & $\begin{array}{l}\text { Second } \\
\text { Harvest }\end{array}$ & $\begin{array}{l}\text { Central \& } \\
\text { Northeast }\end{array}$ & St. Louis & Southeast & Total \\
\hline No Service & $98.4 \%$ & $97.1 \%$ & $100 \%$ & $93.2 \%$ & $96.8 \%$ & $94.6 \%$ & $96.4 \%$ \\
\hline Referral & $1.6 \%$ & $1.0 \%$ & $0 \%$ & $4.5 \%$ & $3.2 \%$ & $5.4 \%$ & $2.7 \%$ \\
\hline Direct Service & $0 \%$ & $2.0 \%$ & $0 \%$ & $2.3 \%$ & $0 \%$ & $0 \%$ & $0.9 \%$ \\
\hline Mean Importance & 2.63 & 2.53 & 1.78 & 2.58 & 2.36 & 2.29 & 2.46 \\
\hline
\end{tabular}

Drug \&/or Alcohol Treatment. Food insecurity has been associated with an increased risk of substance disorders (McLaughlin, et. al., 2012). Food pantries may provide space and times for local health professionals and treatment centers to meet with clients, provide referrals to treatment centers, or post fliers with information on where clients can obtain more information or assistance with substance abuse. Providing drug 
"WE ONLY DO FOOD”

and alcohol treatment supports or referrals ranked $8^{\text {th }}$ in importance to ideal food pantry services within health and personal care supports $(\mathrm{M}=2.59, \mathrm{SD}=1.56)$.

Table 40. Drug and Alcohol Treatment Supports by Food Bank Region

\begin{tabular}{l|c|c|c|c|c|c|c|} 
& $\begin{array}{c}\text { Ozark Food } \\
\text { Harvest }\end{array}$ & Harvesters & $\begin{array}{c}\text { Second } \\
\text { Harvest }\end{array}$ & $\begin{array}{c}\text { Central \& } \\
\text { Northeast }\end{array}$ & St. Louis & Southeast & Total \\
\cline { 2 - 10 } No Service & $93.4 \%$ & $86.3 \%$ & $94.7 \%$ & $93.2 \%$ & $85.5 \%$ & $86.5 \%$ & $88.6 \%$ \\
Referral & $3.3 \%$ & $9.8 \%$ & $5.3 \%$ & $4.5 \%$ & $12.9 \%$ & $5.4 \%$ & $8.1 \%$ \\
Direct Service & $3.3 \%$ & $3.9 \%$ & $0 \%$ & $2.3 \%$ & $1.6 \%$ & $8.1 \%$ & $3.3 \%$ \\
Mean Importance & 2.65 & 2.71 & 1.83 & 2.44 & 2.62 & 2.54 & 2.59
\end{tabular}

Chronic Disease Management. Food pantry clients have a higher incidence of chronic diseases or health conditions (Stuff et. al., 2004). Food pantries may provide opportunities for local health professionals to meet with food pantry clients, provide referrals to local health clinics that provide services to low-income populations, or post information on where clients can meet with health professionals to address concerns with chronic diseases. Providing chronic disease management supports or referrals ranked $11^{\text {th }}$ in importance to ideal food pantry services within health and personal care supports $(\mathrm{M}=2.42, \mathrm{SD}=1.47)$

Table 41. Chronic Disease Management Supports by Food Bank Region

\begin{tabular}{l|c|c|c|c|c|c|c|} 
& $\begin{array}{c}\text { Ozark Food } \\
\text { Harvest }\end{array}$ & Harvesters & $\begin{array}{c}\text { Second } \\
\text { Harvest }\end{array}$ & $\begin{array}{c}\text { Central \& } \\
\text { Northeast }\end{array}$ & St. Louis & Southeast & Total \\
\cline { 2 - 10 } No Service & $96.7 \%$ & $97.1 \%$ & $100 \%$ & $97.7 \%$ & $96.8 \%$ & $94.6 \%$ & $96.4 \%$ \\
\hline Referral & $3.3 \%$ & $2.0 \%$ & $0 \%$ & $2.3 \%$ & $3.2 \%$ & $2.7 \%$ & $3.0 \%$ \\
Direct Service & $0 \%$ & $0.9 \%$ & $0 \%$ & $0 \%$ & $0 \%$ & $2.7 \%$ & $0.6 \%$ \\
\hline Mean Importance & 2.4 & 2.64 & 1.61 & 2.3 & 2.51 & 2.17 & 2.42 \\
\hline
\end{tabular}

Domestic Violence Resources. A large proportion of domestic violence survivors rely on food assistance supports to meet their basic needs (Goodman, 2018).

Furthermore, individuals leaving abusive environments are often at a great risk of poverty and limited resource. Food pantries may provide space for local organizations that 
"WE ONLY DO FOOD"

provide domestic violence supports to meet with clients, provide referrals, or post materials outlining domestic violence community resources. Providing domestic violence resources or referrals ranked $5^{\text {th }}$ in importance to ideal food pantry services within health and personal care supports $(\mathrm{M}=2.79, \mathrm{SD}=1.64)$.

Table 42. Domestic Violence Resource by Food Bank Region

\begin{tabular}{l|c|c|c|c|c|c|c} 
& $\begin{array}{c}\text { Ozark Food } \\
\text { Harvest }\end{array}$ & Harvesters & $\begin{array}{c}\text { Second } \\
\text { Harvest }\end{array}$ & $\begin{array}{c}\text { Central \& } \\
\text { Northeast }\end{array}$ & St. Louis & Southeast & Total \\
\cline { 2 - 9 } No Service & $85.2 \%$ & $90.2 \%$ & $94.7 \%$ & $90.9 \%$ & $82.3 \%$ & $94.6 \%$ & $88.3 \%$ \\
Referral & $6.6 \%$ & $5.9 \%$ & $0 \%$ & $9.1 \%$ & $17.7 \%$ & $5.4 \%$ & $8.7 \%$ \\
Direct Service & $8.2 \%$ & $3.9 \%$ & $5.3 \%$ & $0 \%$ & $0 \%$ & $0 \%$ & $3.0 \%$ \\
Mean Importance & 2.88 & 3.1 & 2.0 & 2.56 & 2.79 & 2.51 & 2.79 \\
\hline
\end{tabular}

Health Insurance Information. Food pantry clients have noted a lack of health insurance coverage and financial burden related to unpaid medical bills (Weinfield et. al., 2014). Food pantries can help address the inequity in health insurance coverage for clients by sponsoring events to help clients apply for Medicaid, referring to local organizations that specialize in assisting low-income residents obtain health insurance, or posting information about insurance resources in their community. Providing health insurance information or referrals ranked $6^{\text {th }}$ in importance to ideal food pantry services within health and personal care supports $(\mathrm{M}=2.76, \mathrm{SD}=1.56)$.

Table 43. Health Insurance Information by Food Bank Region

\begin{tabular}{|c|c|c|c|c|c|c|c|}
\hline & $\begin{array}{c}\text { Ozark Food } \\
\text { Harvest }\end{array}$ & Harvesters & $\begin{array}{l}\text { Second } \\
\text { Harvest }\end{array}$ & $\begin{array}{c}\text { Central \& } \\
\text { Northeast }\end{array}$ & St. Louis & Southeast & Total \\
\hline No Service & $72.1 \%$ & $83.3 \%$ & $100 \%$ & $79.5 \%$ & $74.2 \%$ & $94.6 \%$ & $81.1 \%$ \\
\hline Referral & $6.6 \%$ & $4.9 \%$ & $0 \%$ & $9.1 \%$ & $8.1 \%$ & $0 \%$ & $5.7 \%$ \\
\hline Direct Service & $21.3 \%$ & $11.8 \%$ & $0 \%$ & $11.4 \%$ & $17.7 \%$ & $5.4 \%$ & $13.2 \%$ \\
\hline Mean Importance & 2.91 & 3.02 & 2.0 & 2.77 & 2.72 & 2.34 & 2.76 \\
\hline
\end{tabular}

Personal Care Items. Households facing food insecurity may also lack the funds necessary to purchase personal care items (i.e. deodorant, toothpaste, period products). 
"WE ONLY DO FOOD”

Food pantries may provide some of these resources to clients at food distributions or provide referrals to local organizations that can help connect clients to personal care items. Providing personal care items or referrals to obtain these items ranked $1^{\text {st }}$ in importance to ideal food pantry services within health and personal care supports $(\mathrm{M}=4.21, \mathrm{SD}=1.09)$.

Table 44. Personal Care Items by Food Bank Region

\begin{tabular}{l|c|c|c|c|c|c|c} 
& $\begin{array}{c}\text { Ozark Food } \\
\text { Harvest }\end{array}$ & Harvesters & $\begin{array}{c}\text { Second } \\
\text { Harvest }\end{array}$ & $\begin{array}{c}\text { Central \& } \\
\text { Northeast }\end{array}$ & St. Louis & Southeast & Total \\
\cline { 2 - 10 } No Service & $29.5 \%$ & $12.7 \%$ & $15.8 \%$ & $27.3 \%$ & $3.2 \%$ & $21.6 \%$ & $17.1 \%$ \\
Direct Service & $70.5 \%$ & $87.3 \%$ & $84.2 \%$ & $72.7 \%$ & $96.8 \%$ & $78.4 \%$ & $82.9 \%$ \\
Mean Importance & 4.05 & 4.19 & 3.76 & 4.14 & 4.5 & 4.23 & 4.21
\end{tabular}

Diapers. Diapers are a necessary item for families with infants and young children. However, this expense may be difficult for individuals using food pantries to afford. Food pantries may provide this resource to families with infants and young children during food distributions or provide referrals to local organizations that can connect clients to the diapers that they need. Providing diapers or referrals to obtain diapers ranked $3^{\text {rd }}$ in importance to ideal food pantry services within health and personal care support $(\mathrm{M}=3.73, \mathrm{SD}=1.44)$.

Table 45. Diaper Provisions by Food Bank Region

\begin{tabular}{|c|c|c|c|c|c|c|c|}
\hline & $\begin{array}{c}\text { Ozark Food } \\
\text { Harvest }\end{array}$ & Harvesters & $\begin{array}{l}\text { Second } \\
\text { Harvest }\end{array}$ & $\begin{array}{c}\text { Central \& } \\
\text { Northeast }\end{array}$ & St. Louis & Southeast & Total \\
\hline No Service & $41.0 \%$ & $35.3 \%$ & $52.6 \%$ & $25.0 \%$ & $24.2 \%$ & $32.4 \%$ & $33.2 \%$ \\
\hline Referral & $3.3 \%$ & $2.0 \%$ & $0 \%$ & $2.3 \%$ & $4.8 \%$ & $0 \%$ & $2.7 \%$ \\
\hline Direct Service & $55.7 \%$ & $62.7 \%$ & $47.4 \%$ & $72.7 \%$ & $71.0 \%$ & $67.6 \%$ & $64.1 \%$ \\
\hline Mean Importance & 3.69 & 3.59 & 3.12 & 3.93 & 3.9 & 3.86 & 3.73 \\
\hline
\end{tabular}

Household Items. Purchasing general household items (i.e. cleaning supplies, paper towels, toilet paper) are an expense that some food pantry clients may have trouble with. Pantries can distribute an assortment of household items during food distributions 
"WE ONLY DO FOOD”

or refer clients to local organizations that provide these items. Providing household items or referrals to obtain these items ranked $2^{\text {nd }}$ in importance to ideal food pantry services within health and personal care supports $(\mathrm{M}=3.81, \mathrm{SD}=1.28)$.

Table 46. Household Item Provisions by Food Bank Region

\begin{tabular}{l|c|c|c|c|c|c|c|} 
& $\begin{array}{c}\text { Ozark Food } \\
\text { Harvest }\end{array}$ & Harvesters & $\begin{array}{c}\text { Second } \\
\text { Harvest }\end{array}$ & $\begin{array}{c}\text { Central \& } \\
\text { Northeast }\end{array}$ & St. Louis & Southeast & Total \\
\cline { 2 - 10 } No Service & $32.8 \%$ & $28.4 \%$ & $31.6 \%$ & $47.7 \%$ & $16.1 \%$ & $37.8 \%$ & $30.8 \%$ \\
Referral & $1.6 \%$ & $0 \%$ & $5.3 \%$ & $2.3 \%$ & $1.6 \%$ & $5.4 \%$ & $1.8 \%$ \\
Direct Service & $65.6 \%$ & $71.6 \%$ & $63.2 \%$ & $50.0 \%$ & $82.3 \%$ & $56.8 \%$ & $67.4 \%$ \\
Mean Importance & 3.78 & 3.76 & 3.12 & 3.95 & 4.08 & 3.83 & 3.81
\end{tabular}

\section{Organizational Structuring}

The ways in which food pantries structure their organizations, the additional services they offer, and the ways in which they setup the physical environment of the pantry play a central role on the value of this resource, and its accessibility for clients.

Organizing and structuring pantry services to center on the needs of pantry clients can ensure the pantries to provide the most efficient and effective supports for the clients that are attempting to reach. Client centered organizational structuring ranked $1^{\text {st }}$ of 5 pantry service domains in importance to ideal food pantry services $(M=3.12)$ among respondents.

Table 47. Organizational Structuring Mean Importance Rank by Food Bank Region

\begin{tabular}{|c|c|c|c|c|c|c|c|}
\hline & $\begin{array}{l}\text { Ozark Food } \\
\text { Harvest }\end{array}$ & Harvesters & $\begin{array}{l}\text { Second } \\
\text { Harvest }\end{array}$ & $\begin{array}{l}\text { Central \& } \\
\text { Northeast }\end{array}$ & St. Louis & Southeast & Total \\
\hline Thrift Shop & 7 & 7 & 7 & 9 & 7 & 7 & 7 \\
\hline Religious Programming & 11 & 9 & 11 & 11 & 8 & 6 & 9 \\
\hline Visible Signage & 2 & 3 & 1 & 2 & 3 & 2 & 3 \\
\hline $\begin{array}{l}\text { Clearly Identified Hours of } \\
\text { Operation }\end{array}$ & 1 & 1 & 1 & 1 & 1 & 1 & 1 \\
\hline $\begin{array}{l}\text { Up-to-date Website/Social } \\
\text { Media }\end{array}$ & 4 & 5 & 4 & 5 & 5 & 5 & 5 \\
\hline Seating Area for Clients & 3 & 2 & 3 & 3 & 2 & 3 & 2 \\
\hline Area for Children & 6 & 6 & 6 & 7 & 6 & 8 & 6 \\
\hline
\end{tabular}


"WE ONLY DO FOOD”

Opportunity for Client
Feedback
Opportunity for Clients to
Serve on Board/Staff
Pantry Newsletter
Social \&/or Cultural Events

5
9
8
10

\begin{tabular}{|l|l|}
\hline 4 & 5 \\
\hline 8 & 9 \\
\hline 11 & 8 \\
\hline 10 & 10 \\
\hline
\end{tabular}

4
6
8
10

4
11
10
8

\begin{tabular}{c|c}
4 & 4 \\
9 & 8 \\
10 & 9 \\
11 & 11 \\
\hline
\end{tabular}

Thrift Shop or Clothing Wardrobe. Thrift shops and clothing wardrobes provide donated items for purchase low-costs. This resource can help food pantry clients access the household items and clothing that they and their families need. Additionally, thrift shops can provide additional income to cover operating costs when affiliated with food pantries. Operating or providing information on local thrift-shops ranked $7^{\text {th }}$ in importance to ideal food pantry services within organizational structuring $(M=2.73$, $\mathrm{SD}=1.65)$.

Table 48. Thrift Shops by Food Bank Region

\begin{tabular}{|c|c|c|c|c|c|c|c|}
\hline & $\begin{array}{c}\text { Ozark Food } \\
\text { Harvest }\end{array}$ & Harvesters & $\begin{array}{l}\text { Second } \\
\text { Harvest }\end{array}$ & $\begin{array}{c}\text { Central \& } \\
\text { Northeast }\end{array}$ & St. Louis & Southeast & Total \\
\hline No Service & $54.1 \%$ & $55.9 \%$ & $63.2 \%$ & $63.6 \%$ & $54.8 \%$ & $64.9 \%$ & $57.8 \%$ \\
\hline Referral & $4.9 \%$ & $7.8 \%$ & $0 \%$ & $4.5 \%$ & $12.9 \%$ & $8.1 \%$ & $7.5 \%$ \\
\hline Direct Service & $41.0 \%$ & $36.3 \%$ & $36.8 \%$ & $31.8 \%$ & $32.3 \%$ & $27.0 \%$ & $34.7 \%$ \\
\hline Mean Importance & 3.08 & 2.77 & 2.53 & 2.2 & 2.77 & 2.76 & 2.73 \\
\hline
\end{tabular}

Religious Programming. Food pantries are often affiliated with religious organizations and may be located in a church or church owned property. Food pantries may include religious programming into their services in a range of ways, from praying before food distributions, holding prayer or study groups, providing religious materials, or referring clients to a range of local church services and activities. Religious programming ranked $9^{\text {th }}$ in importance to ideal food pantry services within organizational structuring $(\mathrm{M}=2.3, \mathrm{SD}=1.57)$. 
"WE ONLY DO FOOD”

Table 49. Religious Programming by Food Bank Region

\begin{tabular}{l|c|c|c|c|c|c|c} 
& $\begin{array}{c}\text { Ozark Food } \\
\text { Harvest }\end{array}$ & Harvesters & $\begin{array}{c}\text { Second } \\
\text { Harvest }\end{array}$ & $\begin{array}{c}\text { Central \& } \\
\text { Northeast }\end{array}$ & St. Louis & Southeast & Total \\
\cline { 2 - 10 } No Service & $90.2 \%$ & $85.3 \%$ & $100 \%$ & $93.2 \%$ & $87.1 \%$ & $67.6 \%$ & $86.5 \%$ \\
Referral & $1.6 \%$ & $4.9 \%$ & $0 \%$ & $2.3 \%$ & $0 \%$ & $10.8 \%$ & $3.3 \%$ \\
Direct Service & $8.2 \%$ & $9.8 \%$ & $0 \%$ & $4.5 \%$ & $12.9 \%$ & $21.6 \%$ & $10.2 \%$ \\
Mean Importance & 2.16 & 2.47 & 1.63 & 1.86 & 2.27 & 2.78 & 2.3
\end{tabular}

Visible Signage. Having visible signage can help create a public presence for food pantries and make locating this service easier for clients. Signage may be posted by the road or on the building the food pantry is located in. Having visible signage ranked $3^{\text {rd }}$ in importance to ideal food pantry services in organizational structuring $(M=4.03$, $\mathrm{SD}=1.32)$.

Table 50. Visible Signage by Food Bank Region

\begin{tabular}{l|c|c|c|c|c|c|c|} 
& $\begin{array}{c}\text { Ozark Food } \\
\text { Harvest }\end{array}$ & Harvesters & $\begin{array}{c}\text { Second } \\
\text { Harvest }\end{array}$ & $\begin{array}{c}\text { Central \& } \\
\text { Northeast }\end{array}$ & St. Louis & Southeast & Total \\
\cline { 2 - 10 } No Service & $14.8 \%$ & $55.9 \%$ & $26.3 \%$ & $25.0 \%$ & $30.6 \%$ & $40.5 \%$ & $36.2 \%$ \\
Direct Service & $85.2 \%$ & $44.1 \%$ & $73.7 \%$ & $75.0 \%$ & $69.4 \%$ & $59.5 \%$ & $63.8 \%$ \\
Mean Importance & 4.32 & 3.84 & 4.47 & 4.07 & 3.98 & 3.97 & 4.03
\end{tabular}

Clearly Identified and Accurate Hours. Food pantries are not often open on a regular basis, and clearly identified and accurate hours can assist clients in organizing their schedule to access the food pantry at the correct times and avoid additional costs of additional trips to receive food. Pantries can post hours at their physical location or make it available through local media and internet sites. Having clearly identified and accurate hours ranked $1^{\text {st }}$ in importance to ideal food pantry services within organizational structuring $(\mathrm{M}=4.42, \mathrm{SD}=1.11)$. 
"WE ONLY DO FOOD”

Table 51. Clearly Identified and Accurate Hours by Food Bank Region

\begin{tabular}{l|c|c|c|c|c|c|c|} 
& $\begin{array}{c}\text { Ozark Food } \\
\text { Harvest }\end{array}$ & Harvesters & $\begin{array}{c}\text { Second } \\
\text { Harvest }\end{array}$ & $\begin{array}{c}\text { Central \& } \\
\text { Northeast }\end{array}$ & St. Louis & Southeast & Total \\
\cline { 2 - 9 } No Service & $9.8 \%$ & $25.5 \%$ & $31.6 \%$ & $20.5 \%$ & $11.3 \%$ & $37.8 \%$ & $21.0 \%$ \\
Direct Service & $90.2 \%$ & $74.5 \%$ & $68.4 \%$ & $79.5 \%$ & $88.7 \%$ & $62.2 \%$ & $79.0 \%$ \\
Mean Importance & 4.67 & 4.3 & 4.47 & 4.59 & 4.4 & 4.11 & 4.42 \\
\hline
\end{tabular}

Up-to-date Website or Social Media Page. Having an up-to-date digital space is becoming increasingly important for organizations to connect with clients and share important information regarding food pantry operations. Simple websites or social media pages can provide information about food pantry location, hours of operation, and special events. Social media is also a great platform for pantries to further establish a presence in their community and engage with community members and elected officials. Having an up-to-date website or social media page ranked $5^{\text {th }}$ in importance to ideal food pantry services within organizational structuring $(\mathrm{M}=3.51, \mathrm{SD}=1.53)$.

Table 52. Up-to-date Website or Social Media Page by Food Bank Region

\begin{tabular}{l|c|c|c|c|c|c|c|} 
& $\begin{array}{c}\text { Ozark Food } \\
\text { Harvest }\end{array}$ & Harvesters & $\begin{array}{c}\text { Second } \\
\text { Harvest }\end{array}$ & $\begin{array}{c}\text { Central \& } \\
\text { Northeast }\end{array}$ & St. Louis & Southeast & Total \\
\cline { 2 - 8 } No Service & $39.3 \%$ & $50.0 \%$ & $57.9 \%$ & $47.7 \%$ & $50.0 \%$ & $64.9 \%$ & $50.6 \%$ \\
Direct Service & $60.7 \%$ & $50.0 \%$ & $42.1 \%$ & $52.3 \%$ & $50.0 \%$ & $35.1 \%$ & $49.4 \%$ \\
Mean Importance & 3.75 & 3.58 & 3.37 & 3.59 & 3.29 & 3.22 & 3.51 \\
\hline
\end{tabular}

Seating Area for Clients. Accessing food pantry services often requires clients to wait to for both check-in and receive or select food. Having seating areas for clients is a way in which pantries can provide a more comfortable experience for clients when visiting the food pantry. Having a seating are for clients ranked $2^{\text {nd }}$ in importance for ideal food pantry services within organizational structuring $(\mathrm{M}=4.04, \mathrm{SD}=1.34)$. 
"WE ONLY DO FOOD”

Table 53. Seating Area for Clients by Food Bank Region

\begin{tabular}{l|c|c|c|c|c|c|c|} 
& $\begin{array}{c}\text { Ozark Food } \\
\text { Harvest }\end{array}$ & Harvesters & $\begin{array}{c}\text { Second } \\
\text { Harvest }\end{array}$ & $\begin{array}{c}\text { Central \& } \\
\text { Northeast }\end{array}$ & St. Louis & Southeast & Total \\
\cline { 2 - 10 } No Service & $24.6 \%$ & $26.5 \%$ & $0 \%$ & $31.8 \%$ & $21.0 \%$ & $27.0 \%$ & $24.6 \%$ \\
Direct Service & $75.4 \%$ & $73.5 \%$ & $100 \%$ & $68.2 \%$ & $79.0 \%$ & $73.0 \%$ & $75.4 \%$ \\
Mean Importance & 4.15 & 3.98 & 4.21 & 3.98 & 4.11 & 3.95 & 4.04
\end{tabular}

Area for Children. Families may need to bring their children to the food pantry. Having a space setup for children to wait can allow parents and caregivers to check-in and select foods without the added stress of keeping their children engaged during this process. Children spaces may also make the experience more pleasant for children as well. Having an area for children ranked $6^{\text {th }}$ in importance to ideal food pantry services within organizational structuring $(\mathrm{M}=2.83, \mathrm{SD}=1.50)$.

Table 54. Area for Children by Food Bank Region

\begin{tabular}{l|c|c|c|c|c|c|c|} 
& $\begin{array}{c}\text { Ozark Food } \\
\text { Harvest }\end{array}$ & Harvesters & $\begin{array}{c}\text { Second } \\
\text { Harvest }\end{array}$ & $\begin{array}{c}\text { Central \& } \\
\text { Northeast }\end{array}$ & St. Louis & Southeast & Total \\
\cline { 2 - 10 } No Service & $68.9 \%$ & $69.6 \%$ & $78.9 \%$ & $84.1 \%$ & $75.8 \%$ & $75.7 \%$ & $74.0 \%$ \\
Direct Service & $31.1 \%$ & $30.4 \%$ & $21.1 \%$ & $15.9 \%$ & $24.2 \%$ & $24.3 \%$ & $26.0 \%$ \\
Mean Importance & 3.12 & 3.01 & 2.58 & 2.57 & 2.81 & 2.46 & 2.83 \\
\hline
\end{tabular}

Opportunity for Client Feedback. Establishing and promoting opportunities for client feedback can provide great insight for pantries to tailor their service to the clients that they are serving. Opportunities can take many forms at food pantries, from actively managing a suggestion box to holding community meetings or focus groups. Providing opportunity for client feedback ranked $4^{\text {th }}$ in importance to ideal food pantry services within organizational structuring $(\mathrm{M}=3.54, \mathrm{SD}=1.45)$. 
"WE ONLY DO FOOD"

Table 55. Opportunity for Client Feedback by Food Bank Region

\begin{tabular}{l|c|c|c|c|c|c|c|} 
& $\begin{array}{c}\text { Ozark Food } \\
\text { Harvest }\end{array}$ & Harvesters & $\begin{array}{c}\text { Second } \\
\text { Harvest }\end{array}$ & $\begin{array}{c}\text { Central \& } \\
\text { Northeast }\end{array}$ & St. Louis & Southeast & Total \\
\cline { 2 - 8 } No Service & $49.2 \%$ & $59.8 \%$ & $52.6 \%$ & $40.9 \%$ & $38.7 \%$ & $48.6 \%$ & $50.0 \%$ \\
Direct Service & $50.8 \%$ & $40.2 \%$ & $47.4 \%$ & $59.1 \%$ & $61.3 \%$ & $51.4 \%$ & $50.0 \%$ \\
Mean Importance & 3.5 & 3.65 & 2.84 & 3.8 & 3.65 & 3.27 & 3.54
\end{tabular}

Opportunity for Clients to Serve on Board/Staff. Food pantries often operate

under the direction of individuals or boards that are themselves removed from food pantry utilization. This separation can limit the understanding of how pantries can most affectively meet the needs of pantry clients, as well as promoting power structure between 'helpers' and 'helped'. Providing opportunity for clients to serve on the board or take part in organizational decision making ranked $8^{\text {th }}$ in importance to ideal food pantry operations within organizational structuring $(\mathrm{M}=2.39, \mathrm{SD}=1.48)$.

Table 56. Opportunity for Clients to Serve on Board/Staff by Food Bank Region

\begin{tabular}{l|c|c|c|c|c|c|c|} 
& $\begin{array}{c}\text { Ozark Food } \\
\text { Harvest }\end{array}$ & Harvesters & $\begin{array}{c}\text { Second } \\
\text { Harvest }\end{array}$ & $\begin{array}{c}\text { Central \& } \\
\text { Northeast }\end{array}$ & St. Louis & Southeast & Total \\
\cline { 2 - 9 } No Service & $82.0 \%$ & $84.3 \%$ & $78.9 \%$ & $68.2 \%$ & $79.0 \%$ & $83.8 \%$ & $79.9 \%$ \\
Direct Service & $18.0 \%$ & $15.7 \%$ & $21.1 \%$ & $31.8 \%$ & $21.0 \%$ & $16.2 \%$ & $20.1 \%$ \\
Mean Importance & 2.33 & 2.54 & 2.0 & 2.7 & 2.13 & 2.3 & 2.39 \\
\hline
\end{tabular}

Social or Cultural Events. Food pantries can host or advertise local social events that pantry clients and community members can attend. Hosting events can help to promote awareness of the food pantry and destigmatize food pantry utilization.

Additionally, promoting opportunity for interactions between different socioeconomic and cultural groups can create great ties within local communities. Hosting or connecting clients to social or cultural events ranked $11^{\text {th }}$ in importance to ideal food pantry operations within organizational structuring $(\mathrm{M}=2.26, \mathrm{SD}=1.47)$. 
"WE ONLY DO FOOD"

Table 57. Social or Cultural Events by Food Bank Region

\begin{tabular}{l|c|c|c|c|c|c|c} 
& $\begin{array}{c}\text { Ozark Food } \\
\text { Harvest }\end{array}$ & Harvesters & $\begin{array}{c}\text { Second } \\
\text { Harvest }\end{array}$ & $\begin{array}{c}\text { Central \& } \\
\text { Northeast }\end{array}$ & St. Louis & Southeast & Total \\
\cline { 2 - 9 } No Service & $91.8 \%$ & $82.4 \%$ & $89.5 \%$ & $88.6 \%$ & $82.3 \%$ & $83.8 \%$ & $85.0 \%$ \\
Referral & $0 \%$ & $1.0 \%$ & $0 \%$ & $6.8 \%$ & $4.8 \%$ & $0 \%$ & $2.4 \%$ \\
Direct Service & $8.2 \%$ & $16.7 \%$ & $10.5 \%$ & $4.5 \%$ & $12.9 \%$ & $16.2 \%$ & $12.6 \%$ \\
Mean Importance & 2.23 & 2.41 & 1.89 & 2.19 & 2.27 & 2.14 & 2.26
\end{tabular}

Pantry Newsletter. Food pantries can provide a digital or print newsletter to send to clients that updates them on services offered or community events that may be useful. Newsletters are a great way for pantries to keep clients up to date in lieu of maintaining a website or social media page. Providing a pantry newsletter ranked $9^{\text {th }}$ in importance to ideal food pantry services within organizational structuring $(\mathrm{M}=2.3, \mathrm{SD}=1.42)$.

Table 58. Pantry Newsletter by Food Bank Region

\begin{tabular}{|c|c|c|c|c|c|c|c|}
\hline & $\begin{array}{c}\text { Ozark Food } \\
\text { Harvest }\end{array}$ & Harvesters & $\begin{array}{l}\text { Second } \\
\text { Harvest } \\
\end{array}$ & $\begin{array}{l}\text { Central \& } \\
\text { Northeast }\end{array}$ & St. Louis & Southeast & Total \\
\hline No Service & $86.9 \%$ & $90.2 \%$ & $84.2 \%$ & $88.6 \%$ & $82.3 \%$ & $94.6 \%$ & $88.0 \%$ \\
\hline Referral & $1.6 \%$ & $1.0 \%$ & $0 \%$ & $0 \%$ & $0 \%$ & $2.7 \%$ & $0.9 \%$ \\
\hline Direct Service & $11.5 \%$ & $8.8 \%$ & $15.8 \%$ & $11.4 \%$ & $17.7 \%$ & $2.7 \%$ & $11.1 \%$ \\
\hline Mean Importance & 2.45 & 2.3 & 2.24 & 2.47 & 2.2 & 2.17 & 2.3 \\
\hline
\end{tabular}

\section{Systemic Supports}

The causes of hunger and the need to utilize food pantries lie deeper than simply a lack of access to food. A growing group of food pantries and hunger advocates are attempting to not only meet the immediate food needs of households, but also address deeper systemic causes of food insecurity that lead clients to needing food pantry provisions. Providing supports for systemic causes of hunger and food pantry utilization ranked $4^{\text {th }}$ of 5 pantry service domains in importance to ideal food pantry services $(\mathrm{M}=2.63)$ among respondents. 
"WE ONLY DO FOOD”

Table 59. Systemic Supports Mean Importance Rank by Food Bank Region

\begin{tabular}{|c|c|c|c|c|c|c|c|}
\hline & $\begin{array}{c}\text { Ozark Food } \\
\text { Harvest }\end{array}$ & Harvesters & $\begin{array}{l}\text { Second } \\
\text { Harvest }\end{array}$ & $\begin{array}{l}\text { Central \& } \\
\text { Northeast }\end{array}$ & St. Louis & Southeast & Total \\
\hline Utility Assistance & 2 & 5 & 7 & 8 & 1 & 6 & 4 \\
\hline Housing/Rent Assistance & 3 & 7 & 7 & 10 & 6 & 10 & 8 \\
\hline Transportation Assistance & 5 & 10 & 5 & 9 & 10 & 7 & 9 \\
\hline $\begin{array}{l}\text { Engagement with Elected } \\
\text { Officials }\end{array}$ & 4 & 3 & 2 & 1 & 3 & 1 & 2 \\
\hline Job Skills Training & 6 & 4 & 4 & 4 & 5 & 2 & 3 \\
\hline Employment Opportunities & 1 & 1 & 1 & 2 & 2 & 3 & 1 \\
\hline $\begin{array}{l}\text { Educational } \\
\text { Programming/Assistance }\end{array}$ & 9 & 8 & 9 & 6 & 6 & 4 & 7 \\
\hline Financial Literacy Training & 6 & 2 & 6 & 3 & 3 & 4 & 5 \\
\hline Voter Registration & 10 & 8 & 9 & 6 & 9 & 9 & 9 \\
\hline Translation Services & 6 & 5 & 3 & 5 & 8 & 8 & 6 \\
\hline
\end{tabular}

Utility Assistance. Food pantry clients may be choosing between paying their utilities or purchasing foods. This issue is compounded by the housing that some clients may be living in. Older houses and mobile housing units often have higher costs for utilities due to inefficient heating and cooling systems, lower insulation ratings, and less efficient building materials (i.e. single pane windows). Providing utility assistance or referrals to appropriate community partners that provide utility assistance ranked $4^{\text {th }}$ in importance to ideal food pantry services within systemic supports $(\mathrm{M}=2.68, \mathrm{SD}=1.59)$.

Table 60. Utility Assistance by Food Bank Region

\begin{tabular}{l|c|c|c|c|c|c|c} 
& $\begin{array}{c}\text { Ozark Food } \\
\text { Harvest }\end{array}$ & Harvesters & $\begin{array}{c}\text { Second } \\
\text { Harvest }\end{array}$ & $\begin{array}{c}\text { Central \& } \\
\text { Northeast }\end{array}$ & St. Louis & Southeast & Total \\
\cline { 2 - 10 } No Service & $57.4 \%$ & $57.8 \%$ & $84.2 \%$ & $75.0 \%$ & $51.6 \%$ & $78.4 \%$ & $62.6 \%$ \\
Referral & $16.4 \%$ & $10.8 \%$ & $0 \%$ & $0 \%$ & $9.7 \%$ & $10.8 \%$ & $9.6 \%$ \\
Direct Service & $26.2 \%$ & $31.4 \%$ & $15.8 \%$ & $25.0 \%$ & $38.7 \%$ & $10.8 \%$ & $27.8 \%$ \\
Mean Importance & 2.89 & 2.75 & 1.84 & 2.14 & 3.18 & 2.41 & 2.68
\end{tabular}

Housing/Rent Assistance. Households utilizing food pantries identify that they have to make decisions between purchasing food and paying for housing or rent costs at 
"WE ONLY DO FOOD”

times (Weinfield et. al, 2014). Providing housing/rent assistance or referrals to appropriate community partners that provide housing or rent assistance ranked $8^{\text {th }}$ in importance to ideal food pantry services within systemic supports $(M=2.49, S D=1.57)$.

Table 61. Housing/Rent Assistance by Food Bank Region

\begin{tabular}{|c|c|c|c|c|c|c|c|}
\hline & $\begin{array}{c}\text { Ozark Food } \\
\text { Harvest }\end{array}$ & Harvesters & $\begin{array}{l}\text { Second } \\
\text { Harvest }\end{array}$ & $\begin{array}{l}\text { Central \& } \\
\text { Northeast }\end{array}$ & St. Louis & Southeast & Total \\
\hline No Service & $65.6 \%$ & $72.5 \%$ & $84.2 \%$ & $84.1 \%$ & $71.0 \%$ & $89.2 \%$ & $75.4 \%$ \\
\hline Referral & $9.8 \%$ & $9.8 \%$ & $5.3 \%$ & $2.3 \%$ & $9.7 \%$ & $8.1 \%$ & $8.1 \%$ \\
\hline Direct Service & $24.6 \%$ & $17.6 \%$ & $10.5 \%$ & $13.6 \%$ & $19.4 \%$ & $2.7 \%$ & $16.5 \%$ \\
\hline Mean Importance & 2.82 & 2.7 & 1.84 & 1.98 & 2.68 & 2.11 & 2.49 \\
\hline
\end{tabular}

Transportation Assistance. Households utilizing food pantries often note having to make decisions between purchasing food and paying for transportation expenses (Weinfield et. al, 2014). Without access to reliable personal or public transportation, individuals lack the ability to access resources in their local communities or hold steady employment. Previous studies of food pantry use have found that car ownership is a primary factor in predicting food pantry use (Daponte, Lewis, Sanders, \& Taylor, 1998). Food pantries may provide programs that assist clients with transportation needs or connect client to local organizations that provide reliable low-cost or free transportation to qualifying individuals. Providing transportation assistance or referrals for transportation assistance ranked $9^{\text {th }}$ in importance to ideal food pantry services within systemic supports $(\mathrm{M}=2.45, \mathrm{SD}=1.46)$.

Table 62. Transportation Assistance by Food Bank Region

\begin{tabular}{|c|c|c|c|c|c|c|c|}
\hline & $\begin{array}{c}\text { Ozark Food } \\
\text { Harvest }\end{array}$ & Harvesters & $\begin{array}{l}\text { Second } \\
\text { Harvest }\end{array}$ & $\begin{array}{l}\text { Central \& } \\
\text { Northeast }\end{array}$ & St. Louis & Southeast & Total \\
\hline No Service & $73.8 \%$ & $86.3 \%$ & $89.5 \%$ & $90.9 \%$ & $87.1 \%$ & $83.8 \%$ & $84.4 \%$ \\
\hline Referral & $6.6 \%$ & $3.9 \%$ & $5.3 \%$ & $4.5 \%$ & $6.5 \%$ & $8.1 \%$ & $6.0 \%$ \\
\hline Direct Service & $19.7 \%$ & $9.8 \%$ & $5.3 \%$ & $4.5 \%$ & $6.5 \%$ & $8.1 \%$ & $9.6 \%$ \\
\hline Mean Importance & 2.77 & 2.51 & 2.05 & 2.0 & 2.52 & 2.32 & 2.45 \\
\hline
\end{tabular}


"WE ONLY DO FOOD”

Engagement with Elected Officials. Food pantries may engage with local and state officials to promote their organization and the services that they offer. Increased knowledge and support can result in greater support for programs that fund food pantry services. Additionally, engaging with elected public officials provides a space for food pantry organizations to advocate for the clients that they serve and the needs that they may have; specifically relating to the public programs and legislative measures that would benefit clients and provide less need for 'emergency' food services (i.e. higher minimum wage, affordable housing, more comprehensive government benefits, affordable healthcare, health insurance coverage, public transportation investments). Engaging elected official to promote food pantry efforts ranked $2^{\text {nd }}$ in importance to ideal food pantry operations within systemic supports $(\mathrm{M}=2.81, \mathrm{SD}=1.51)$.

Table 63. Engagement with Elected Officials by Food Bank Region

\begin{tabular}{l|c|c|c|c|c|c|c|} 
& $\begin{array}{c}\text { Ozark Food } \\
\text { Harvest }\end{array}$ & Harvesters & $\begin{array}{c}\text { Second } \\
\text { Harvest }\end{array}$ & $\begin{array}{c}\text { Central \& } \\
\text { Northeast }\end{array}$ & St. Louis & Southeast & Total \\
\cline { 2 - 8 } No Service & $78.7 \%$ & $81.4 \%$ & $68.4 \%$ & $86.4 \%$ & $69.4 \%$ & $78.4 \%$ & $77.8 \%$ \\
Direct Service & $21.3 \%$ & $18.6 \%$ & $31.6 \%$ & $13.6 \%$ & $30.6 \%$ & $21.6 \%$ & $22.2 \%$ \\
Mean Importance & 2.8 & 2.79 & 2.32 & 3.02 & 2.85 & 2.78 & 2.81 \\
\hline
\end{tabular}

Job Skills Training. Food pantry clients may lack skills necessary for changing job markets or need support in developing skills needed for successful employment. Food pantries may provide opportunities for job skills training through the pantry, coordinate with job skills training and coaching organizations in their community, or refer clients to these organizations. Providing or referring clients to job skills training opportunities was ranked $3^{\text {rd }}$ in importance to ideal food pantry operations within systemic supports $(M=2.69, \mathrm{SD}=1.67)$. 
"WE ONLY DO FOOD"

Table 64. Job Skills Training by Food Bank Region

\begin{tabular}{|c|c|c|c|c|c|c|c|}
\hline & $\begin{array}{c}\text { Ozark Food } \\
\text { Harvest }\end{array}$ & Harvesters & $\begin{array}{l}\text { Second } \\
\text { Harvest }\end{array}$ & $\begin{array}{c}\text { Central \& } \\
\text { Northeast }\end{array}$ & St. Louis & Southeast & Total \\
\hline No Service & $86.9 \%$ & $81.4 \%$ & $89.5 \%$ & $86.4 \%$ & $80.6 \%$ & $86.5 \%$ & $83.5 \%$ \\
\hline Referral & $8.2 \%$ & $10.8 \%$ & $5.3 \%$ & $9.1 \%$ & $11.3 \%$ & $2.7 \%$ & $9.3 \%$ \\
\hline Direct Service & $4.9 \%$ & $7.8 \%$ & $5.3 \%$ & $4.5 \%$ & $8.1 \%$ & $10.8 \%$ & $7.2 \%$ \\
\hline Mean Importance & 2.68 & 2.77 & 2.17 & 2.65 & 2.77 & 2.6 & 2.69 \\
\hline
\end{tabular}

Employment Opportunities. While food pantries often provide volunteer opportunities, they can also provide opportunities for employment for pantry clients. Employment may serve as a transitional or training opportunity for clients as they gain experience or search for other employment positions. Providing employment opportunities for clients also creates a system in which pantry services are more informed by the populations that they are serving. Providing employment opportunities for pantry clients or referring to known employment opportunities was ranked $1^{\text {st }}$ in importance to ideal food pantry services within systemic supports $(\mathrm{M}=2.9, \mathrm{SD}=1.63)$.

Table 65. Panty Client Employment Opportunities by Food Bank Region

\begin{tabular}{|c|c|c|c|c|c|c|c|}
\hline & $\begin{array}{c}\text { Ozark Food } \\
\text { Harvest }\end{array}$ & Harvesters & $\begin{array}{l}\text { Second } \\
\text { Harvest } \\
\end{array}$ & $\begin{array}{c}\text { Central \& } \\
\text { Northeast }\end{array}$ & St. Louis & Southeast & Total \\
\hline No Service & $85.2 \%$ & $76.5 \%$ & $89.5 \%$ & $79.5 \%$ & $77.4 \%$ & $86.5 \%$ & $80.2 \%$ \\
\hline Referral & $6.6 \%$ & $9.8 \%$ & $0 \%$ & $6.8 \%$ & $11.3 \%$ & $8.1 \%$ & $9.0 \%$ \\
\hline Direct Service & $8.2 \%$ & $13.7 \%$ & $10.5 \%$ & $13.6 \%$ & $11.3 \%$ & $5.4 \%$ & $10.8 \%$ \\
\hline Mean Importance & 3.11 & 2.97 & 2.56 & 2.81 & 3.02 & 2.57 & 2.9 \\
\hline
\end{tabular}

Educational Programs/Assistance. Pantry clients have a wide range of educational backgrounds, but many pantry clients may still have a high school diploma, equivalent, or less. Food pantries can coordinate with local adult education organizations to offer GED classes or technical training for clients, provide or post referrals to local organizations that provide adult education classes or college courses, or even support clients in applying for post-secondary education. Providing educational supports or 
"WE ONLY DO FOOD”

referrals was ranked $7^{\text {th }}$ in importance to ideal food pantry services within systemic supports $(\mathrm{M}=2.55, \mathrm{SD}=1.61)$.

Table 66. Educational Programs or Assistance by Food Bank Region

\begin{tabular}{|c|c|c|c|c|c|c|c|}
\hline & $\begin{array}{c}\text { Ozark Food } \\
\text { Harvest }\end{array}$ & Harvesters & $\begin{array}{l}\text { Second } \\
\text { Harvest }\end{array}$ & $\begin{array}{c}\text { Central \& } \\
\text { Northeast }\end{array}$ & St. Louis & Southeast & Total \\
\hline No Service & $90.2 \%$ & $90.2 \%$ & $94.7 \%$ & $90.9 \%$ & $85.5 \%$ & $89.2 \%$ & $88.9 \%$ \\
\hline Referral & $6.6 \%$ & $3.9 \%$ & $5.3 \%$ & $6.8 \%$ & $4.8 \%$ & $5.4 \%$ & $6.0 \%$ \\
\hline Direct Service & $3.3 \%$ & $5.9 \%$ & $0 \%$ & $2.3 \%$ & $9.7 \%$ & $5.4 \%$ & $5.1 \%$ \\
\hline Mean Importance & 2.6 & 2.63 & 1.78 & 2.51 & 2.68 & 2.43 & 2.55 \\
\hline
\end{tabular}

Financial Literacy. Food pantry clients may need assistance in financial planning, tax preparation, or asset management related to qualifying for public assistance programs. Food pantries may provide space for financial literacy consultations in partnership with local organizations, offer referrals to pantry clients, or post information on where pantry clients can obtain needed financial assistance. Providing financial literacy supports or referrals was ranked $5^{\text {th }}$ in importance to ideal food pantry services within systemic supports $(\mathrm{M}=2.67, \mathrm{SD}=1.64)$.

Table 67. Financial Literacy Training by Food Bank Region

\begin{tabular}{|c|c|c|c|c|c|c|c|}
\hline & $\begin{array}{c}\text { Ozark Food } \\
\text { Harvest }\end{array}$ & Harvesters & $\begin{array}{l}\text { Second } \\
\text { Harvest } \\
\end{array}$ & $\begin{array}{c}\text { Central \& } \\
\text { Northeast }\end{array}$ & St. Louis & Southeast & Total \\
\hline No Service & $88.5 \%$ & $89.2 \%$ & $100 \%$ & $93.2 \%$ & $93.5 \%$ & $94.6 \%$ & $91.3 \%$ \\
\hline Referral & $3.3 \%$ & $3.9 \%$ & $0 \%$ & $4.5 \%$ & $1.6 \%$ & $5.4 \%$ & $3.6 \%$ \\
\hline Direct Service & $8.2 \%$ & $6.9 \%$ & $0 \%$ & $2.3 \%$ & $4.8 \%$ & $0 \%$ & $5.1 \%$ \\
\hline Mean Importance & 2.68 & 2.82 & 2.0 & 2.67 & 2.85 & 2.43 & 2.67 \\
\hline
\end{tabular}

Voter Registration. Voting opportunities for food pantry clients allows for client voices to play a role in determining elected officials and the subsequent policies that these individuals support. Food pantries can help clients register to vote, post information about any registration deadlines, or connect clients to organizations or local offices that can assist in registering to vote. Providing opportunities for voter registration or 
"WE ONLY DO FOOD"

information voter registration was ranked $9^{\text {th }}$ in importance to ideal food pantry services within systemic supports $(\mathrm{M}=2.45, \mathrm{SD}=1.58)$.

Table 68. Voter Registration by Food Bank Region

\begin{tabular}{|c|c|c|c|c|c|c|c|}
\hline & $\begin{array}{c}\text { Ozark Food } \\
\text { Harvest }\end{array}$ & Harvesters & $\begin{array}{l}\text { Second } \\
\text { Harvest }\end{array}$ & $\begin{array}{l}\text { Central \& } \\
\text { Northeast }\end{array}$ & St. Louis & Southeast & Total \\
\hline No Service & $85.2 \%$ & $88.2 \%$ & $94.7 \%$ & $86.4 \%$ & $87.1 \%$ & $94.6 \%$ & $88.0 \%$ \\
\hline Referral & $8.2 \%$ & $1.0 \%$ & $0 \%$ & $6.8 \%$ & $6.5 \%$ & $2.7 \%$ & $4.5 \%$ \\
\hline Direct Service & $6.6 \%$ & $10.8 \%$ & $5.3 \%$ & $6.8 \%$ & $6.5 \%$ & $2.7 \%$ & $7.5 \%$ \\
\hline Mean Importance & 2.51 & 2.63 & 1.78 & 2.51 & 2.53 & 2.14 & 2.45 \\
\hline
\end{tabular}

Translation Services. Some food pantry clients are not native English speakers and don't use English as their primary language at home. For these individuals, accessing services may be more difficult due to language barriers. Food pantries may provide translation services and translated materials to assist with pantry utilization, as well as provide or link clients to translation supports for other needs that they may have.

Providing translation services was ranked $6^{\text {th }}$ in importance to ideal food pantry services within systemic supports $(\mathrm{M}=2.59, \mathrm{SD}=1.50)$.

Table 69. Translation Services by Food Bank Region

\begin{tabular}{l|c|c|c|c|c|c|c|} 
& $\begin{array}{c}\text { Ozark Food } \\
\text { Harvest }\end{array}$ & Harvesters & $\begin{array}{c}\text { Second } \\
\text { Harvest }\end{array}$ & $\begin{array}{c}\text { Central \& } \\
\text { Northeast }\end{array}$ & St. Louis & Southeast & Total \\
\cline { 2 - 10 } No Service & $77.0 \%$ & $84.3 \%$ & $94.7 \%$ & $88.6 \%$ & $83.9 \%$ & $86.5 \%$ & $84.7 \%$ \\
Direct Service & $23.0 \%$ & $15.7 \%$ & $5.3 \%$ & $11.4 \%$ & $16.1 \%$ & $13.5 \%$ & $15.3 \%$ \\
Mean Importance & 2.68 & 2.75 & 2.26 & 2.61 & 3.65 & 2.19 & 2.59 \\
\hline
\end{tabular}

\section{Food Pantry Directors}

Survey participants included food pantry directors from all of the regional food banks affiliated with Feeding Missouri. Respondents were predominantly white $(n=278$, $83.5 \%)$, Christian $(n=258,77.5 \%)$, female $(n=247,74.0 \%)$, with at least a high school diploma or GED education level or higher $(n=291,89.0 \%)$. Respondents were most 
"WE ONLY DO FOOD"

likely to identify as politically conservative $(n=126,38.0 \%)$, currently financially secure $(n=193,59.4 \%)$, financial stable or better off financially than they were ten years prior $(n=269,82.8 \%)$, had grown up in an environment with some level of financial security $(n=249,76.4 \%)$, and primarily held a structural attribution of poverty $(n=246,77.8 \%)$.

The age of respondents ranged from 22-89 years, with the mean age of the sample being 59.53 years. Food pantry directors had been affiliated with the food pantry in some capacity for an average of 8.38 years. The majority of pantry directors $(n=180,55.7 \%)$ had occupied the management position for five or less years, but the average time in the position of pantry director for the sample was 6.63 years. It was also common for directors to have not personally utilized food pantry services before $(n=222,66.9 \%)$. Table 69 provides a complete breakdown of overall demographic information for the sample. 
"WE ONLY DO FOOD"
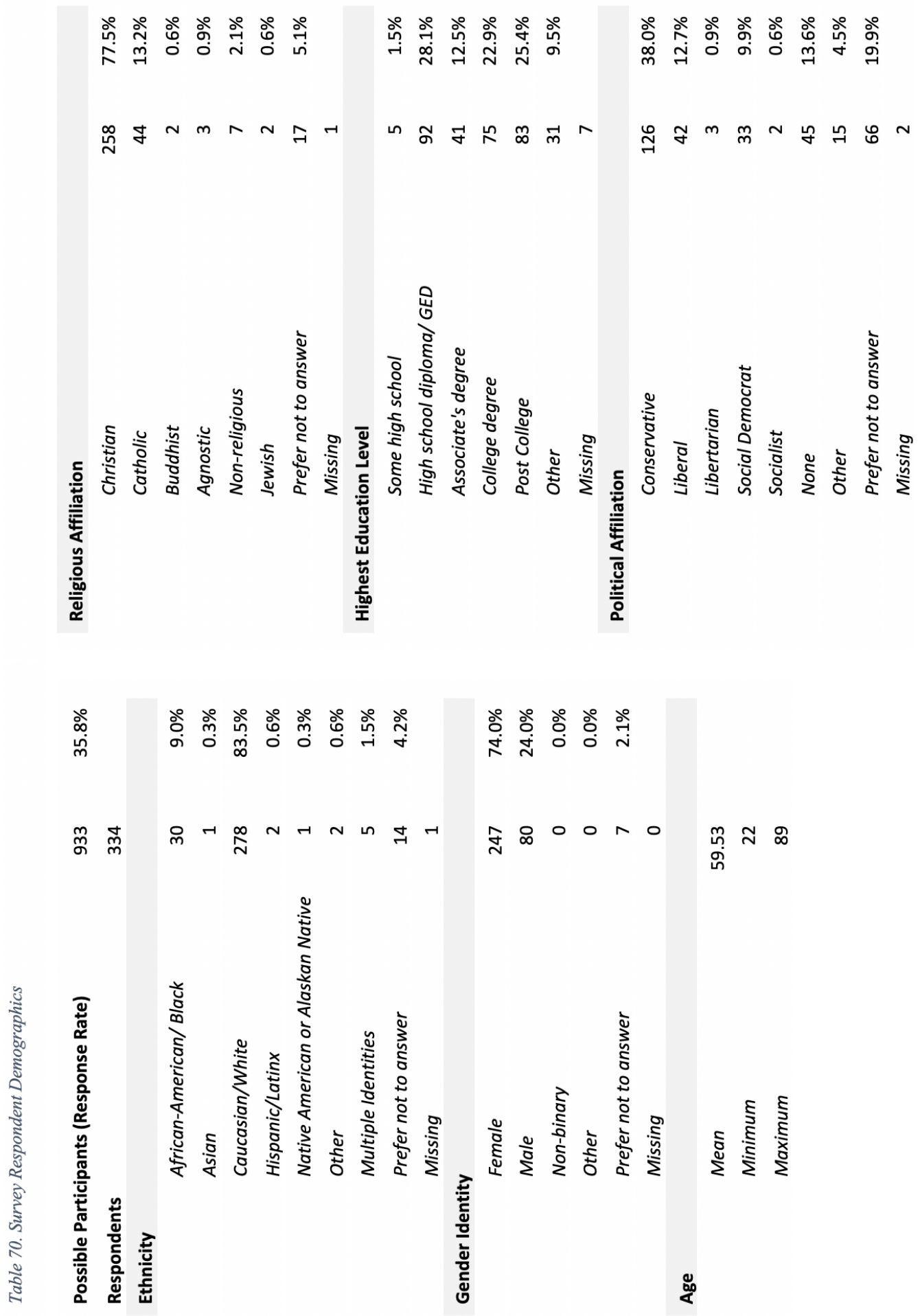
"WE ONLY DO FOOD"
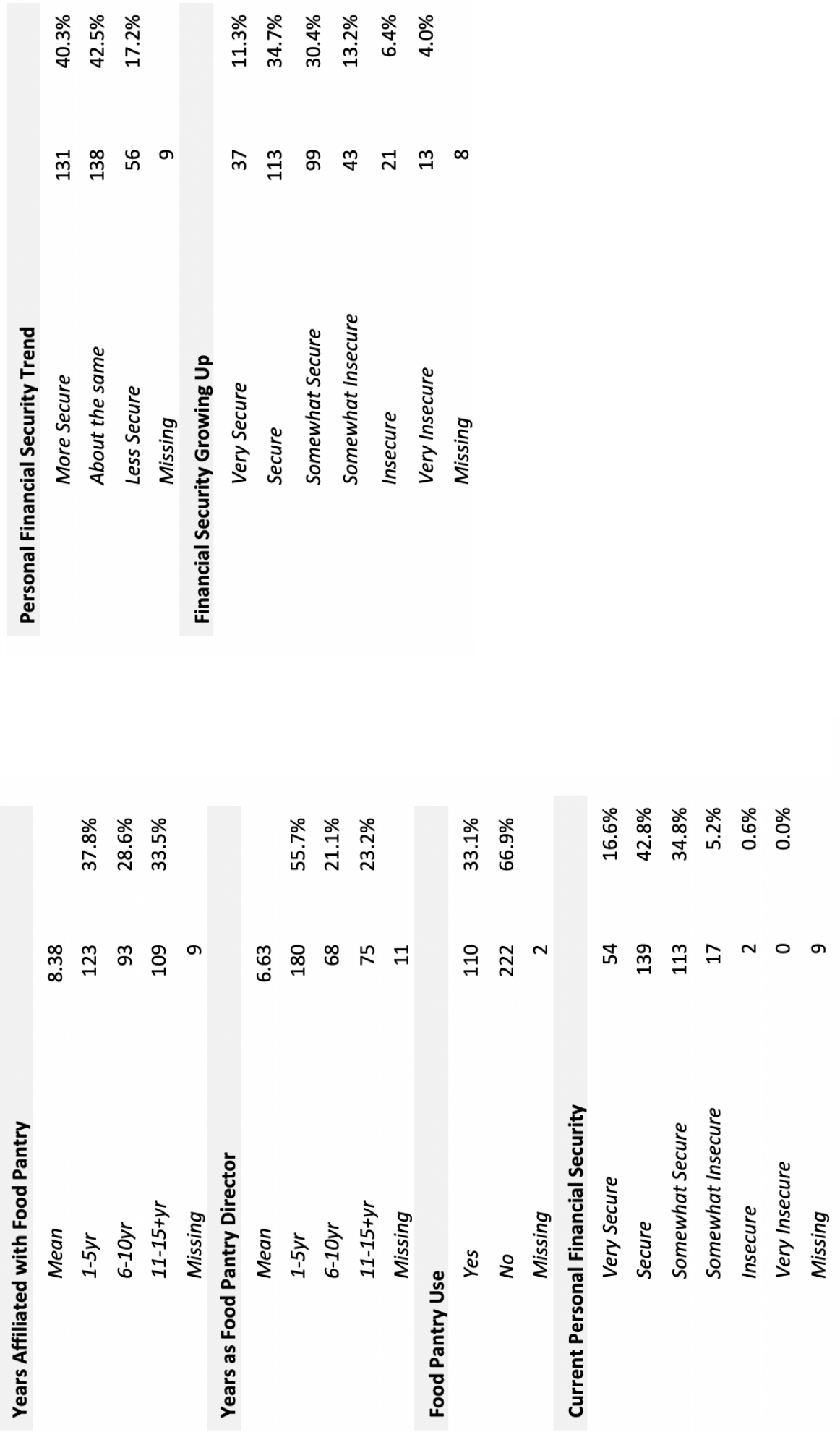
"WE ONLY DO FOOD”

\section{Attributions of Poverty}

Multi-dimensional attributions of poverty were measured across the domains of personal deficiency, stigma, and structural perspectives of poverty attribution. Each domain was standardized to account for the slightly inconsistent number of questions within each attribution category. Standardized scores were calculated by taking the average response of agreement within each domain. Scores can range from 1-5, with higher scores indicated a greater agreement to the corresponding attribution of poverty. Directors showed the highest levels of agreement with structural attributions of poverty $(\mathrm{M}=3.54, \mathrm{SD}=.59)$, and the least agreement with personal deficiency attributions of poverty $(\mathrm{M}=2.19, \mathrm{SD}=.51)$.

Table 71. Average Attribution Domain Scores by Food Bank Region

\begin{tabular}{|c|c|c|c|c|c|c|c|}
\hline & $\begin{array}{c}\text { Ozark Food } \\
\text { Harvest }\end{array}$ & Harvesters & $\begin{array}{l}\text { Second } \\
\text { Harvest }\end{array}$ & $\begin{array}{l}\text { Central \& } \\
\text { Northeast }\end{array}$ & St. Louis & Southeast & Total \\
\hline $\begin{array}{l}\text { Personal } \\
\text { Deficiency }\end{array}$ & 2.39 & 2.11 & 2.12 & 2.21 & 2.05 & 2.29 & 2.19 \\
\hline Stigma & 2.83 & 2.53 & 2.85 & 2.69 & 2.53 & 2.93 & 2.67 \\
\hline Structural & 3.32 & 3.64 & 3.57 & 3.52 & 3.73 & 3.34 & 3.54 \\
\hline
\end{tabular}

The standardization of scores also allowed for the identification of primary attributions of poverty for each food pantry director. Similar to the multi-dimensional results, pantry directors were most likely to primarily hold a structural attribution of poverty.

Table 72. Director Primary Poverty Attribution Domain by Food Bank Region

\begin{tabular}{|c|c|c|c|c|c|c|c|}
\hline & $\begin{array}{c}\text { Ozark Food } \\
\text { Harvest }\end{array}$ & Harvesters & $\begin{array}{l}\text { Second } \\
\text { Harvest }\end{array}$ & $\begin{array}{l}\text { Central \& } \\
\text { Northeast }\end{array}$ & St. Louis & Southeast & Total \\
\hline $\begin{array}{l}\text { Personal } \\
\text { Deficiency }\end{array}$ & $3.5 \%$ & $0 \%$ & $0 \%$ & $4.9 \%$ & $0 \%$ & $0 \%$ & $1.3 \%$ \\
\hline Stigma & $31.6 \%$ & $15.2 \%$ & $29.4 \%$ & $14.6 \%$ & $12.1 \%$ & $38.9 \%$ & $20.9 \%$ \\
\hline Structural & $64.9 \%$ & $84.8 \%$ & $70.6 \%$ & $80.5 \%$ & $87.9 \%$ & $61.1 \%$ & $77.8 \%$ \\
\hline
\end{tabular}


"WE ONLY DO FOOD"

\section{Beliefs About Food Pantry Services}

Pantry directors largely believed that clients at their food pantries weren't different than most other people that are poor $(71.3 \%, \mathrm{n}=238)$, and believed that food pantry serves were critical to their clients being able to 'get by' $(78.4 \%, \mathrm{n}=261)$.

Additionally, $38.4 \%$ of food pantry directors $(n=127)$ identified that food pantries are a better solution to hunger than government funded assistance programs, and believed that, as the director of the food pantry, they had played a major role in the structuring of their organizations services $(96.4 \%, \mathrm{n}=320)$.

\section{Table 73. Food Pantry Director Beliefs About Food Pantry Services}

Clients that use your food pantry are different than most other people that are poor

$\begin{array}{lrr}\text { Strongly Agree } & 1 & 0.3 \% \\ \text { Agree } & 15 & 4.5 \% \\ \text { Neutral } & 80 & 24.0 \% \\ \text { Disagree } & 169 & 50.6 \% \\ \text { Strongly Disagree } & 69 & 20.7 \%\end{array}$

Clients that us your food pantry could get by without the food/resources that they get from the pantry

$\begin{array}{lrr}\text { Strongly Agree } & 1 & 0.3 \% \\ \text { Agree } & 11 & 3.3 \% \\ \text { Neutral } & 60 & 18.0 \% \\ \text { Disagree } & 165 & 49.5 \% \\ \text { Strongly Disagree } & 96 & 28.8 \%\end{array}$

Food pantries are a better solution to hunger than government funded assistance programs

$\begin{array}{lrr}\text { Strongly Agree } & 32 & 9.7 \% \\ \text { Agree } & 95 & 28.7 \% \\ \text { Neutral } & 137 & 41.4 \% \\ \text { Disagree } & 59 & 17.8 \% \\ \text { Strongly Disagree } & 8 & 2.4 \%\end{array}$

I have had a major role in determining how the food pantry I manage is organized.

$\begin{array}{lrr}\text { Strongly Agree } & 226 & 68.1 \% \\ \text { Agree } & 94 & 28.3 \% \\ \text { Disagree } & 9 & 2.7 \% \\ \text { Strongly Disagree } & 3 & 0.9 \%\end{array}$


"WE ONLY DO FOOD”

\section{Chapter 5: Multivariate Results}

RQ1: What help-giving typologies exist within food pantries?

Latent Profile Analysis (LPA) was conducted using Mplus 8.0 (Muthén \& Muthén, 1998-2017) to explore possible underlying groupings of food pantries in regard to the services pantries offer and the ways in which they organize their operations. Model fit and selection was determined through the evaluation of Akaike Information Criterion (AIC), Bayesian Information Criterion (BIC), Entropy, and Lo-Mendell-Rubin Adjusted Likelihood Ratio Test (LMR-LRT) statistical measures, as well as theoretical considerations related to food pantry organization. Analysis was conducted specifying models with two to six latent profiles. Table 1 provides these indices for the overall LPA analysis, and the basis for model selection.

The 4-profile model was identified as the most appropriate model. This model provided AIC and BIC indices similar to the more parsimonious model, and a similarly robust Entropy. While the LMT-LRT for this model does not indicate a significantly stronger explanation of the data, the examination of group latent class counts and mean scores within the various constructs across group were considered in relationship to existing theoretical perspectives on food pantry organization; specifically, the organizational practices of food pantries that employ a food justice-oriented approach to services. Figure 1 provides the means for each group across the five constructs utilized for LPA.

Latent class 1 within the 4-class profile model reports the lowest mean scores across all of the constructs included in the model/study. Consistently low scores are indicative of the provision of fewer services through their pantry directly, the lack of 


\section{"WE ONLY DO FOOD"}

referrals \&/or vouchers for any additional services for clients, organizational structuring that doesn't promote a client-centered approach, and minimal attempts to engage with structural causes of hunger. This class was identified as the "Traditional Food Pantry" $(n=144 ; 43.1 \%)$, as this model closely follows the historical pantry model that primarily focuses on distributing emergency food provisions.

Latent class 2 within the 4-class profile model reports higher scores across all domains than the "Traditional Food Pantry" class, and has fairly consistent scores across all domains. Scores for this class are generally lower than those of the subsequent classes across all domains. This trend is indicative of a greater number of service referrals when pantry resources may not allow for the provision of specific services, and was why this class was identified as the "Linking Pantry" $(n=127 ; 38 \%)$.

Latent class 3 within the 4-class profile model reports consistently higher scores across all constructs than both the "Traditional Food Pantry" and "Linking Pantry" classes. These scores are indicative of an organization that provides a number of "response" services, connecting food pantry clients to both food provisions, public food assistance programs, and utilizing client-centered organizational approaches, but doesn't prioritize resources to address systemic causes of hunger, and is why this class was identified as the "Services-Focused Pantry" ( $n=47 ; 14.1 \%)$.

Latent class 4 in the 4-class profile model reports the highest scores across all of the constructs included in the model/study. This group displays some of the traits discussed in food justice literature that separate it from the "Services-Focused Pantry", and provides the critical point of selection of this model. This profile, labeled as "Food Justice Oriented Pantry" sub-group in this study ( $n=16 ; 4.8 \%)$, reports similar scores to 
"WE ONLY DO FOOD”

the other high-performing "service-focused pantries" in the constructs of direct food provisions and organizational structuring; however, this class reports higher scores in domains more strongly tied to the systemic causes and alleviation strategies of food insecurity. This is evident in greater connection to public assistance programs, health and personal care supports, and systemic supports. Items within these constructs include activities or referrals for health screenings, dental screenings, voter registration, job skills training, employment opportunities, utility assistance, transportation assistance, and health insurance supports, among others previously identified.

Figure 1: Latent profile analysis profile characteristics $(n=334)$

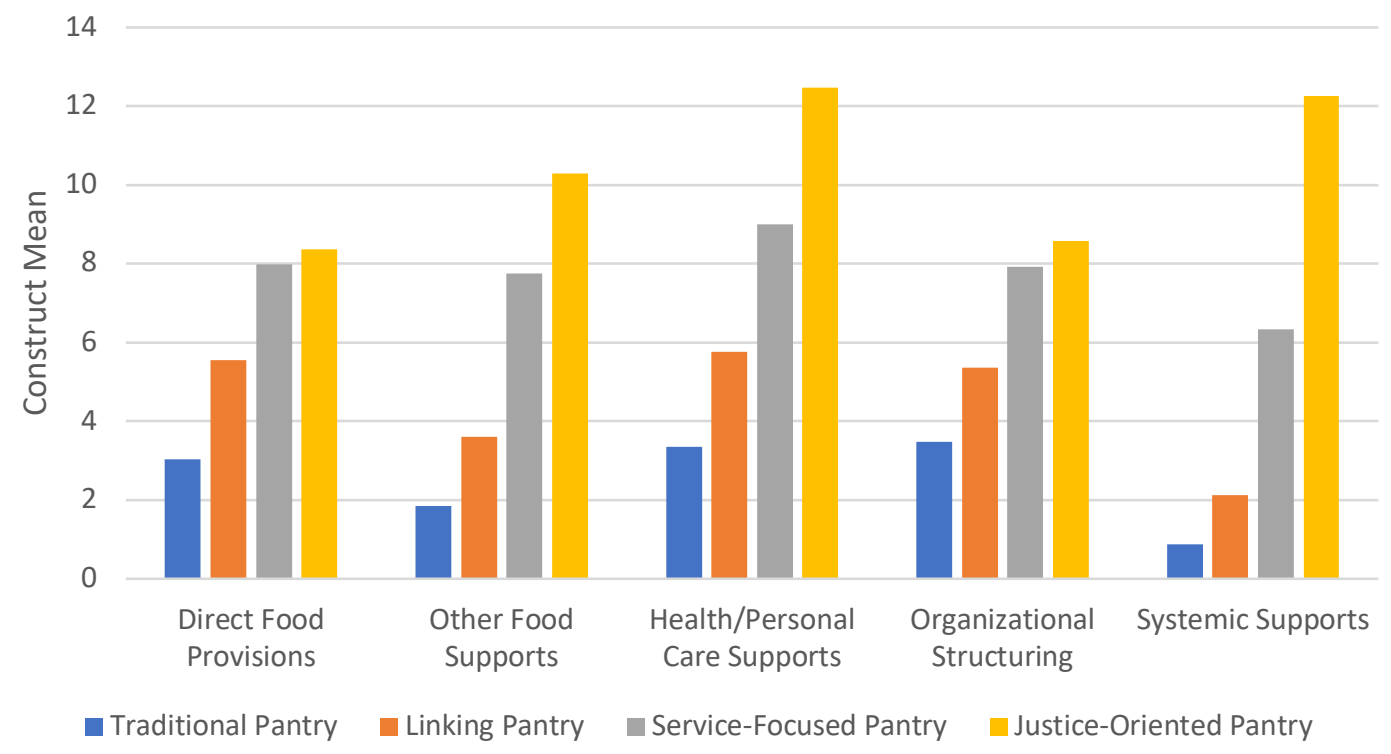




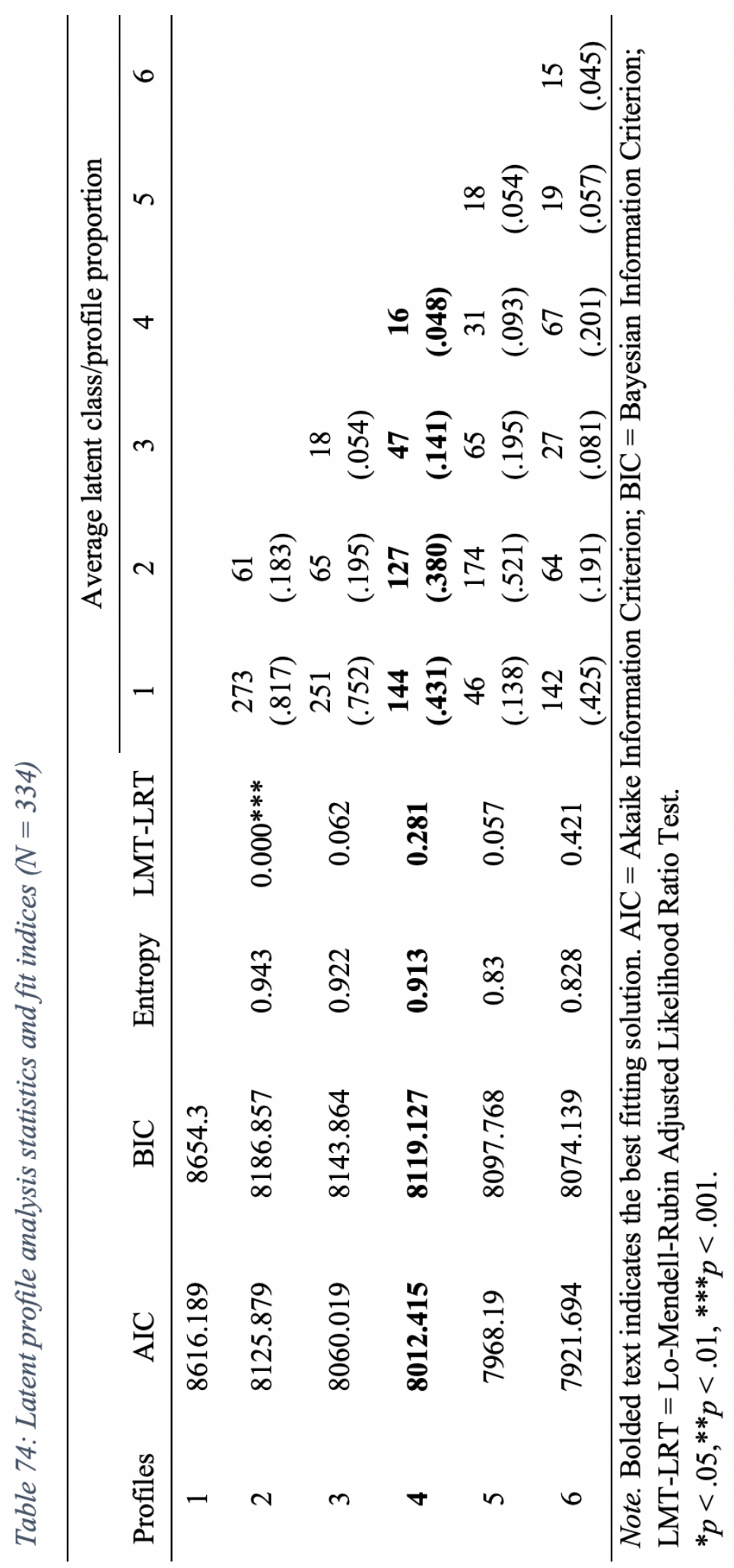


FOOD PANTRY STRUCTURING

$R Q 2:$ What, if any, relationship exists between the views and assumptions of poverty and the poor held by food pantry directors and food help-giving strategies/typologies?

A multivariate analysis of variance (MANOVA) was conducted using SPSS 25 to compare multidimensional assumptions of poverty across the four class profiles identified through LPA. Composite scores for Personal, Stigma, and Structural attributional dimensions were identified as the multiple dependent variables. Food panty class membership, as determined by LPA analysis, was acted as the fixed factor independent variable. There was no statistically significant difference in attribution of poverty scores based on food pantry typology class affiliation, $F(9,777)=1.711, p=.083$; Wilk's $\Lambda=$ .953, partial $\eta^{2}=.016$

RQ3: How do food pantry directors' personal demographic characteristics and histories relate to food pantry help-giving strategies/typologies?

An omnibus Pearson chi-square test was performed to the assess the relationship between categorical food pantry director demographic predictors and food pantry typology class affiliation. Post-hoc testing was completed for significant omnibus results using contingency table analysis that utilized chi-square scores derived from adjusted z-scores.

$R H 3-A$ : Social Class Origin

There was no significant association between food pantry typology and pantry director social class origin $\chi^{2}(3, \mathrm{~N}=326)=1.57, p=.666$

RH3-B: Current Personal Financial Security

There was no significant association between food pantry typology and pantry director current financial security $\chi^{2}(3, \mathrm{~N}=325)=3.38, p=.337$ 
FOOD PANTRY STRUCTURING

\section{RH3-C: Personal Financial Security Trend}

There was a significant association between food pantry typology and pantry director financial security trend $\chi^{2}(6, \mathrm{~N}=325)=16.49, p=.011$. The effect size for this finding, Cramer's $V$, was moderate, .159 (Cohen, 1988).

Contingency table analysis revealed that food pantry directors in Justice Oriented pantries were more likely to be more secure financially than they were 10 years earlier $(A d j-Z=2.90, p=.0037)$ than individuals that were less secure or about the same. Comparison with the Bonferroni corrected alpha $(p=.0042)$ indicate that this is significant at the adjusted .05 level.

$R H 3-D$ : Political affiliation

There was no significant association between food pantry typology and pantry director political affiliation $\chi^{2}(6, \mathrm{~N}=221)=6.18, p=.403$

RH3-E: Gender identity

There was no significant association between food pantry typology and pantry director gender $\chi^{2}(3, \mathrm{~N}=327)=4.54, p=.208$

RH3-G: Race

There was no significant association between food pantry typology and pantry director race $\chi^{2}(3, \mathrm{~N}=319)=5.75, p=.124$

RH3-H: Personal Religious Affiliation

There was a significant association between food pantry typology and pantry director religious affiliation $\chi^{2}(3, \mathrm{~N}=316)=20.95, p<.001$. The effect size for this finding, Cramer's $V$, was moderate, .258 (Cohen, 1988). Contingency table analysis revealed that food pantry directors identifying as non-religious 
FOOD PANTRY STRUCTURING

or agnostic were more likely to be affiliated with Justice Oriented pantries $(\operatorname{Adj}-Z=3.66, p=.0003)$ than directors that identified as religious. Comparison with the Bonferroni corrected alpha $(p=.0063)$ indicate that this is significant at the adjusted .05 level.

RH3-I: Rurality

There was no significant association between food pantry typology and pantry geographic location $\chi^{2}(9, \mathrm{~N}=333)=13.80, p=.129$

A one-way analysis of variance (ANOVA) was performed to the assess the relationship between continuous food pantry director demographic predictors and food pantry typology class affiliation. Tukey HSD post-hoc tests were completed to explore significant differences between food pantry typologies.

RH3-F: Food Pantry Director Age

There was a statistically significant difference in food pantry director age between food pantry typologies $F(3,312)=7.103, p<.001$. Tukey HSD post-hoc tests revealed that mean food pantry director age for Traditional Food Pantries $(\mathrm{M}=60.51, \mathrm{SD}=12.65)$ was significantly higher than Justice-Oriented Pantries $(\mathrm{M}=49.06, \mathrm{SD}=13.32, p=.003)$. Additionally, the average food pantry director age for Linking Pantries $(\mathrm{M}=61.38, \mathrm{SD}=11.61)$ was significantly higher than High Service Pantries $(\mathrm{M}=55.28, \mathrm{SD}=11.96, p=.019)$ and Justice-Oriented pantries $(\mathrm{M}=49.06, \mathrm{SD}=13.32, p=.001)$. 
FOOD PANTRY STRUCTURING

Figure 2. Mean age of directors by food panty typology

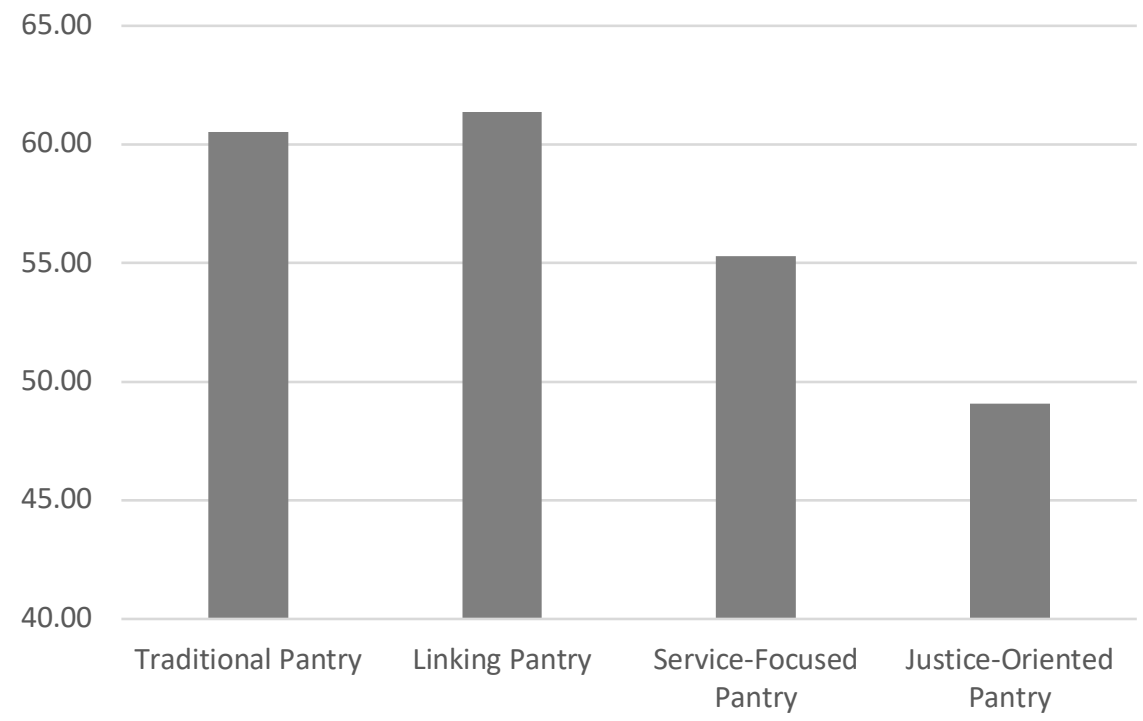

\section{RH3-J: Years as Pantry Director}

There was no statistically significant difference between food pantry typologies

based on experience of food pantry director $F(3,319)=1.610, p=.187$. 
FOOD PANTRY STRUCTURING

\section{Chapter 6: Discussion}

The need for research on food pantry services remains similar to that outlined by Janet Poppendieck over two decades ago in her seminal work on emergency food systems, Sweet Charity. Rapid growth and widespread participation in emergency food systems still warrants a more complete understanding of these services (Poppendieck, 1999). Moving beyond historic investigations of emergency food programs, there is a need for a deeper understanding of their structuring and organization. While food pantries may be providing for food to a growing number of Americans facing food insecurity, the ways in which they are organized and the services they provide are varied. While previous research has looked at the scale of services (Nester, 2015) and the food distribution model, little work has been done to understand and categorize food pantries more holistically. Additionally, little work has been done to understand the assumptions that food pantry directors have related to poverty in connection to services that food pantries provide and the ways these organizations are structured to provide supports to pantry clients.

This study sought to shed light on these gaps in knowledge through a state-wide survey of food pantry directors in Missouri. Analysis of pantry operations across the state of Missouri indicate that there is a clear separation in the work that food pantries do. Even with a range of approaches to structuring and operating food pantries, there is a strong commonality in attributions of poverty among pantry directors. Past predictors of attribution dispositions failed to hold up among the pantry directors that participated in the study. Moreover, there appears to be a disconnect between the programs that food pantry directors find important to operating ideal food pantries and the services that they 
FOOD PANTRY STRUCTURING

provide directly or even offer referrals for. As assumptions from previous research and other helping professions falls short in providing a basis for understanding food pantry structuring, our understanding the how and why pantries are organized is still bit less clear. However, some insights from this study provide opportunity for critical reflection and paths to developing a deeper understanding that can inform emergency food service policies, organization, and initiatives.

\section{Key Findings}

RQ1: What help-giving typologies exist within food pantries?

There was a clear grouping of food pantry service models.

While food pantries have often been discussed in a homogenous manner, these organizations are far from uniform. Food pantries occupy a range of service spaces, with some functioning out of small rooms or closets in larger organizations, while others maintain larger facilities with teaching kitchens, large cool storage units, computer rooms, and areas for children to play while family members register and select food for the household. I have also seen a wide range of available services provided through food pantries, with some working to simply distribute the most food that they can as efficiently as possible, while others seek to connect clients with other resources in the community and assist in broader needs that the clients may have in addition to needing food. Results from this study provided a framework for discerning between the ways that food pantries organize their operations and the varying access to a range of programs and services. While food pantry operational approaches/models are largely based upon the number of services that they provide and the types of services they support, an emerging model of emergency food service structuring was identified within the latent profile analysis. 
FOOD PANTRY STRUCTURING

Analysis of food pantry operational profiles found that food pantries generally fall into four groups. Many food pantries focus their services on direct food provisioning, with very few additional services, and limited referrals. These "Traditional Food Pantries" are what individuals often think of when characterizing a food pantry and follow a model reminiscent of breadlines of the Great Depression. In addition to the limited number of services and referrals, these organizations follow more traditional organizational strategies, most commonly distributing prescribed boxes with no, or little, client input, having longer wait times for check-in and food pick-up, offering less opportunity for client feedback, and greater limits on the number of times clients can access pantry services.

The second largest class of food pantry extends services beyond the direct food provisions and provides some additional assistance to pantry clients in the form of limited referrals. These "Linking Pantries" recognize some of the additional needs of pantry clients and opportunities for these needs to be met by other community organizations, but provide very few services directly. Additionally, these pantries still do little to engage with many of the structural causes of poverty and largely organize pantry services in ways similar to "Traditional Food Pantries". These two models of food pantry organization make up the majority of food pantries in this study $(n=271 ; 81.1 \%)$ and share a limited service model for food pantry operations.

This concentration of limited service pantries largely fits with my field experience working in food pantries across the state. Many pantries focus most, if not all, of their attention on simply getting food out the door. This focusing of efforts is potentially tied to some of the pantry demographic indicators identified by directors and provides insight 
FOOD PANTRY STRUCTURING

into possible reasons why so many pantries don't extend services beyond the central food distribution. As most food pantries in the state largely rely on volunteers to carry out all aspects of pantry operations $(n=204,61.1 \%)$, with many volunteers being older community members, food pantries may lack the capacity in personnel to develop, coordinate, and implement additional services through the pantry. This potentially extends to efforts to provide referrals to additional community resources, as maintaining an up-to-date database of available services within the community, county, or state can be a difficult task. Additionally, more detailed intakes and connections with clients would be needed to better understand client needs. This, however, doesn't seem likely as the provisioning or referral of assistance programs to address broader needs of clients was often identified as less important to ideal food pantry operations by directors.

Moving beyond limited service pantry models, profile analysis also identified two distinct groups within higher-service food pantries models. "Service-focused Pantries" provide additional services and/or offer a range of referrals to community partners that can assist in meeting the broad needs that pantry clients may have. While these pantries do provide these additional supports, these pantries still have limited engagement in services related to the structural causes of poverty and food insecurity, focusing efforts on addressing the outcomes of these experiences. This model is the most common within the high service group $(n=47 ; 14.1 \%)$ and has been the most common model that I've encountered when working with food pantries that are attempting to broaden their efforts to assist clients.

The small group of remaining high-services pantries are potentially of the most interest from this study. Results from profile analysis identified a group of pantries that 
FOOD PANTRY STRUCTURING

provides additional services but is focusing additional efforts on addressing structural causes of poverty and food insecurity though more structural-based solutions. These "Justice-Oriented Pantries" are providing supports to clients in obtaining federally funded food assistance (i.e. SNAP and WIC), promoting health and wellness supports, providing assistance in job readiness and searches, providing and connecting clients to transportation and housing assistance programs, and offering services in a manner that prioritizes clients choice, feedback, and involvement. This group of pantries shows support for a growing argument for emergency food structuring found within food justice approaches to emergency food system work. More specifically, efforts to addresses these structural issues do not coincide with an increase in direct food provisions. In fact, direct food provisions remained consistent with "Service-Focused Pantries", embodying the assumption that pantry operations will begin to shift efforts away from the continued expansion of food provisioning as efforts are made to address structural issues.

This approach is a paradigm shift within emergency food systems. As a larger model of hunger relief, the success of food pantries and emergency food networks is often discussed and measured by the number of individuals, meals, or pounds of food served. Moreover, this model focuses on the continued expansion of financial donations, corporate connections, and growth of networks. The call for a shift in focus from response to prevention among emergency food providers has been supported by many food scholars. In practice, Nick Saul and Andrea Curtis highlight this transition in the transformation of The Stop, a food bank in Toronto, away from a more traditional food pantry model and into a community food center (2013). Moreover, Saul and Curtis identify this to be the critical shift necessary in the emergency food service paradigm to a 
FOOD PANTRY STRUCTURING

truly embrace a justice-oriented approach to emergency food services. This call for action directly maps on to Janet Poppendieck's arguments following her critical evaluation of the food pantry model of hunger alleviation rooted in charity. If emergency food systems are to be a 'just' system for addressing food insecurity, they need to transition efforts to social change that prioritize the expanding publicly funded safety-nets again and create a system of collaboration that attempts to reestablish the ties between people instead of highlighting the disparities between the helpers and those helped (Poppendieck, 1999). In a panel discussion with Poppendieck and Saul at the 2015 Closing the Hunger Gap conference, the transition needed in emergency food systems is still a shift away from charity as the root for emergency food service to one of collaboration and solidarity.

The investigation of novel typologies within the general spectrum of food pantry services provides opportunity for more complete and multi-dimensional understanding of food pantries. Through the utilization of profile analysis strategies, food pantry groupings/typologies were able to be identified from existing service models, speaking to the range of experiences that pantry client encounter dependent on where they live, or the pantry they choose to use. The development of food pantry service categories carries the potential to provide a framework for discourse through which future research may examine the outcomes of these intervention models. With a shared language, emergency food scholars can work more collaboratively on deepening the understanding of food pantry services. Additionally, a clearer recognition of service models highlights spaces for moving forward in promoting food pantry services that best meet the needs of pantry clients while recognizing the ways in which pantries are currently operating. 
FOOD PANTRY STRUCTURING

RQ2: How do the views and assumptions of poverty and the poor shape emergency

food services at the pantry level, as determined by food pantry directors?

Food pantry director assumptions of poverty were not a strong predictor for food pantry structuring.

Food pantry directors most commonly identified a structural attribution of poverty as their primary ascription to the roots of poverty and perception of persons in poverty $(75.7 \%, \mathrm{n}=246)$. This common support for systemic roots of poverty is supported by past research with food pantry directors (Duffy et al., 2006; Robinson, 2012). It is also important to note that the vast majority of food pantry directors identified that they had had a major role in determining how their food pantry is organized and managed $(96.4 \%$, $n=320$ ). Past research on the connection between attitudes and actions would then promote the assumption that food pantries would more generally prioritize services that address the underlying structural causes of hunger and food pantry utilizations. However, this was not the case among the food pantry directors surveyed, as primary assumptions of directors were not found to be a predictor of food pantry organization. Additionally, organizational structuring that provided services and referrals to address the broad range of needs of clients, while prioritizing the structural causes of poverty and food pantry use was the smallest group of pantries within the typologies identified ("Food Justice Oriented Pantry"; $n=16 ; 4.8 \%$ ). These results indicate a break between the expressed beliefs of food pantry directors and behaviors of those same directors in structuring their organizations. While pantry directors responded to questions on the survey in a way that supported a disposition to attribute poverty to structural causes, many of their services do little to addresses underlying structural causes of poverty and food pantry use. We are left 
FOOD PANTRY STRUCTURING

with looming questions as to why this break between personal assumptions and behaviors is being seen.

Issues related to pantry capacity. As previously identified, many food pantries are restricted by the capacity of their organization. Food pantries may be located in aging buildings, operating with donated equipment, relying almost entirely on a volunteer staff, with many volunteers often over the age of 65 , and providing services only a few days each month. The breakdown between director assumptions about the causes of poverty and the services that they offer could very well be influenced by the limited capacity of food pantries to engage with activities beyond the distribution of emergency food supplies. When $61.1 \%$ of food pantries included in the study have no paid staff, including the director, there is little support (i.e. financial reimbursement) for the time necessary to establish and conduct programs that address deeper issues that directors appear cognizant of.

This breakdown due to capacity is further supported by data from the survey on the 'importance' of pantry activities to the perceived 'ideal' pantry model of food pantry directors. For each activity, program, or organizational component included in the food pantry typology domains, directors also indicated how 'important' the same activities would be if they were to operate their 'ideal' pantry if no barriers were present. For many activities, directors indicated a high level of importance to what they believed would be the best food pantry model. Despite high mean importance scores for some of the activities, there was very low overall engagement in these same activities. Not only did pantries not provide the service, they also didn't offer any referrals to other agencies in their communities that could provide related assistance. For example, 'food for chronic 
FOOD PANTRY STRUCTURING

conditions/allergies/preferences' was rated as the second highest item within 'direct food provisions', the category identified as the most 'important'. Despite having a mean importance rating of 3.51 on a 5-point likert scale, only $33.5 \%$ of pantries provided food options for individuals with dietary restrictions.

This breakdown between perceived importance and pantry activities didn't correspond to all domains of panty modeling. Food pantry directors didn't believe that programs addressing larger systemic issues were as important to operating their 'ideal' food pantry. While organizational structuring and direct food provisions were the two most important domains when considering 'ideal' food pantry operations; the domains most related to structural responses and supports were the last three. Specifically, providing "systemic supports" was ranked $4^{\text {th }}$ out of the five domains. It is with this information that the disconnect between belief and action becomes a bit less clear. Even if issues of capacity were eliminated, programs that would be most directly aligned to their attributions of poverty would be some of the least important within when structuring their services. Because of this, capacity may play some role in the provision of services, but it likely isn't the only constraint.

What is the frame of the 'system'? There are clear constraints in attributing the lack of significant connection between beliefs and action simply to food pantry capacity. If we were to still hold the connection between beliefs and action as empirically true, we would need to pivot discussion away from the action component to the belief portion of the connection. Once again, we can return to food pantry directors perceived importance of pantry services as a potential clue to where another potential source of this break may occur and potentially gain some insight into the complexity of this (dis)connection. 
FOOD PANTRY STRUCTURING

If directors believe that poverty, or food insecurity, is largely caused by structural forces in society, and we again hold the connection between belief and action to be true, the programs and services that food pantries are implementing are structural approaches to addressing the need of clients in the views of pantry directors. The disconnect would then lie in how the researcher and food pantry director's operationalization what "structures" are at play in client need for food assistance. Insights from the survey may help to clarify the "structures" that directors are attempting to work within. When identifying the services that food pantries provide, multiple pantry directors took time to note that they only provided services related to food distribution when asked about additional services that the pantry could potentially provide. "We only do food", was a particularly illustrative comment from one director that echoed the other comments directors made in relationship to being asked about additional services. Directors noted this sentiment at the end of multiple blocks, seeming to convey some level of frustration that the survey was continuing to ask about programs that extended beyond direct food provisions, and potentially beyond the scope of work, or structures, that food pantries work within. Thus, the structures of food insecurity may be seen among food pantry directors as limited to a simply supply issue of food items. In this way a structural approach would then focus on the lack of access to food through traditional food acquisition strategies (i.e. purchasing) or public programs (i.e. SNAP), and seek to provide structures that allow for food access. This is a distinctly different operationalization of a structural approach, as the research is operating under the assumption that larger structures influence food access, like socioeconomic status, physical and mental health, employment, transportation, education, political policies and 
FOOD PANTRY STRUCTURING

institutions, in addition to others. With this assumption, a structural approach would seek to provide services that address access to resources that can assist in these areas.

If this limited view of the structural and systemic causes of food insecurity is true, it may be linked to the experiences that have shaped food pantry directors understanding of poverty and food insecurity, namely their financial histories. The majority of pantry directors have never used food pantry services before $(n=222 ; 66.9 \%)$, currently identify as generally financially secure $(n=306 ; 94.2 \%)^{4}$, are equally or more financially secure than they were ten years prior $(n=269 ; 82.8 \%)$, and grew up in an environment that was generally financially secure $(n=249 ; 76.4 \%)^{5}$. Based upon these measures of lived experience of pantry directors, the majority of them don't share the same lived experiences as their clients. The lack of this experience may limit their ability to understand, and in turn recognize, the various causes that led pantry clients to seek food assistance from their food pantry. While past research has indicated increased levels of empathy with experience in various social service positions, food pantry directors may also not be directly interacting with clients as often as other volunteer or staff positions.

Given the results related to this research question, it's clear that the answer to the connection between pantry director beliefs and food pantry structuring is complicated and potentially a place for future investigation.

RQ3: How do food pantry directors' personal characteristics (i.e., social class origin, political orientation, gender, age, race, religiosity, pantry location, years of experience) relate to food pantry help-giving strategies/typologies?

Many key demographic indictors were not strong predictors for food pantry structuring.

4,2 Current financial security of food pantry directors, and financial security trends were self-reported prior to the economic crisis related to the COVID-19 pandemic. 
FOOD PANTRY STRUCTURING

Past research findings on attribution style and help-giving strategies among food pantry workers and other social service personnel were the basis for research hypotheses on director demographic indicators and food pantry typologies. While key indicators had been strong predictors of attribution style and service tendencies in past empirical investigation, very few of these proved to be strong indicators of food pantry typology group affiliation. Specifically, director personal financial security trend, personal religious affiliation, and the age of the food pantry director were the only factors found to be predictors of pantry typology affiliation.

Personal financial indicators of pantry directors had little predictive capacity of food pantry organizational model affiliation. While personal experiences with poverty may support greater levels of empathy, a deeper understanding of the causes of poverty and food insecurity, and the supports needed to address these systemic causes (Bullock, 1999), little connection between these experiences and the ways that pantry directors organized pantry services was found. The only statistically significant relationship was observed between personal financial security trend and "Justice-Oriented Pantries". Directors at "justice-oriented pantries" were more likely to report being more financially secure than they were ten years prior, when compared to directors that are less financially secure or about the same within the same time period.

In evaluating this finding, it is important to note the cultural contexts of the question. Ten years prior to the survey, the United States was in the middle of the Great Recession, marked by high unemployment rates and an extremely fragile housing market. Many households faced financial insecurities during this time period. This context is 
FOOD PANTRY STRUCTURING

likely supported by survey results, as many food pantry directors $(40.5 \%)$ report being more secure financially than they were ten years prior.

Despite this context, this finding provides some insight into how personal experiences of pantry directors may play in the organization of food pantries. Table 1 provides an added level of context for the financial situations of pantry directors that operate "Justice-Oriented Pantries". While the survey failed to have directors self-assess their financial security ten years prior, many directors that identified being "more secure" than they were ten years prior did not identify as "very secure" financially currently. This provides space to assume that some of the directors, namely those that currently identify as "somewhat secure" and being "more secure" than they were then years prior, have potential lived experiences that allow for a deeper understanding of what services are needed to address financial insecurities, and also food insecurities.

Table 75. "Justice-Oriented Pantry" Directors Financial Trend Breakdown

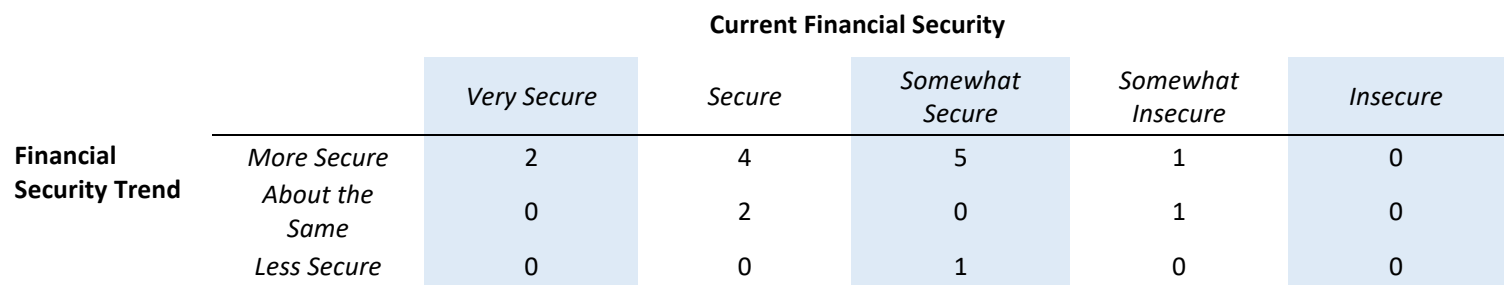

While financial indicators were expected to play a more clear role as a predictor of food pantry structuring, this may have been limited by the commonly held financial security of pantry directors, with many having never used food pantry services before $(n=$ $222 ; 66.9 \%)$, currently identifying as generally financially secure $(n=306 ; 94.2 \%)^{6}$, and growing up in an environment that was generally financially secure $(n=249 ; 76.4 \%)$.

\footnotetext{
${ }^{6}$ Current financial security of food pantry directors was self-reported prior to the economic crisis related to the COVID-19 pandemic.
} 
FOOD PANTRY STRUCTURING

These demographics may not be a representative or normal distribution of financial experiences; however, controlling this distribution isn't possible within this context of social science research.

Justice-oriented pantries were also more likely to be headed by directors that identified as non-religious or agnostic. Past research by Reingold \& Liu found that faithbased and government organizations were more likely to hold individualistic attributions of poverty over non-governmental and food service agencies (2009). Holding to assumptions that beliefs shape organizational structuring, this finding directly maps onto previous empirical findings. This association also seems to carry greater weight when considering the demographic trends of pantry directors. The vast majority of food pantry directors identified a religious affiliation (91.6\%), most commonly of a "Christian" denomination $(77.5 \%)$. Only $3 \%(n=10)$ of food pantry directors identified as nonreligious or agnostic, yet they made up the majority of justice-oriented food pantries.

While many religious institutions have some type of call to service for others, the way in which service is carried out may transmit the assumptions and ideologies held within that social institution. The classic sociological theorist Max Weber wrote about the role of religion in society, specifically within capitalistic systems. "The fortunate is seldom satisfied with the fact of being fortunate. Beyond this, he needs to know that he has the right to his good fortune. He wants to be convinced that he 'deserves' it, and above all, that he deserves it in comparison to others." (Weber, 1958, p. 271). For Weber, religion provided a means for understanding the disparities that exist within society and absolve the individuals from the pain of participation and supporting of social structures that perpetuate disparity and human suffering. Through the use of the Protestant Ethic, 


\section{FOOD PANTRY STRUCTURING}

American society was built on the ideals of individualism and hard work (Weber, 1958). Strong support for the Protestant Ethic among participants was identified in past research related to attributions of poverty among in the context of the United States, with internal attributuion (i.e. individualistic) more likely for individuals holding strong Protestant work ethic values (Cozzarelli, Wilkinson, \& Tagler, 2001). This would thus support the individualistic attributions of poverty and limited service models of food pantry structuring among food pantry directors that identify as religious. Moreover, Poppendieck maintains that religious ideals also provide the space for action and absolving of the pain of social hierarchies that exist within society, without the need for larger systemic change to address hunger (1999). Through charitable emergency food models (i.e. food pantries, canned food drives, etc.), small personal actions provide emotional relief on the personal level and provide a sense of accomplishment in meeting the needs of community members that are experiencing hunger.

Food pantry typologies that provide fewer services, referrals, and client-centered organizational approaches have older pantry directors. More specifically, traditional and linking pantries have directors that are on average more than five years older than service-focused pantries and more than ten years older than justice-oriented pantries. Past research has found that older Americans are more likely to utilize emergency food systems than publicly funded food assistance programs (Daponte, 2000; Martin, Cook, Rogers, \& Joseph, 2003), while also expressing great levels of discomfort in receiving food stamps or SNAP benefits (Martin, Cook, Rogers, \& Joseph, 2003). These trends would more align with the food pantry structuring trends among older pantry directors found in this study. Underlying insecurities about publicly funded food assistance 
FOOD PANTRY STRUCTURING

programs would support food pantry services that focused on food distribution while not promoting more systemic supports.

The association of director age and pantry typology may be confounded by geographic and capacity issues of food pantries. Missouri's population 65 and older grew quicker than the state population overall between 2000 and 2010. Additionally, many rural counties in the state have higher proportions of the population 65 and older (Missouri Census Data Center, 2020). This context is important to note when evaluating results related to director age and pantry typology, as many of traditional and linking pantry models are located in rural areas of the state. Pantries in these areas are more likely to operate entirely on volunteer staffing and be open on a more limited basis, making issues of capacity potentially playing a confounding role to this relationship.

\section{Implications}

In the final stages of writing this dissertation, the implications of emergency food scholarship drastically changed. Beginning in January 2020, the United States experienced the dramatic effects of the novel coronavirus (COVID-19) pandemic. This global public health crisis has stressed health systems, already infecting nearly 2 million and killing 120,000 individuals globally, with the United States currently reporting the largest number of cases and deaths from the virus. The pandemic has also had a profound impact on economic systems. Stresses to global markets and supply chains has resulted in a massive economic downturn with record setting losses in U.S. stock markets. Economic shocks have transmitted to millions of households in the in the United States as a recordsetting number of individuals have been filing for unemployment insurance, 710,000 nonfarm jobs lost, and unemployment jumping from $3.5 \%$ to $4.4 \%$ in the between 
FOOD PANTRY STRUCTURING

February and March of 2020 (U.S. Department of Labor, 2020), with many speculating that unemployment rates will reach levels similar to those during the height of the Great Recession.

Given the wide-ranging effects on American workers, it's not surprising that the shocks to personal budgets and the loss of income have resulted in an increased demand for emergency food systems. Food banks in Missouri are reporting an increase of $40 \%$ in client requests for food assistance at partner locations (Harvesters, 2020). The economic effects of the pandemic are expected to continue to grow, with corresponding increases in food pantry usage. Furthermore, this dependence on food pantries isn't likely to subside in accord with economic indicators, as food pantry utilization rose dramatically during the Great Recession, the last economic crisis in the United States, and continue to rise for five years after the recession ended by economic indicators (Coleman-Jenson, Rabbitt, Gregory, \& Singh, 2018).

With emergency food systems a pillar of hunger alleviation in the United States, and the looming reliance on this hunger alleviation strategy, it is critical that our understanding of these organizations match their significance within society and antihunger efforts. Through efforts in understanding the organizational drivers of food pantries, researchers, practitioners, and community advocates can have a better foundation for informing the efforts of food banks and their affiliated pantries, while working to improve or expanding services for pantry clients. Knowledge gleaned from this study holds implications within the fields of food studies, public health, community development, and social work. More specifically, a deeper understanding of the role that beliefs and assumptions about poverty plays in shaping food pantry structuring may 
FOOD PANTRY STRUCTURING

provide greater direction for broader food justice efforts in hunger alleviation that encompasses a multi-disciplinary approach from all these fields.

A growing focus on food justice within emergency food systems is imperative, and occurring on a small scale, as evident by the small number of food pantries transitioning to a justice-oriented approach that prioritizes client interactions and addressing systemic causes of hunger in this study. When considering the increased reliance on food pantries as a means for acquiring food, there is a dire need for a closer look at the factors associated with the organizational structures of food pantries. By creating a deeper understanding of such structures, we may be able to find points of intervention for introducing change that centers client needs and experiences in the organizing of food pantry services. Specifically, by creating knowledge of the processes for determining panty-client interactions and the types of services offered at justiceoriented pantries, work can be done to build upon the experiences of these pantries in helping other pantries incorporate more justice-oriented strategies. Through this, collaborative efforts could begin to occur to improve operations for both the institution, through increases in efficiency, and the pantry clients. It is the goal of this research to work toward a critical understanding of food pantry organization decision-making in hopes of promoting greater efficiency for food pantries and a more equitable experience for pantry clients, as recent research has indicated that food pantries maintain potential to improve both food security and the lives of individuals they serve (Bazerghi, McKay, \& Dunn, 2016), especially when implementing client-centered practices that incorporate client choice and healthy food options for pantry clients, as well as comfortable physical 
FOOD PANTRY STRUCTURING

spaces to wait for pantry services (Greer, Cross-Denny, McCabe, \& Castrogivanni, 2016).

\section{Limitations}

As with any study, limitations are sure to exist. This study faced limitations of geographic specificity, as well as methodological limitations related to study design and instruments for measuring social phenomenon. However, through the acknowledgement of these potential limitations, efforts were made to address or reconcile their influence within this study, provide a context for interpreting and applying study results, and provide insight into future research recommendations.

Temporal and financial constraints often dictate much of the research that is done within the social sciences. In the face of these common limitations, attempts to obtain the richest data were taken to provide the deepest understanding of the research topic as possible. The utilization of a cross-sectional survey methodology inherently affects the depth of understanding that can be obtained within a study. Understandings are rooted in the quality of survey measures, design, and user interface; however, best practices for survey design often limit the opportunity for more direct participant input (i.e. openended \& follow-up questions). This limitation is offset by the scope that is possible with this methodology. If researchers were to conduct interviews with such a broad sample of food pantry directors at state, or even regional level, the time and financial requirements would be far higher. The use of a self-administered survey in this study provided the greatest opportunity to obtain data in a timely and cost-effective manner, while also potentially promoting a greater sense of privacy and eliciting more candid responses to possibly sensitive questions regarding poverty attributions. 
FOOD PANTRY STRUCTURING

The study was conducted within a specific region of the United States, more specifically, with food pantry directors associated with the six regional food banks of Feeding Missouri. Given the geographic specificity of this study sample, the findings may not fully address processes and organizational strategies that exist at all food pantries within the state, across the United States, or among the growing number of food pantries globally. Missouri presents a unique set of circumstances from an organizational standpoint, as state and regional emergency food organizations must balance operations that range from the very rural to the urban core. This geographic variability is often accompanied by variations in the size of food pantry operations, available volunteers, and capacity for more extensive programs. Additionally, Missouri may be slower to adopting new food pantry models and programs than states on the coasts.

Additionally, the views and assumptions of poverty held by pantry directors may not be representative of those held by pantry directors across the United States and globally. Missouri presents a unique set of social and cultural influences that may be drawn upon to inform the beliefs of pantry directors, and in turn, potential organizational strategies. Missouri is a largely a politically conservative state, voting for a republican presidential candidate in 8 of 10 presidential elections since 1980 and the dramatic growth of emergency food systems. This is supported by study results, with the most commonly identified political affiliation of pantry directors being "conservative". This political context is important to note when considering organizational efforts of pantry directors and the ability to apply conclusions to more progressive or liberal settings. Efforts were made to ensure sampling from both urban and rural pantry directors, providing the greatest opportunity to capture diversity of views and backgrounds and 


\section{FOOD PANTRY STRUCTURING}

engage pantry directors from settings that are more traditionally politically liberal within the context of Missouri (i.e. urban areas).

Apart from the limitations of the sample reference, methodological limitations exist within this study. The reliance on a cross-sectional survey and quantitative methodologies presents opportunities for error within sampling and measurement (Visser, Krosnnick, \& Lavrakas, 2000). As with any sample, sampling error may have occurred within this study, resulting in a discrepancy between the sample and the population. Statistical measures will be taken to account for potential error and establish confidence intervals for observed sample statistics. Additionally, coverage error is inevitable given the sampling frame and methodologies for this study.

The use of a cross-sectional survey methods included inherent potential for questionnaire design/ measurement error, as it is often driven by a top-down epistemological approach. To help address issues of questionnaire design and measurement error, the researcher worked collaboratively with other researchers, familiar with work in food pantries and food systems, and food bank staff in the development of the survey tool, as well as research design and implementation. Additionally, the survey was pilot tested within a group of food pantry directors and food bank staff to obtain feedback on the survey and its validity in measurement. These efforts were utilized to provide the greatest breadth of predicting possible variability within the measures of interest.

While the Attributions of Poverty- Short Form instrument had shown to be a reliable measure in its development, it has possible limitations in its application within this context. Despite attempts by the researcher to provide anonymity and promote honest 
FOOD PANTRY STRUCTURING

engagement with the instrument, there is still potential for concern in the validity of the responses from food pantry directors. Pressures of social acceptability may come in to play for how food pantry directors relate to presented questions. While no personal identification was tied to responses, pantry directors are still subject to the assumptions that they have related to the social views that food pantry directors are expected to have. This social expectation may help explain the high percentage of structural primary attributions of poverty amongst respondents, when anecdotal evidence from conversations with pantry directors had by the researcher would support greater levels of attributions of personal deficiencies. Attempts by researchers to soften language around social myths or misconceptions (i.e. "welfare mothers") and employ a person-first approach to discussing personal deficiency attributions was done in hopes to promote honest identification of personal attitudes; however, this may not have been enough to move beyond social expectations for how food pantry directors should view the clients that they serve.

While the Attributions of Poverty- Short Form instrument uses a multidimensional attribution approach, it may fail to capture the nuances in food pantry director assumptions. Multiple food pantry directors took time to note that they had a hard time answering the questions as they felt it difficult to identify agreement with statements on such a broad scale. In personal communications, pantry directors noted that they may not have felt that statements of 'personal deficiencies' were true for any or all their clients, but that they couldn't say more generally that these same statements may not apply to other individuals. The complexities of food pantry director assumptions may require a more nuanced approach to understanding, potentially employing a qualitative 
FOOD PANTRY STRUCTURING

methodology to increase the depth of understanding that is possible related with regard personal assumptions.

\section{Future Research}

While the use of food pantries as an intervention strategy for hunger was not necessarily a planned or empirically supported endeavor, developing organically from the concerns of individuals and organizations in the face of unmet need and solutions that appeared to be seemingly obvious in a society that experienced both hunger and food waste (Poppendieck, 1999), our efforts moving forward shouldn't remain uninformed. Through expanding research in the context of food pantries, and other emergency food outlets, there are opportunities to empirically investigate the relative advantages and challenges associated with food pantry use, the execution and fidelity within food pantry structures, and possible institutionalization or sustainability of emergency food systems.

\section{Food Pantry Structuring and Programming}

While this study provides insight into the services and organizational strategies of food pantries, further investigation is needed to understand the 'why' that drives the structuring of food pantry services. While results indicated that there was no difference in beliefs about poverty in relationship to food pantry structuring, this break between beliefs and actions is critically important to understand. More importantly, a broader understanding of beliefs of emergency food systems personnel is needed to understand the context for program development.

Additionally, research also needs to extend beyond the food pantry organization and engage with pantry clients. Understandings of food pantry services and the creation of organizational structures and programs largely employs a top-down approach; 
FOOD PANTRY STRUCTURING

however, there is an opportunity to examine the expectations that clients have of pantry services, and what these services would ideally offer, in comparison to beliefs of directors at the pantries that they are utilizing. Further research with food pantry clients across the state could incorporate questions about desired services that directly map onto the constructs utilized within this study. Through the utilization of the constructs utilized in this study, further research could build upon new knowledge and would provide greater insight into what the efficacy of food pantry services in Missouri to meet the needs of those that face food insecurity and hunger in the state.

This study was an initial investigation to identify the typologies. More research is needed to assess the application of these groups in other social and geographic contexts. As noted previously, the geographic specificity of this study provides potential limits to the applicability of results to larger scales. While results may hold true for other Midwestern states with similar demographic and social contexts, similar studies need to be done in other geographic locations to support the use of these typologies moving forward in emergency food scholarship and literature. However, the typologies used provide specificity in relationship to specific help-giving strategies, yet are general enough to hopefully accommodate use on a broad scale.

\section{Emergency Food Organization and Public Health Crises Response}

Given strain placed on emergency food systems by the COVID-19 pandemic, future research should also examine the organizational structuring of emergency food systems in relationship to their ability to address large-scale public health crises. National and state-level organizations should will have an opportunity to use this pandemic for evaluating the shortcomings of current organizational structures and supply lines for 
FOOD PANTRY STRUCTURING

obtaining food for distribution through food pantries. As channels for food distribution in schools and restaurants have come to a halt, suppliers and processers are left unable to fulfill past agreements and farmers are dumping milk and using fresh produce for mulch as buyers and processers can't move product. All the while, state-level emergency food organizations are struggling to secure enough food for distribution at food pantries for the growing client base. By examining this paradox, future efforts can be made to create a more agile food system that can accommodate shifts in distribution channels in the event of large-scale public health crises.

Organizational structuring at food pantries should also be examined to understand front-line agency responses to large-scale public health crises. Scott Baker with Feeding Missouri indicated that the response across the state has been varied. Some regions have seen a major influx of food pantry clients, while others have maintained more consistent. Additionally, some regions have seen a number of food pantries close entirely, while others have maintained most of their operations in a drive-through format. Mapping of these varied responses should occur in conjunction with qualitative inquiry with food pantry directors on how their organizations made decisions about pivoting pantry operations to meet a growing need amidst increasing health concerns. Investigation should also target difficulties that were experienced by pantry directors that had to close and the determining factors for why food pantries were unable to continue providing services. Feeding Missouri representatives have noted state and local restrictions and "essential business" designations as some of the obstacles that emergency food organizations dealt with in attempting to continue providing services.

\section{Food Pantry Director Assumptions of Poverty}


FOOD PANTRY STRUCTURING

Deeper investigation is needed to better understand the assumptions that food pantry directors have of poverty. While this study didn't find a distinct connection between food pantry director attributions of poverty and the organization of pantry services, the connection between beliefs and actions is still widely accepted. As noted in the discussion on limitations, a different methodological approach is needed to gain a deeper level of understanding of director attitudes toward poverty, specially through the use of qualitative interviewers with food pantry directors. Additional investigation would provide both the opportunity for a deeper understanding of the nuances of pantry director assumptions and offer the potential to evaluate the efficacy of survey measures in examining social attributions. This line of work would provide insight and opportunity for further engagement within food justice work at food pantries and approaching program development with pantry directors.

\section{Policy Recommendations}

\section{Regional food banks should provide support to food pantries to increasingly provide}

\section{access to information on community resources.}

While food pantry directors have a range of beliefs about what is most important to operating an 'ideal' food pantry, many programs don't engage with a wide range of activities to support the broad range of needs that food pantry clients often have, even if they believe that it is important to provide some form of service related to a specific support. While it isn't feasible, or realistic, for every pantry to provide all of the types of services identified in this study, it is possible for pantries to increasingly provide referrals and connections to community organizations and resources that can assist clients with their broader needs. 
FOOD PANTRY STRUCTURING

The number of pantries that provide minimal services and limited referrals is not only the largest group of food pantries in this study, but also the largest group of pantries where even small efforts can have a large impact on the value that food pantries can play in the lives of clients. Through supporting increased awareness of community resources pantries can increasingly act as a source of information for new and existing clients. If state and regional emergency food organizations could identify existing resource guides for their communities or counties, or develop up-to-date guides if necessary, pantries may be better able to provide referrals to services that clients express needs for. It is also important for "Traditional Food Pantries" to easily incorporate referrals for their clients, with support or incentives from regional and state organizations potentially helpful in supporting this shift in food pantry services.

Emergency food organizations should work to evaluate organizational constraints at all levels of emergency food services.

The COVID-19 pandemic has stressed emergency food system in the United States, and further solidified this system as a critical component to meeting the food needs of Americans facing food insecurity. Emergency food systems originally emerged to meet "household food emergencies", transitioned to "societal emergency response" during the financial crisis of the 1980's, and has become an institution on which the United States has relied on to feed the people and fill the gaps left by public assistance programs and policies. This system has been able to meet public health emergencies in the past by relying on partners from non-affected areas (S. Baker, personal communication, March 19, 2020); however, new strategies are needed moving forward, 
FOOD PANTRY STRUCTURING

as plans are not in place to deal with national, or global emergencies that restrict the ability to gain assistance from other partners.

The pandemic has also exposed vulnerabilities with the current model of emergency food programming. Wide-ranging economic impacts triggering a dramatic increase in the number of individuals seeking assistance from food pantries, and traditional supply lines for pantry provisions depleted due to increased consumer purchasing at grocery stores to stock for shelter-in-place orders and social distancing recommendations, state and federal emergency food organizations are attempting to find build the plane as they fly it in this crisis. When faced with times of stress, we don't often have the opportunity to establish the most effective plans. Emergency food systems should start preparing to develop strategic plans for future large-scale public health emergences. Importantly, it is critical that these pantries are supported in the creation of emergency plans that still center client choice and dignity.

This crisis has also shed light on the need to evaluate resource supply chains for food pantries. The taxing of grocery stores through consumer hoarding and stockpiling has dramatically depleted the resources available for distribution through emergency food systems and highlighted a critical vulnerability within the current organizational structuring. Shocks to emergency food system supplies through retail supply chains isn't a new concern. As retailers established connections during the growth of the emergency food systems, inefficiencies and sources of waste within retail supply chains was highlighted. This allowed retailers to change the ways food stuffs were shipped and the containers they were in to minimize product loss in attempts to maximize profits (Poppendieck, 1999). While new incentives were found to promote continued donations 
FOOD PANTRY STRUCTURING

from retailers, emergency food systems that rely largely on a system of charitable donations and product recovery are at the mercy of consumer purchasing at the retail level.

At local levels, food pantries are facing organizational constraints of their own. Pantries are primarily operated by volunteers, specifically older volunteers. This population has been identified to have a heightened risk of death related to COVID-19, causing decreases in volunteers at food pantries. Additionally, food pantries have been closing due to an inability to effectively distribute food while keeping people safe.

Having little financial capacity for sourcing additional personal protective equipment, or the physical space to conduct necessary activities in a manner that keeps both volunteers and clients safe, many pantries have opted to close or dramatically shift pantry distribution models. Feeding America has recommended a drive-thru model for pantries, making the opportunity for client choice difficult or impossible.

If emergency food systems are going to be able to address hunger across a range of emergencies, it needs to find avenues for diversifying their food acquisition strategies, create space for flexibility within food delivery models, and ensure that organizations have acces to the necessary supports during emergencies.

Emergency food organizations should work to better understand the drivers of pantry organization and programming, while also promoting collaboration in emergency food system structuring.

With fluctuating financial supports for public food assistance programs like SNAP, and complexities in qualifications, applications, and processing or federal food assistance benefits, the role of food pantries in addressing food insecurity in the United 
FOOD PANTRY STRUCTURING

States is critical, especially in the context of emergency response. As already noted, a deeper understanding of how and why food pantries organize their services is important to ensuring that pantries are meeting the needs of pantry clients while also being efficient with the capacity and resource that they have. Additionally, a deeper level of investigation is needed to understand the underpinnings of organizational structuring at regional, state, and federal levels of emergency food services. Through the critical evaluation of organizational motivations, we can further evaluate the underpinnings for how these systems are created and maintained, as well as the space for systemic change that centers the needs of clients.

Focusing efforts within a food-justice lens still carries its own inherent constraints. Julie Guthman, the critical geographer, argues that food justice works faces limitations due to its place within a market-driven system, the exploitation and co-opting of community-based strategies, and the hyper focus on urban experiences at the expense of other actors in food systems experiencing injustices (2009). The food-justice movement originated through grassroots organizing in communities to address food insecurity and access. Through a community-based approach, the voice of community members is centered and a bottom-up approach to development is typically employed. The utilization of this model on a broad scale can be difficult, as the community voice and influence can give way as the scope of organizational influence increases.

As this growth has occurred, corporate interests have found their way into food justice initiatives. Large movements need funding, and the major funders of food access work are the same organizations that play a critical role in the disparities related to food access. For example, in 2019 the Walmart Foundation provided over \$1.4 billion in 
FOOD PANTRY STRUCTURING

philanthropic grants to programs that focus on creating opportunity, enhancing sustainability, and strengthening community (Walmart.org, 2020). Community food justice programs and organizations have received six-figure grants to complete projects that improve healthy food access from an organization that has been tied to the loss of small local retailers, increased globalization and industrialization of food systems, and the promotion of a cheap food structure. Additionally, Walmart has received intense criticism for promoting part-time employment over more expensive full-time wages and access to benefits, leaving many employees forced to rely on federal assistance programs like SNAP, and emergency food systems to meet their own food needs. With these organizations funding activities, it logical to assume that organizations and their activities are influenced by the interests of their financial sponsors.

By continuing to pivot organizational efforts across the emergency food system to prioritize collaboration, solidarity, and client wellness and rights, this system can work to not only provide food for individuals in need, but also to address the deeper forces that lead people to need their services. Food pantries can work to ensure that client input and choice are rooted in their activities, while regional food banks can continue to better support food pantry efforts to meet the needs and provide space for pantry input into regional organizational strategies. Through collective action, emergency food organizations may have a greater voice for change; however, it waits to be seen if these organizations are truly interested in such chances, as dramatic shifts related to a more justice-oriented approach may challenge the robust financial institutions that emergency food organizations have become and the underlying ideals that shape this approach to social support. 
FOOD PANTRY STRUCTURING

\section{References}

Akaike, H. (1987). Factor analysis and AIC. Psychometrika, 52, 317-332.

Atherton, C. R., Gemmel, R. J., Haagenstad, S., Holt, D. J., Jensen, L. A., O’Hara, D. F., \& Rehner, T. A. (1993). Measuring attitudes toward poverty: A new scale. In Social Work Research and Abstracts (Vol. 29, pp. 28-28). NATIONAL ASSOCIATION OF SOCIAL WORKERS.

Baker, S. (2020, April $\left.7^{\text {th }}\right)$. Personal Communication.

Bazerghi, C., McKay, F. H., \& Dunn, M. (2016). The role of food banks in addressing food insecurity: A systematic review. Journal of community health, 41(4), 732740.

Beebe, T. J., Jacobson, R. M., Jenkins, S. M., Lackore, K. A., \& Finney Rutten, L. J. (2018). Testing the Impact of Mixed-Mode Designs (Mail and Web) and Multiple Contact Attempts within Mode (Mail or Web) on Clinician Survey Response. Health Services Research, (4), 3070. https://doiorg.proxy.mul.missouri.edu/10.1111/1475-6773.12827

Burns, E. K., Deaton, E. A., \& Levinson, A. H. (2011). Rates and reasons: Disparities in low intentions to use a state smoking cessation quitline. American Journal of Health Promotion: AJHP, 25(5 Suppl), 59-65. doi:10.4278/ajhp.100611-QUAN183.

Cafer, A., Foulkes, M., Heflin, C., Hermsen, J., Raedeke, N., \& Rikoon, S. (2013). Coping with hunger in 2013: Food pantry clients and households in the service region of the Food Bank for Central and Northeast Missouri. Columbia, MO; University of Missouri. 
FOOD PANTRY STRUCTURING

Cohen, J. (1988). Statistical power analysis for the behavioral sciences (2nd ed.).

Hillsdale, NJ: Lawrence Erlbaum.

Coleman-Jenson, Rabbitt, M. P., Gregory, C. A., \& Singh, A. (2017) Household food security in the United States in 2016. USDA-EER-237.

Coleman-Jenson, Rabbitt, M. P., Gregory, C. A., \& Singh, A. (2018) Household food security in the United States in 2017. USDA-EER-256.

Cozzarelli, C., Tagler, M. J., \& Wilkinson, A. V. (2001). Attitudes Toward the Poor and Attributions for Poverty. Journal of Social Issues, 57(2), 207. https://doi.org/10.1111/0022-4537.00209

Crumley, E. (2013). An Examination of the Attitudes, Attributions, and Beliefs Held Towards Poverty and Individuals Living in Poverty (Doctoral dissertation).

Daponte, B. O. (2000). Private versus public relief: use of food pantries versus food stamps among poor households. Journal of Nutrition Education, 32(2), 72-83.

Daponte, O., Lewis, G. H., Sanders, S., \& Taylor, L. (1998). Food pantry use among lowincome households in Allegheny County, Pennsylvania. Journal of Nutrition Education, 30(1), 50-57.

Daponte, O., Sanders, S., \& Lowell, T. (1999). Why do low-income households not use food stamps? Evidence from an experiment. The Journal of Human Resources, 34(3), 612-628.

Duffy, P. A., Irimia-Vladu, M., Cashwell, S., Bartkowski, J. P., Molnar, J. J., \& Casanova, V. (2006). Food pantries and the populations they serve: Strange bedfellows or strategic partners?. Sociological inquiry, 76(4), 502-527.

Ellison, J. (2004). Hunger in America: A history of public and private responses. 
FOOD PANTRY STRUCTURING

Engel, S. (2017). Shame, Poverty and Development Studies. Journal of International Development, 29(8), 1215-1226.

Evans, J. R., \& Mathur, A. (2018). The value of online surveys: a look back and a look ahead. INTERNET RESEARCH, 28(4), 854-887. https://doiorg.proxy.mul.missouri.edu/10.1108/IntR-03-2018-0089

Feagin, J. R. (1972). Poverty: We still believe that God helps those who help themselves. Psychology Today, 101-129.

Feagin, J. R. (1975). Subordinating the poor: Welfare and American beliefs. Englewood Cliffs, NJ: Prentice Hall.

Feeding America. (2011). Food banks: Hunger's new staple. Research Brief.

Feeding America. (2014). Hunger in America 2014: Executive summary.

Feeding Missouri. (2020, March 17). Missouri's food banks respond to COVID-19. https://feedingmissouri.org/missouris-food-banks-respond-to-covid-19/

Ferrante, J. (2006). Sociology: A global perspective (6 $6^{\text {th }}$ ed.). Belmont, CA: Thomson Wadsworth.

Fisher, A. (2017). Fight hunger by fighting poverty and powerlessness. Chronicle of Philanthropy, 30(2), 27.

Foulkes, M., Heflin, C., Hermsen, J., Raedeke, N., \& Rikoon, S. (2011). Coping with hunger: Food pantry clients and households in the service region of the Food Bank for Central and Northeast Missouri. Columbia, MO; University of Missouri.

Foulkes, M., Hermsen, J., Raedeke, N., Rikoon, S., \& Whiting, E. (2005). Coping with hunger: Food pantry clients in the Central Missouri Food Bank Region. Columbia, MO; University of Missouri. 
FOOD PANTRY STRUCTURING

Giddens, A. (1984). The constitution of society: Outline of the theory of structuration. University of California Press.

Greenlaw, C., \& Brown-Welty, S. (2009). A Comparison of Web-Based and Paper-Based Survey Methods: Testing Assumptions of Survey Mode and Response Cost. Evaluation Review, 33(5), 464-480. Retrieved from http://search.ebscohost.com.proxy.mul.missouri.edu/login.aspx?direct=true $\& d b=e$ ric\&AN=EJ853949\&site $=$ eds-live $\&$ scope $=$ site

Greer, A., Cross-Denny, B., McCabe, M., \& Castrogivanni, B. (2016). Giving Economically Disadvantaged, Minority Food Pantry Patrons' a Voice: Implications for Equitable Access to Sufficient, Nutritious Food. Family \& Community Health, 39, 199-206. https://doi.org/10.1097/FCH.0000000000000105

Griffis, S. E., Goldsby, T. J., \& Cooper, M. (2003). Web-Based and Mail Surveys: A Comparison of Response, Data and Cost. Journal of Business Logistics, 24(2), 237-258. https://doi-org.proxy.mul.missouri.edu/10.1002/j.21581592.2003.tb00053.x

Grow Well Missouri. (2017). Program post-test interviews with food pantry directors: Perceptions and attitudes about healthy food, food security, and food pantry users. Unpublished manuscript.

Gundersen, C., Fan, L., Baylis, K., Dys, T. D., Park, T., \& Hake, M. (2016). The Use of Food Pantries and Soup Kitchens by Low-Income Households. In 2016 Annual Meeting, July 31-August 2, 2016, Boston, Massachusetts (No. 236172). Agricultural and Applied Economics Association. 
FOOD PANTRY STRUCTURING

Guthman, J. (2009). Neoliberalism and the constitution of contemporary bodies. The fat studies reader, 187-196.

Harvesters. (2020, April 3). How Harvesters is responding to the pandemic.

https://www.harvesters.org/News/April-2020/How-Harvesters-is-Responding-tothe-Pandemic

Hopkins, D. J. (2009). Partisan reinforcement and the poor: The impact of context on explanations for poverty. Social Science Quarterly, 90(3), 744-764.

Jamal, A., Homa, D. M., O’Connor, E., et al. (2015). Current Cigarette Smoking Among Adults-United States, 2005-2014. MMWR. Morbidity and Mortality Weekly Report, 64(44), 1233-1240. doi:10.15585/mmwr.mm6444a2.

Kim, M., Ohils, J., Cohen, R. (2001). Hunger in America 2001: National report prepared for America's Second Harvest.

Kingfisher, C. P. (1998). How providers make policy: An analysis of everyday conversation in a welfare office. Journal of community \& applied social psychology, 8(2), 119-136.

Kluegel, J. R., \& Smith, E. R. (1986). Beliefs about inequality: Americans' views of what is and what ought to be. New Brunswick: Transaction Publishers, 1986.

Lo, Y., Mendell, N., \& Rubin, D. (2001). Testing the number of components in a normal mixture. Biometrika, 88, 767-778.

Mabli, J., \& Worthington, J. (2017). Supplemental Nutrition Assistance Program participation and emergency food pantry use. Journal of nutrition education and behavior, 49(8), 647-656. 
FOOD PANTRY STRUCTURING

Mabli, J., Cohen, R., Potter, F., Zhao, Z. (2010). Hunger in America 2010: National report prepared for Feeding America.

Martin, K. S., Cook, J. T., Rogers, B. L., \& Joseph, H. M. (2003). Public versus private food assistance: Barriers to participation differ by age and ethnicity. Journal of Nutrition Education and Behavior, 35(5), 249-254.

McLaughlin, K. A., Green, J. G., Alegría, M., Costello, E. J., Gruber, M. J., Sampson, N. A., \& Kessler, R. C. (2012). Food insecurity and mental disorders in a national sample of US adolescents. Journal of the American Academy of Child \& Adolescent Psychiatry, 51(12), 1293-1303.

Missouri Census Data Center. (2020). Census 2010 Profiles. Available from https://census.missouri.edu/census2010/.

Molnar, J. J., Duffy, P. A., Claxton, L., \& Bailey, C. (2001). Private food assistance in a small metropolitan area: Urban resources and rural needs. Journal of Sociology \& Social Welfare, 28, 187-209.

Nester, J. A. (2015). An exploratory case study of three scales of food pantries in Story County, Iowa. https://lib.dr.iastate.edu/etd/14920.

Nylund, K. L., Asparouhov, T., \& Muthén, B. O. (2007). Deciding on the number of classes in latent class analysis and growth mixture modeling: A Monte Carlo simulation study. Structural equation modeling: A multidisciplinary Journal, 14(4), 535-569.

O’Brien, D. L., \& Aldeen, H. T. (2006). Hunger in America 2006: America’s Second Harvest- the nation's food bank network fourth National hunger study. 
FOOD PANTRY STRUCTURING

Perkett, M., Robson, S. M., Kripalu, V., Wysota, C., McGarry, C., Weddle, D., Papas, M. A., \& Patterson, F. (2017). Characterizing cardiovascular health and evaluating a low-intensity intervention to promote smoking cessation in a food-assistance population. Journal of Community Health. 44, 605-611. doi:10.1007/s10900-0160295-2.

Poppendieck, J. (1999). Sweet charity?: Emergency food and the end of entitlement. New York, NY: Penguin.

Reeser, L. C., \& Epstein, I. (1987). Social workers' attitudes toward poverty and social action: 1968-1984. Social Service Review, 61(4), 610-622.

Rehner, T., Ishee, J., Salloum, M., \& Velasques, D. (1997). Mississippi social workers’ attitudes toward poverty and the poor. Journal of Social Work Education, 33(1), $131-142$.

Reingold, D. A., \& Liu, H. K. (2009). Do poverty attitudes of social service agency directors influence organizational behavior?. Nonprofit and Voluntary Sector Quarterly, 38(2), 307-332.

Robinson, D. A. (2012). Perceptions of the food insecure: Does direct authority construct understanding. Western Illinois University.

Robinson, J. W. (2009) American poverty cause beliefs and structured inequality legitimation. Sociological Spectrum, 29(4), 489-518.

DOI:10.1080/02732170902904681

Schiller, B. R. (2007). The economics of poverty and discrimination (10 ${ }^{\text {th }}$ ed.). Upper Saddle River, NJ: Pearson Prentice Hall. 
FOOD PANTRY STRUCTURING

Schwartz, G. (1978). Estimating the dimension of a model. The Annals of Statistics, 6, 461-464.

Seccombe, K., James, D., \& Walters, K. B. (1998). " They think you ain't much of nothing": The social construction of the welfare mother. Journal of Marriage and the Family, 849-865.

Second Harvest. (1997). Hunger 1997: The faces and facts. Chicago: Second Harvest.

Semega, J. L., Fontenot, K. R., \& Kollar, M. A. (2017). Income and poverty in the United States: 2016. Current Population Reports, P60-259.

Sheffer, C. E., Stitzer, M., Landes, R., Brackman, S. L., Munn, T., \& Moore, P. (2012). Socioeconomic disparities in community-based treatment of tobacco dependence. Ameri- can Journal of Public Health, 102(3), e8-e16. doi:10.2105/

AJPH.2011.300519.

Stein, M. (1989). Gratitude and attitude: A note on emotional welfare. Social Psychology Quarterly, 242-248.

Taking Stock. (2016). Interdisciplinary Center for Food Security- University of Missouri. Retrieved from: http://foodsecurity.missouri.edu/projects/taking-stock/

Tein, J. Y., Coxe, S., \& Cham, H. (2013). Statistical power to detect the correct number of classes in latent profile analysis. Structural equation modeling: a multidisciplinary journal, 20(4), 640-657.

Triandis, H. C. (1995). New directions in social psychology. Individualism \& collectivism. Boulder, CO: Westview press.

U.S. Department of Labor. (2020). The employment situation- March 2020. USDL-200521. 
FOOD PANTRY STRUCTURING

Visser, P. S., Krosnick, J. A., \& Lavrakas, P. J. (2000). Survey research. In H. T. Reis \& C. M. Judd (Eds.), Handbook of research methods in social and personality psychology (pp. 223-252). New York: Cambridge University Press.

Walmart. (2020). Working together to spark change. https://walmart.org

Weber, M. (1958). From Max Weber: essays in sociology. New York, NY. Oxford University Press.

Weiner, B. (2010). Attribution theory. Corsini Encyclopedia of Psychology.

Weiner, B. (2010). The development of an attribution-based theory of motivation: A history of ideas. Educational psychologist, 45(1), 28-36.

Weiner, B. (2014). The attribution approach to emotion and motivation: History, hypotheses, home runs, headaches/heartaches. Emotion Review, 6(4), 353-361.

Weinfield, N. S., Mills, G., Borger, C., Gearing, M., Macaluso, T., Montaguila, J., \& Zediewski, S. (2014). Hunger in America 2014: national report prepared for Feeding America.

Yun, S. H., \& Weaver, R. D. (2010). Development and validation of a short form of the attitude toward poverty scale. Advances in Social Work, 11(2), 174-187. 


\section{Appendix A: 2019 Missouri Food Pantry Director Survey}

\section{Start of Block: Informed Consent}

Welcome to the Missouri Food Pantry Director research study!

This survey is conducted through a partnership between The Interdisciplinary Center for Food Security at the University of Missouri, Feeding Missouri, and the regional food banks of Missouri.

We are interested in understanding the services that food pantries offer, the ways that food pantry services are structured, and the thoughts that food pantry directors have about issues related to poverty and food insecurity. You will be asked to identify services that your food pantry offers, as well as your opinion on the types services that are most important to a successful/ideal food pantry more generally. Additionally, you will be asked a series of questions about the people that typically use your food pantry, as well as questions about what may cause people to need to use a food pantry. Please be assured that your responses will be kept anonymous and completely confidential.

The survey should take roughly 20 minutes to complete. You will also have the opportunity to enter a drawing for one of ten $\$ 50$ Visa gift cards for your participation at the end of the survey.

Your participation in this research is voluntary. Your responses will be anonymous and confidential, all your personal information/identification will not be tied to your responses. You have the right to withdraw at any point during the study, for any reason, and without any prejudice. Please answer openly and truthfully to each of the questions. Your voice and thoughts about food pantry services is very important, providing great insight into how food pantry services operate across the state of Missouri, and the role that they play in meeting the needs of Missourians.

If you would like to contact the Principal Investigator in the study to discuss this research, please e-mail Darren Chapman (drcbn7@mail.missouri.edu).

The survey can be completed on a range of electronic devices. Please note that this survey will be best displayed on a laptop or desktop computer, as some features of the survey may be less compatible for use on a mobile device or tablet.

By consenting to participate, you acknowledge that your participation in the study is voluntary, you are 18 years of age, a director of a food pantry in one of Missouri's food bank regions, and that you are aware that you may choose to end your participation in the study at any time and for any reason.

I consent, begin the survey (1)

I do not consent, I do not wish to participate (2)

Skip To: End of Survey If By consenting to participate, you acknowledge that your participation in the study is voluntary,... = I do not consent, I do not wish to participate 
FOOD PANTRY STRUCTURING

The following questions are intended to gather information about the food pantry that you work with, the services it offers, and the ways in which your organization is structured. Additional questions are included to understand your thoughts and beliefs about what services and organizational structures would be included in operating your 'ideal' food pantry.

Please answer openly and truthfully. Personal identification will not be tied to responses.

\section{End of Block: FPS Instructions}

\section{Start of Block: Food Pantry Services}

FPS1 What are the hours of operation for your pantry during a typical month? Please indicate the open and close time for each day that your pantry is open. (ex. 10:00-4:00)

\begin{tabular}{|c|c|c|c|c|c|c|c|}
\hline & $\begin{array}{l}\text { Sunday } \\
\text { (1) }\end{array}$ & $\begin{array}{l}\text { Monday } \\
\text { (2) }\end{array}$ & $\begin{array}{c}\text { Tuesday } \\
\text { (3) }\end{array}$ & $\begin{array}{c}\text { Wednesday } \\
\text { (4) }\end{array}$ & $\begin{array}{c}\text { Thursday } \\
\text { (5) }\end{array}$ & $\begin{array}{l}\text { Friday } \\
\text { (6) }\end{array}$ & $\begin{array}{c}\text { Saturday } \\
\text { (7) }\end{array}$ \\
\hline $\begin{array}{c}\text { Week } 1 \\
\text { (1) }\end{array}$ & & & & & & & \\
\hline $\begin{array}{c}\text { Week } 2 \\
\text { (2) }\end{array}$ & & & & & & & \\
\hline $\begin{array}{c}\text { Week } 3 \\
\text { (3) }\end{array}$ & & & & & & & \\
\hline $\begin{array}{c}\text { Week } 4 \\
(4)\end{array}$ & & & & & & & \\
\hline
\end{tabular}

FPS2 What is the average number of households your pantry serves per month?

FPS3 What is the average number of individuals your pantry serves per month? 
FOOD PANTRY STRUCTURING

FPS4 Is your pantry serving: MORE PEOPLE / FEWER PEOPLE / OR ABOUT THE SAME as last year?

More people (1)

About the same (2)

Fewer/Less people (3)

FPS5 Is your food pantry a religious based/affiliated organization?

Yes (1)

No (2)

\section{Display This Question:}

If Is your food pantry a religious based/affiliated organization? = Yes

FPS5a What religious organization?

FPS6 What documents are required for individuals/households to utilize your pantry? (Select all that apply)

None (1)

Photo Identification (2)

Other form of personal identification (3)

Social Security Card (4)

Proof of Address (5)

Proof of number of individuals in household (6)

Verbal statement of need based on income (7)

Proof of Financial Need/ Documentation of income (8)

Other (Please Specify) (9)

FPS7 How often are these documents required?

Each Visit (1)

Multiple times per year (2)

Once a year (3)

Only when status changes (4)

Never (5) 
FOOD PANTRY STRUCTURING

FPS8 How often can people utilize your pantry?

Anytime (1)

Weekly (2)

Monthly (3)

Other (Please Specify) (4)

FPS9 What best describes where your clients wait to check-in?

Outside waiting line without seating (1)

Outside waiting line with seating (2)

Inside waiting line without seating (3)

Inside waiting line with seating (4)

FPS10 How long do clients typically have to wait to check-in?

0-10 minutes (1)

10-30 minutes (2)

30-60 minutes (3)

$60+$ minutes $(4)$

FPS11 What best describes where your clients wait to receive/select their food after checking in?

Outside waiting line without seating (1)

Outside waiting line with seating (2)

Inside waiting line without seating (3)

Inside waiting line with seating (4)

FPS12 How long do clients typically have to wait to receive/select their food after checking in?

$0-10$ minutes (1)

10-30 minutes (2)

30-60 minutes (3)

$60+$ minutes (4)

FPS13 Is your food pantry accessible by persons of all abilities?

No, with no access (1)

Yes, with limited access or alternative entry (2)

Yes, with fully accessible main entrance and exit (3) 
FOOD PANTRY STRUCTURING

FPS14 Which of the following best describes the way your pantry distributes food?

Volunteers select and package all foods based on a formula (1)

Volunteers select and package most foods based on a formula and clients select a portion of the food for themselves (2)

Clients select their own food based on a formula, but a volunteer packs or handles the food (3)

Clients select and pack all foods themselves, based on a formula, without assistance (4)

Clients select and pack all foods themselves, without a formula or assistance (5)

FPS15a Which of these services/programs (or similar) does your pantry provide?

Commodity distribution (1)

Senior Box (2)

Food Delivery Services (3)

Meal Program/ Soup Kitchen (4)

Buddy Pack or BackSnack (5)

SNAP Enrollment (Supplemental Nutrition Assistance Program) (6)

WIC Enrollment (Women, Infant, \& Children Food \& Nutrition Service) (7)

TANF Enrollment (Temporary Assistance for Needy Families) (8)

Utility Assistance (9)

Housing Assistance (10)

Thrift Shop or Clothing Wardrobe (11)

Religious Programming (12)

Transportation Assistance/ Services (13)

Carry Forward Unselected Choices from "Which of these services/programs (or similar) does your pantry provide?" 
FOOD PANTRY STRUCTURING

FPS15b Which of these services/programs (or similar) does your pantry provide a voucher for service or referral?

Commodity distribution (1)

Senior Box (2)

Food Delivery Services (3)

Meal Program/ Soup Kitchen (4)

Buddy Pack or BackSnack (5)

SNAP Enrollment (Supplemental Nutrition Assistance Program) (6)

WIC Enrollment (Women, Infant, \& Children Food \& Nutrition Service) (7)

TANF Enrollment (Temporary Assistance for Needy Families) (8)

Utility Assistance (9)

Housing Assistance (10)

Thrift Shop or Clothing Wardrobe (11)

Religious Programming (12)

Transportation Assistance/ Services (13)

FPS15c If you were operating your 'ideal' food pantry, please identify how "Important" do you believe it is to provide each of the following services through the food pantry.

\begin{tabular}{l|lllll} 
& $\begin{array}{c}\text { Not At All } \\
\text { Important }\end{array}$ & $\begin{array}{c}\text { Somewhat } \\
\text { Important }\end{array}$ & \multicolumn{2}{c}{ Very Important } \\
\hline Commodity Distribution & 1 & 2 & 3 & 4 & 5 \\
\hline Senior Box & 1 & 2 & 3 & 4 & 5 \\
\hline Food Delivery Services & 1 & 2 & 3 & 4 & 5 \\
\hline Meal Program/ Soup Kitchen & 1 & 2 & 3 & 4 & 5 \\
\hline Buddy Pack or BackSnack & 1 & 2 & 3 & 4 & 5 \\
\hline SNAP Enrollment & 1 & 2 & 3 & 4 & 5 \\
\hline WIC Enrollment & 1 & 2 & 3 & 4 & 5 \\
\hline TANF Enrollment & 1 & 2 & 3 & 4 & 5 \\
\hline Utility Assistance & 1 & 2 & 3 & 4 & 5 \\
\hline Housing/ Rent Assistance & 1 & 2 & 3 & 4 & 5 \\
\hline Thrift Shop/ Clothing Wardrobe & 1 & 2 & 3 & 4 & 5 \\
\hline Religious Programming & 1 & 2 & 3 & 4 & 5 \\
\hline Transportation Assistance/ Services & 1 & 2 & 3 & 4 & 5 \\
\hline
\end{tabular}


FOOD PANTRY STRUCTURING

FPS16a Which of these operational items does your pantry have? (Select all that apply)

Visible signage from the road (1)

Signage clearly indicating accurate hours of operation and contact information (2)

Up-to-date Website or Social Media page (3)

Seating area for clients (4)

Area for children (5)

Selection of foods for those with chronic health conditions, food allergies, or specific food preferences (6)

Health guidelines for purchased \&/or donated foods (7)

Opportunity for client feedback (8)

Opportunity for clients to serve on Board or Staff (9)

Engagement with elected officials to promote food pantry operations (10)

Translation services (11)

FPS16b If you were operating your 'ideal' food pantry, please identify how "Important" you believe each of the following operational items and activities are for the food pantry.

\begin{tabular}{|c|c|c|c|c|c|}
\hline & & & $\begin{array}{l}\text { Somewhat } \\
\text { Important }\end{array}$ & & portant \\
\hline Visible signage from the road & 1 & 2 & 3 & 4 & 5 \\
\hline $\begin{array}{l}\text { Signage clearly indicating accurate hours of } \\
\text { operation and contact information }\end{array}$ & 1 & 2 & 3 & 4 & 5 \\
\hline Up-to-date Website or Social Media page & 1 & 2 & 3 & 4 & 5 \\
\hline Seating area for clients & 1 & 2 & 3 & 4 & 5 \\
\hline Area for children & 1 & 2 & 3 & 4 & 5 \\
\hline $\begin{array}{l}\text { Selection of foods for those with chronic health } \\
\text { conditions, food allergies, or specific food } \\
\text { preferences }\end{array}$ & 1 & 2 & 3 & 4 & 5 \\
\hline $\begin{array}{l}\text { Health guidelines for purchased \&/or donated } \\
\text { foods }\end{array}$ & 1 & 2 & 3 & 4 & 5 \\
\hline Opportunity for client feedback & 1 & 2 & 3 & 4 & 5 \\
\hline $\begin{array}{l}\text { Opportunity for clients to serve on Board or } \\
\text { Staff }\end{array}$ & 1 & 2 & 3 & 4 & 5 \\
\hline $\begin{array}{l}\text { Engagement with elected officials to promote } \\
\text { food pantry operations }\end{array}$ & 1 & 2 & 3 & 4 & 5 \\
\hline Translation services & 1 & 2 & 3 & 4 & 5 \\
\hline
\end{tabular}


FOOD PANTRY STRUCTURING

FPS17a Which of the following health programming services (or similar) does your pantry provide?

Mental Health Services (1)

Health Screenings (2)

Dental Screenings (3)

Reproductive Health (4)

Smoking Cessation (5)

Drug \&/or Alcohol Treatment (6)

Chronic Disease Management (7)

Domestic Violence (8)

Health Insurance Information (9)

Other (Please Specify) (10)

Carry Forward Unselected Choices from "Which of the following health programming services (or similar) does your pantry provide?"

FPS17b Which of the following health programming services (or similar) does your pantry provide a voucher for service or referral?

Mental Health Services (1)

Health Screenings (2)

Dental Screenings (3)

Reproductive Health (4)

Smoking Cessation (5)

Drug \&/or Alcohol Treatment (6)

Chronic Disease Management (7)

Domestic Violence (8)

Health Insurance Information (9)

Other (Please Specify) (10) 
FOOD PANTRY STRUCTURING

FPS17c If you were operating your 'ideal' food pantry, please identify how "Important" you believe it is to provide each of the following health services through the food pantry.

$\begin{array}{lll}\text { Not At All } & \text { Somewhat } & \text { Very Important } \\ \text { Important } & \text { Important }\end{array}$

\begin{tabular}{l|lllll}
\hline Mental Health Services & 1 & 2 & 3 & 4 & 5 \\
\hline Health Screenings & 1 & 2 & 3 & 4 & 5 \\
\hline Dental Screenings & 1 & 2 & 3 & 4 & 5 \\
\hline Reproductive Health & 1 & 2 & 3 & 4 & 5 \\
\hline Smoking Cessation & 1 & 2 & 3 & 4 & 5 \\
\hline Drug \&/or Alcohol Treatment & 1 & 2 & 3 & 4 & 5 \\
\hline Chronic Disease Management & 1 & 2 & 3 & 4 & 5 \\
\hline Domestic Violence & 1 & 2 & 3 & 4 & 5 \\
\hline Health Insurance Information & 1 & 2 & 3 & 4 & 5 \\
\hline
\end{tabular}

FPS18a Which of the following programs (or similar) does your pantry provide?

On-site Community Garden (1)

Off-site Community Garden (2)

Cooking/ Recipe Demonstrations (3)

Nutrition Education Classes (4)

Job Skills Training (5)

Employment Opportunities (6)

Educational Programs/ Assistance (GED) (7)

Financial Literacy Training (8)

Voter Registration (9)

Social \&/or Cultural Events (10)

Other (Please Specify) (11) 
FOOD PANTRY STRUCTURING

FPS18b Which of the following programs (or similar) does your pantry provide a voucher for service or referral?

On-site Community Garden (1)

Off-site Community Garden (2)

Cooking/ Recipe Demonstrations (3)

Nutrition Education Classes (4)

Job Skills Training (5)

Employment Opportunities (6)

Educational Programs/ Assistance (GED) (7)

Financial Literacy Training (8)

Voter Registration (9)

Social \&/or Cultural Events (10)

Other (Please Specify) (11)

FPS18c If you were operating your 'ideal' food pantry, please identify how "Important" you believe it is to provide each of the following programs through the food pantry.

Not At All Somewhat Very Important Important Important

\begin{tabular}{|c|c|c|c|c|c|}
\hline On-site Community Garden & 1 & 2 & 3 & 4 & 5 \\
\hline Off-site Community Garden & 1 & 2 & 3 & 4 & 5 \\
\hline Cooking/ Recipe Demonstrations & 1 & 2 & 3 & 4 & 5 \\
\hline Nutrition Education Classes & 1 & 2 & 3 & 4 & 5 \\
\hline Job Skills Training & 1 & 2 & 3 & 4 & 5 \\
\hline Employment Opportunities & 1 & 2 & 3 & 4 & 5 \\
\hline Educational Programs/ Assistance (GED) & 1 & 2 & 3 & 4 & 5 \\
\hline Financial Literacy Training & 1 & 2 & 3 & 4 & 5 \\
\hline Voter Registration & 1 & 2 & 3 & 4 & 5 \\
\hline Social \&/or Cultural Events & 1 & 2 & 3 & 4 & 5 \\
\hline
\end{tabular}


FOOD PANTRY STRUCTURING

FPS19a Which of the following supplies (or similar) does your pantry provide?

General Recipes (1)

Recipes specific to foods distributed (2)

Nutrition information via posters and/or fliers (3)

Pantry Newsletter (Print or Digital) (4)

Gardening supplies \&/or education for personal gardening (5)

Household items \&/or cleaning supplies (6)

Diapers (7)

Formula (8)

Personal care items (9)

Other (Please Specify) (10)

Carry Forward Unselected Choices from "Which of the following supplies (or similar) does your pantry provide?"

$X \rightarrow$

FPS19b Which of the following supplies (or similar) does your pantry provide a voucher for service or referral?

General Recipes (1)

Recipes specific to foods distributed (2)

Nutrition information via posters and/or fliers (3)

Pantry Newsletter (Print or Digital) (4)

Gardening supplies \&/or education for personal gardening (5)

Household items \&/or cleaning supplies (6)

Diapers (7)

Formula (8)

Personal care items (9)

Other (Please Specify) (10) 
FOOD PANTRY STRUCTURING

FPS19c If you were operating your 'ideal' food pantry, please identify how "Important" you believe it is to provide each of the following supplies through the food pantry.

$\begin{array}{ll}\text { Not At All } & \text { Somewhat } \\ \text { Important } & \text { Important }\end{array}$

\begin{tabular}{|c|c|c|c|c|c|}
\hline General Recipes & 1 & 2 & 3 & 4 & 5 \\
\hline Recipes specific to foods distributed & 1 & 2 & 3 & 4 & 5 \\
\hline Nutrition information via posters and/or fliers & 1 & 2 & 3 & 4 & 5 \\
\hline Pantry Newsletter (Print or Digital) & 1 & 2 & 3 & 4 & 5 \\
\hline $\begin{array}{l}\text { Gardening supplies \&/or education for } \\
\text { personal gardening }\end{array}$ & 1 & 2 & 3 & 4 & 5 \\
\hline Household items \&/or cleaning supplies & 1 & 2 & 3 & 4 & 5 \\
\hline Diapers & 1 & 2 & 3 & 4 & 5 \\
\hline Formula & 1 & 2 & 3 & 4 & 5 \\
\hline Personal care items & 1 & 2 & 3 & 4 & 5 \\
\hline
\end{tabular}

FPS20 Does your food pantry solicit donations from home gardeners, community gardens, local farmers, and/or local farmers markets?

Yes (1)

No (2)

FPS21 How many paid staff work at your food pantry?

$\begin{array}{ll}\text { Full-Time (1) } & \boldsymbol{\nabla} 0(1) \ldots 10+(11) \\ \text { Part-Time (2) } & \boldsymbol{\nabla} 0(1) \ldots 10+(11)\end{array}$

FPS22 On average, how many volunteers work at the food pantry each month?

FPS23 On average, what percentage of volunteers are also clients?
$0-20 \%$ (1)
$21-40 \%(2)$
$41-60 \%$
$61+\%$ 
FOOD PANTRY STRUCTURING

FPS24 I have had a major role in determining how the food pantry I manage is organized.

Strongly Agree (1)

Agree (2)

Disagree (3)

Strongly Disagree (4)

FPS25 In what county is your food pantry located? (Include state if other than Missouri)

FPS25b Does your food pantry primarily serve people from...

A metropolitan city (1)

A large town (2)

Small town (3)

Rural population (4)

The next series of questions focuses on issues related to poverty and food security. Knowing more about how pantry directors think of these issues can help to better understand the ways in which pantries can be assist in providing services.

Again, your responses are confidential, and we hope you will feel free to answer these questions as honestly as possible.

Please answer as openly and honestly as possible. There are no 'right' or 'wrong' answers, and all answers are confidential with no personal identification tied to answers.

\section{End of Block: AP Instructions}

Start of Block: Attributions of Poverty

AP1 People that are poor are different from the rest of society.

Strongly agree (1)

Agree (2)

Neutral (3)

Disagree (4)

Strongly Disagree (5) 
FOOD PANTRY STRUCTURING

AP2 People that are poor are generally honest.

Strongly Agree (1)

Agree (2)

Neutral (3)

Disagree (4)

Strongly disagree (5)

AP3 Most people that are poor are dirty.

Strongly Agree (1)

Agree (2)

Neutral (3)

Disagree (4)

Strongly Disagree (5)

AP4 People that are poor act differently.

Strongly Agree (1)

Agree (2)

Neutral (3)

Disagree (4)

Strongly Disagree (5)

AP5 Children raised on welfare will never amount to anything.

Strongly Agree (1)

Agree (2)

Neutral (3)

Disagree (4)

Strongly Disagree (5)

AP6 I believe people that are poor have a different set of values than do other people.

Strongly Agree (1)

Agree (2)

Neutral (3)

Disagree (4)

Strongly Disagree (5) 
FOOD PANTRY STRUCTURING

AP7 People that are poor generally have the same level of intelligence as non-poor people.

Strongly Agree (1)

Agree (2)

Neutral (3)

Disagree (4)

Strongly Disagree (5)

AP8 There is a lot of fraud among welfare recipients.

Strongly Agree (1)

Agree (2)

Neutral (3)

Disagree (4)

Strongly Disagree (5)

AP9 Some "poor" people live better than I do, considering all their benefits.

Strongly Agree (1)

Agree (2)

Neutral (3)

Disagree (4)

Strongly Disagree (5)

AP10 People that are poor think they deserve to be supported.

Strongly Agree (1)

Agree (2)

Neutral (3)

Disagree (4)

Strongly Disagree (5)

AP11 Parents on welfare have additional children to get more money.

Strongly Agree (1)

Agree (2)

Neutral (3)

Disagree (4)

Strongly Disagree (5) 
FOOD PANTRY STRUCTURING

AP12 An able-bodied person collecting welfare is ripping off the system.

Strongly Agree (1)

Agree (2)

Neutral (3)

Disagree (4)

Strongly Disagree (5)

AP13 Unemployed people that are poor could find jobs if they tried harder.

Strongly Agree (1)

Agree (2)

Neutral (3)

Disagree (4)

Strongly Disagree (5)

AP14 Welfare makes people lazy.

Strongly Agree (1)

Agree (2)

Neutral (3)

Disagree (4)

Strongly Disagree (5)

AP15 Benefits for people that are poor consume a major part of the federal budget.

Strongly Agree (1)

Agree (2)

Neutral (3)

Disagree (4)

Strongly Disagree (5)

AP16 People are poor due to circumstances beyond their control.

Strongly Agree (1)

Agree (2)

Neutral (3)

Disagree (4)

Strongly Diagree (5) 
FOOD PANTRY STRUCTURING

AP17 I would support a program that resulted in higher taxes to support social programs for people that are poor.
Strongly Agree (1)
Agree (2)
Neutral (3)
Disagree (4)
Strongly Disagree (5)

AP18 If I were poor, I would accept welfare benefits.

Strongly Agree (1)

Agree (2)

Neutral (3)

Disagree (4)

Strongly Disagree (5)

AP19 People who are poor should not be blamed for their misfortune.

Strongly Agree (1)

Agree (2)

Neutral (3)

Disagree (4)

Strongly Disagree (5)

AP20 Society has the responsibility to help people that are poor.

Strongly Agree (1)

Agree (2)

Neutral (3)

Disagree (4)

Strongly Disagree (5)

AP21 People that are poor are discriminated against.

Strongly Agree (1)

Agree (2)

Neutral (3)

Disagree (4)

Strongly Disagree (5) 
FOOD PANTRY STRUCTURING

AP22 Clients that use your food pantry are different that most other people that are poor.

Strongly Agree (1)

Agree (2)

Neutral (3)

Disagree (4)

Strongly Disagree (5)

AP23 Clients that use your food pantry could get by without the food/resources that they get from the pantry.

Strongly Agree (1)

Agree (2)

Neutral (3)

Disagree (4)

Strongly Disagree (5)

AP24 Food pantries are a better solution to hunger than government funded assistance programs.

Strongly Agree (1)

Agree (2)

Neutral (3)

Disagree (4)

Strongly Disagree (5)

End of Block: Attributions of Poverty

Start of Block: Demographics Instructions

The following questions are intended to gather some of your demographic information.

Please answer openly and truthfully. Personal identification will not be tied to responses. 
FOOD PANTRY STRUCTURING

D1 What is your gender identity?

Female (1)

Male (2)

Non-binary (3)

Other (Please specify) (4)

Prefer not to answer (5)

D2 What is your age?

D3 What is your ethnicity? (Select all that apply)

African-American/Black (1)

Asian (2)

Caucasian/White (3)

Hispanic/Latinx (4)

$\square$ Native American or Alaska Native (5)

$\square$ Pacific Islander (6)

$\square$ Other (Please specify) (7)

Prefer not to answer (8)

D4 Generally speaking, what would best describe your political affiliation?

Conservative (1)

Liberal (2)

Libertarian (3)

Social Democrat (4)

Socialist (5)

None (6)

Other (Please specify) (7)

Prefer not to answer (8) 
FOOD PANTRY STRUCTURING

D5 Generally speaking, what would best describe your religious affiliation?
Christian (1)
Muslim (2)
Catholic (3)
Buddhist (4)
Athesist (5)
Agnostic (6)
Non-religious (7)
Other (Please specify) (8)
Prefer not to answer (9)

D6 Generally speaking, how would you describe your current financial security?
Very Secure (1)
Secure (2)
Somewhat Secure (3)
Somewhat Insecure (4)
Insecure (5)
Very Insecure (6)

D7 Generally speaking, how would you compare your current financial security to your financial security 10 years ago?

More Secure (1)

About the same (2)

Less Secure (3)

D8 Growing up, how would you describe the financial security of your care givers?

Very Secure (1)

Secure (2)

Somewhat Secure (3)

Somewhat Insecure (4)

Insecure (5)

Very Insecure (6) 
FOOD PANTRY STRUCTURING

D9 How many years have you served as director of the food pantry?

$\boldsymbol{\nabla} 1(1) \ldots 15+(15)$

D10 How many years have you been involved with the food pantry in any capacity?

$\nabla 1(1) \ldots 15+(15)$

D11 Have you ever personally utilized food pantry services?

Yes (1)

No (2)

\section{D12 What is your highest education level?}

Some high school (1)

High school diploma/GED (2)

Associate's degree (3)

College degree (4)

Post college (5)

Other (please specify) (6)

\section{End of Block: Demographics}

Thank you for taking the time to share your insights and thoughts concerning food pantry operations and food insecurity, it is greatly appreciated by the Interdisciplinary Center for Food Security, Feeding Missouri, and the Regional Food Banks across Missouri.

If you have any questions or comments regarding this survey, you can contact Darren Chapman at (drcbn7@mail.missouri.edu).

As a thank you for your participation, you have the opportunity to enter to win a $\$ 50$ Visa gift card. The following link will take you to short survey where you can opt into participation in a raffle for a chance to win one of the ten Visa gift cards. Having this additional survey helps to further keep your responses on this survey confidential.

\section{RAFFLE LINK}

If you don't wish to participate in the raffle, you can simply close out of this window.

Thank you again for your participation! 
FOOD PANTRY STRUCTURING

\section{Appendix B: Attributions of Poverty-Short Form Adjustments}

Individual attitudes toward poverty were measured using an adjusted form of the Attitudes Toward Poverty-Short Form (ATP-SF) scale developed by Hyun Yun \& Weaver (2010). Hyun \& Weaver's short form assessment is an extension of Atherton et al.'s (1993) single-factor Attitude toward Poverty scale and informed by multidimensional measures created by Feagin (1972), Cryns (1977), and Golding \& Middleton (1982).

Changes were made to question wording, as multiple questions in the original survey contained wording that highlighted negative social stereotypes and utilized an overly deficit-based communication model. Changes to wording were made in an attempt to balance negative assumptions that individuals may have, and a person-first approach. Below are the questions in their original form and as presented in the study. Changes to questions are highlighted.

\begin{tabular}{|l|l|}
\hline \multicolumn{1}{|c|}{ Original ATP-SF Question } & \multicolumn{1}{|c|}{ Question Used in Survey } \\
\hline Poor people are different from the rest of society. & $\begin{array}{l}\text { People that are poor } \text { are different from the rest of } \\
\text { society. }\end{array}$ \\
\hline Poor people are dishonest. & People that are poor are generally honest. \\
\hline Most poor people are dirty. & Most people that are poor are dirty. \\
\hline Poor people act differently. & People that are poor act differently. \\
\hline $\begin{array}{l}\text { Children raised on welfare will never amount to } \\
\text { anything. }\end{array}$ & $\begin{array}{l}\text { Children raised on welfare will never amount to } \\
\text { anything. }\end{array}$ \\
\hline
\end{tabular}


FOOD PANTRY STRUCTURING

\begin{tabular}{|c|c|}
\hline $\begin{array}{l}\text { I believe poor people have a different set of } \\
\text { values than do other people. }\end{array}$ & $\begin{array}{l}\text { I believe people that are poor have a different set } \\
\text { of values than do other people. }\end{array}$ \\
\hline $\begin{array}{l}\text { Poor people generally have lower intelligence } \\
\text { than nonpoor people. }\end{array}$ & $\begin{array}{l}\text { People that are poor generally have the same } \\
\text { level of intelligence as non-poor people. }\end{array}$ \\
\hline There is a lot of fraud among welfare recipients. & There is a lot of fraud among welfare recipients. \\
\hline $\begin{array}{l}\text { Some "poor" people live better than I do, } \\
\text { considering all their benefits. }\end{array}$ & $\begin{array}{l}\text { Some "poor" people live better than I do, } \\
\text { considering all their benefits. }\end{array}$ \\
\hline Poor people think they deserve to be supported. & $\begin{array}{l}\text { People that are poor think they deserve to be } \\
\text { supported. }\end{array}$ \\
\hline Welfare mothers have babies to get more money. & $\begin{array}{l}\text { Parents on welfare have additional children to } \\
\text { get more money. }\end{array}$ \\
\hline $\begin{array}{l}\text { An able-bodied person collecting welfare is } \\
\text { ripping off the system. }\end{array}$ & $\begin{array}{l}\text { An able-bodied person collecting welfare is } \\
\text { ripping off the system. }\end{array}$ \\
\hline $\begin{array}{l}\text { Unemployed poor people could find jobs if they } \\
\text { tried harder. }\end{array}$ & $\begin{array}{l}\text { Unemployed people that are poor could find jobs } \\
\text { if they tried harder. }\end{array}$ \\
\hline Welfare makes people lazy. & Welfare makes people lazy. \\
\hline $\begin{array}{l}\text { Benefits for poor people consume a major part of } \\
\text { the federal budget. }\end{array}$ & $\begin{array}{l}\text { Benefits for people that are poor consume a } \\
\text { major part of the federal budget. }\end{array}$ \\
\hline $\begin{array}{l}\text { People are poor due to circumstances beyond } \\
\text { their control. }\end{array}$ & $\begin{array}{l}\text { People are poor due to circumstances beyond } \\
\text { their control. }\end{array}$ \\
\hline $\begin{array}{l}\text { I would support a program that resulted in higher } \\
\text { taxes to support social programs for poor people. }\end{array}$ & $\begin{array}{l}\text { I would support a program that resulted in higher } \\
\text { taxes to support social programs for people that } \\
\text { are poor. }\end{array}$ \\
\hline If I were poor, I would accept welfare benefits. & If I were poor, I would accept welfare benefits. \\
\hline $\begin{array}{l}\text { People who are poor should not be blamed for } \\
\text { their misfortune. }\end{array}$ & $\begin{array}{l}\text { People who are poor should not be blamed for } \\
\text { their misfortune. }\end{array}$ \\
\hline Society has the responsibility to help poor people. & $\begin{array}{l}\text { Society has a responsibility to help people that } \\
\text { are poor. }\end{array}$ \\
\hline
\end{tabular}


FOOD PANTRY STRUCTURING

Poor People are discriminated against.

People that are poor are discriminated against. 
FOOD PANTRY STRUCTURING

\section{Vita}

Darren R. Chapman was born in Joplin, MO on March 15, 1988. He received his high school diploma from Carthage High School in Carthage, MO in May, 2006. He attended Crowder College in Neosho, MO, where he earned an Associates of Arts (A.A.) degree in Psychology with a minor in Sociology, graduating with honors in December, 2007. Darren continued his undergraduate education at Missouri Southern State University in Joplin, MO, where he earned his Bachelor of Arts (B.A.) degree in Psychology and a minor certificate in Sociology, graduating with honors in May 2010. After completing his undergraduate education, Darren worked in social service positions, providing daily living skills training education and training for individuals with mental illness and developmental disabilities. He moved to Columbia, MO and began his graduate studies in Rural Sociology at the University of Missouri- Columbia in 2013. He earned his Master of Science (M.S.) degree in May 2016, a Graduate Certificate in Public Health in May 2018, and a Doctor of Philosophy (Ph.D.) in May 2020, all from the University of Missouri. While at the University of Missouri-Columbia, Darren was tapped into the Rollins Society in 2015. Darren's research interests are centered around the understanding of food systems and the equitable access to food. He is especially interested in the role of food pantries in addressing hunger, and the ways in which these organizations can act as change agents for clients and communities. 